University of Louisville

ThinkIR: The University of Louisville's Institutional Repository

8-2006

\title{
Screening guide for critical river crossing structures with earthquake disruption risks.
}

Lindsay M. Ivey 1983-

University of Louisville

Follow this and additional works at: https://ir.library.louisville.edu/etd

\section{Recommended Citation}

Ivey, Lindsay M. 1983-, "Screening guide for critical river crossing structures with earthquake disruption risks." (2006). Electronic Theses and Dissertations. Paper 665.

https://doi.org/10.18297/etd/665

This Master's Thesis is brought to you for free and open access by ThinkIR: The University of Louisville's Institutional Repository. It has been accepted for inclusion in Electronic Theses and Dissertations by an authorized administrator of ThinkIR: The University of Louisville's Institutional Repository. This title appears here courtesy of the author, who has retained all other copyrights. For more information, please contact thinkir@louisville.edu. 


\title{
SCREENING GUIDE FOR CRITICAL RIVER CROSSING STRUCTURES WITH EARTHQUAKE DISRUPTION RISKS
}

\author{
By \\ Lindsay M. Ivey \\ B.S., University of Louisville, 2005

\begin{abstract}
A Thesis
Submitted to the Faculty of the

University of Louisville

Speed Scientific School

As Partial Fulfillment of the Requirements

For the Professional Degree
\end{abstract}

\section{MASTER OF ENGINEERING}

Department of Civil and Environmental Engineering

August 2006 

SCREENING GUIDE FOR CRITICAL RIVER CROSSING STRUCTURES WITH EARTHQUAKE DISRUPTION RISKS

Submitted by:

Lindsay M. Ivey

A Thesis Approved on

(Date)

By the Following Reading and Examination Committee:

Thomas D. Rockaway, Thesis Director

Donald J. Hagerty

James E. Lewis 


\section{ACKNOWLEDGMENTS}

I would like to offer a very special thank you to Dr. Thomas Rockaway for his continued support and patience throughout the process of writing this thesis. Your guidance and insight was sincerely appreciated, and I can now see the light at the end of

the tunnel. I would also like to extend a thanks for your guidance in non-thesis matters. Today I am on a path that one year ago I would have never dreamed to be possible.

Thanks is also extended to Dr. D.J. Hagerty and Dr. J. E. Lewis for their time and assistance while serving as members of my thesis committee. Both of your influences have shaped my future more than you may realize. In addition, thank you to the faculty in the Civil Engineering Department, your dedication to students is greatly appreciated.

Thank you to my parents for all of your love, support, and encouragement throughout my life. You are the main reason I am what I am today and I know that you are proud of me.

A final thank you goes to Adam, Adam, Dave, John, Kevin and Mikey who have stood alongside me for the past five years. Your friendship and support has meant more to me than words can possibly explain and I wish each of you success in wherever life may lead you. 


\begin{abstract}
The following thesis examines the relationship between site geology and ground motion amplification for medium sized earthquake events in the Ohio Valley area. This thesis also includes a Rapid Screening Guide that can be used to estimate earthquake effects for sites located along the Ohio River.

Thirteen typical soil columns at locations along the river were subjected to six earthquake events using the response modeling program Shake91 (University of California, 1991). The response modeling was used to determine initial amplification factors and to examine the relationship between site geology and ground motion effects for each of the different soil columns.

The response modeling was also used to create the Rapid Screening Guide. The guide outlines the method for creating design spectra for known or future structures, and then how to compare velocity spectra to design spectra to determine the probability of damage in an examined structure.
\end{abstract}




\section{TABLE OF CONTENTS}

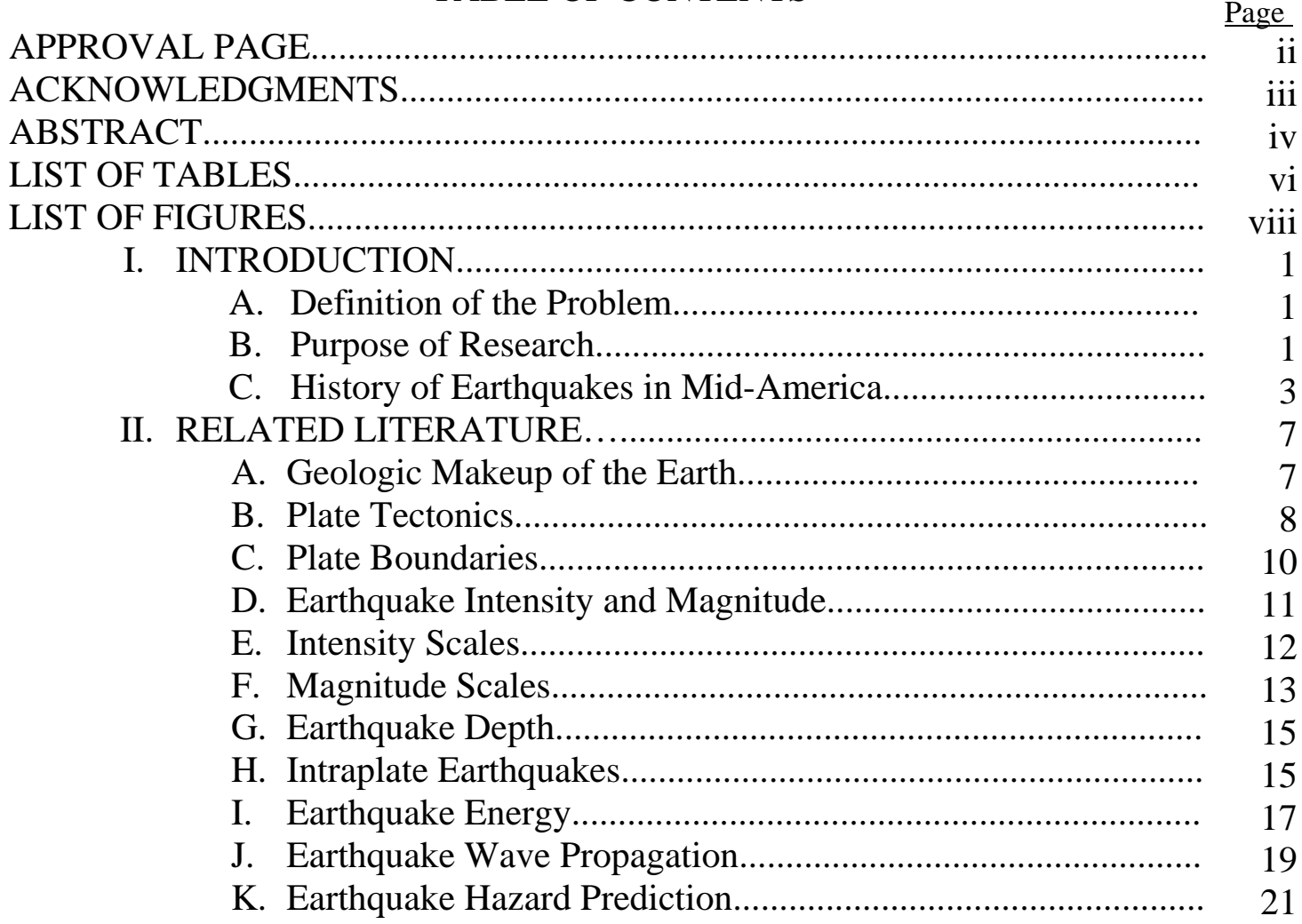

III. PROCEDURE............................................................................... 24

IV. RESULTS AND EVALUATION OF RESULTS............................ 32

A. Ground Motion Amplification............................................. 32

B. Effect of Site Geology on Ground Motion Response............... 36

V. RAPID SCREENING GUIDE........................................................ 41

A. Selecting Appropriate Soil Profile.......................................... 41

B. Initial Bedrock Acceleration................................................. 47

C. Response Spectrum Graphs................................................ 48

D. Design Spectrum............................................................... 61

E. Example........................................................................... 64

F. Damage Estimation............................................................... 72

VI. CONCLUSIONS AND RECOMMENDATIONS............................ 74

A. Conclusions.................................................................. 74

B. Recommendations.......................................................... 75

C. Future Areas of Research..................................................... 77

REFERENCES CITED............................................................................... 78

APPENDIX I. SOIL PROFILE ACCELERATION SPECTRA........................... 80

APPENDIX II. INITIAL TORO BEDROCK ACCELERATIONS..................... 94

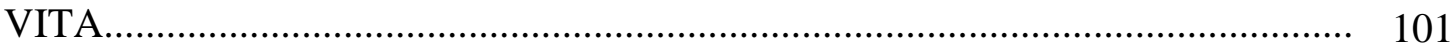




\section{LIST OF TABLES}

Page

I. INTRAPLATE EARTHQUAKES................................................. 16

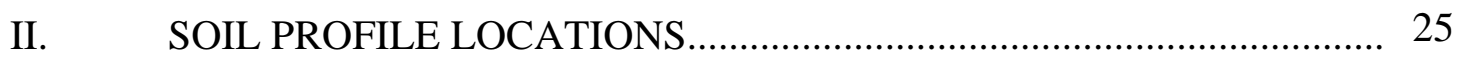

III. SOIL PROFILE EXAMPLE - FLATWOODS KY ............................. 26

IV. TORO MODELING COEFFICIENTS ................................................ 27

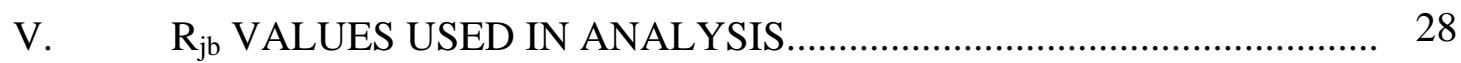

VI. MODEL EARTHQUAKE EVENTS AND MAGNITUDES.................. 28

VII. INITIAL PEAK GROUND ACCELERATIONS THROUGH

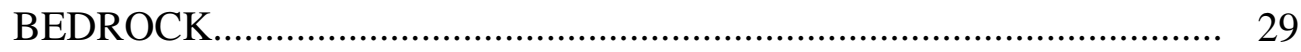

VIII. PEAK GROUND ACCELERATIONS FROM SHAKE........................ 33

IX. AMPLIFICATION FACTORS FOR SOIL PROFILES........................... 34

X. SOIL PROFILE LOCATIONS.................................................... 42

XI. SOIL PROFILE \#1 - FLATWOODS, KY ........................................ 43

XII. SOIL PROFILE \#2 - MAYSVILLE, KY ............................................ 43

XIII. SOIL PROFILE \#3 - NEWPORT, KY .......................................... 43

XIV. SOIL PROFILE \#4 - PETERSBURG, KY ......................................... 44

XV. SOIL PROFILE \#5 - MADISON, IN ............................................. 44

XVI. $\quad$ SOIL PROFILE \#6 - LOUISVILLE, KY .......................................... 44

XVII. SOIL PROFILE \#7 - OWENSBORO, KY .......................................... 45

XVIII. SOIL PROFILE \#8 - HENDERSON, KY 1...................................... 45

XIX. SOIL PROFILE \#9 - HENDERSON, KY 2................................... 45

XX. SOIL PROFILE \#10 - UNIONTOWN, KY ...................................... 46

XXI. SOIL PROFILE \#11 - PADUCAH, KY 1........................................ 46 
XXII. $\quad$ SOIL PROFILE \#12 - PADUCAH, KY 2........................................ 46

XXIII. SOIL PROFILE \#13 - WICKLIFFE, KY .......................................... 47

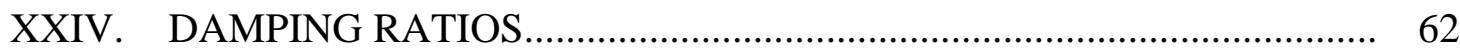

XXV. AMPLIFICATION CALCULATIONS FOR DESIGN SPECTRUM...... 68

XXVI. $\quad$ TORO - SOIL PROFILE \#1.......................................................... 95

XXVII. TORO - SOIL PROFILE \#2,........................................................... 95

XXVIII. TORO - SOIL PROFILE \#3........................................................... 96

XXIX. TORO - SOIL PROFILE \#4..................................................... 96

XXX. TORO - SOIL PROFILE \#5...................................................... 97

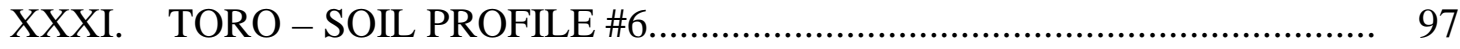

XXXII. TORO - SOIL PROFILE \#7.................................................... 98

XXXIII. TORO - SOIL PROFILE \#8 / \#9.................................................. 98

XXXIV. TORO - SOIL PROFILE \#10.................................................... 99

XXXV. TORO - SOIL PROFILE \#11 / \#12................................................ 99

XXXVI. TORO - SOIL PROFILE \#13............................................................. 100 


\section{LIST OF FIGURES}

Page

1. Map of the New Madrid and Wabash Valley Seismic Zones....................... 4

2. Earth Cutaway.......................................................................... 8

3. Tectonic Plate Map and Relative Movements......................................... 9

4. Tectonic Plate Boundaries............................................................... 10

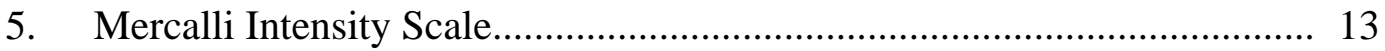

6. $\quad$ P and S Body Waves.................................................................... 18

7. Love and Rayleigh Surface Waves....................................................... 19

8. Seismic Wave Path...................................................................... 20

9. USGS Earthquake Hazard Map.......................................................... 22

10. Example Pseudo Acceleration Graph.................................................... 37

11. Soil Profile Comparison for a Peak Bedrock Acceleration $=0.005 \ldots \ldots \ldots \ldots . .38$

12. Average Range Pseudo Acceleration Graph for Soil Profile \#1................ 49

13. Average Range Pseudo Acceleration Graph for Soil Profile \#2............... 50

14. Average Range Pseudo Acceleration Graph for Soil Profile \#3.............. 51

15. Average Range Pseudo Acceleration Graph for Soil Profile \#4................ 52

16. Average Range Pseudo Acceleration Graph for Soil Profile \#5............. 53

17. Average Range Pseudo Acceleration Graph for Soil Profile \#6............... 54

18. Average Range Pseudo Acceleration Graph for Soil Profile \#7................ 55

19. Average Range Pseudo Acceleration Graph for Soil Profile \#8............... 56

20. Average Range Pseudo Acceleration Graph for Soil Profile \#9............... 57

21. Average Range Pseudo Acceleration Graph for Soil Profile \#10............. 58

22. Average Range Pseudo Acceleration Graph for Soil Profile \#11.............. 59 
23. Average Range Pseudo Acceleration Graph for Soil Profile \#12............. 60

24. Average Range Pseudo Acceleration Graph for Soil Profile \#13.............. 61

25. Construction of Elastic Design Spectrum......................................... 63

26. Plot Design Ground Motions.............................................................. 67

27. Plot of 50\% Nonexceedence Amplification Values.............................. 69

28. Plot of completed 50\% Design Spectrum........................................... 70

29. Plot of 84.1\% Nonexceedence Amplification Values.............................. 71

30. Plot of completed 50\% and 84.1\% Design Spectrum............................ 72

31. Acceleration Spectra \#1.................................................................... 81

32. Acceleration Spectra \#2 ................................................................. 82

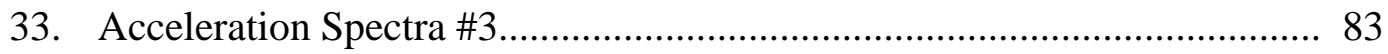

34. Acceleration Spectra \#4............................................................. 84

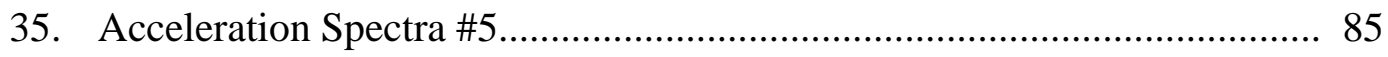

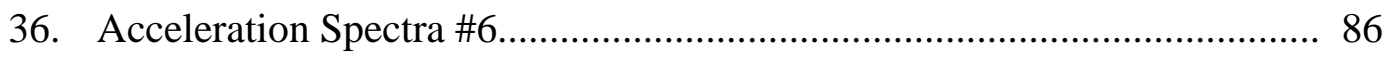

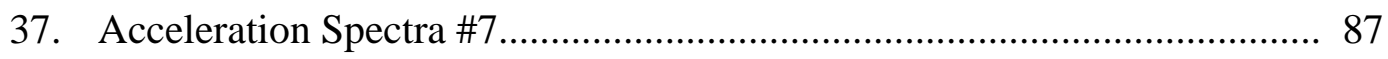

38. Acceleration Spectra \#8.................................................................... 88

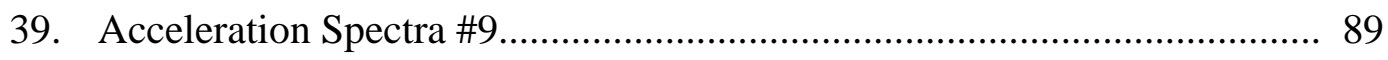

40. Acceleration Spectra \#10.................................................................. 90

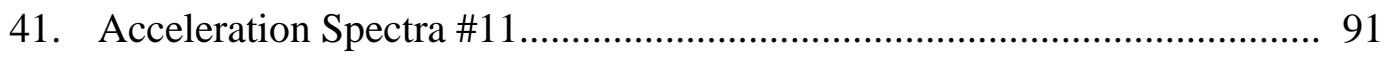

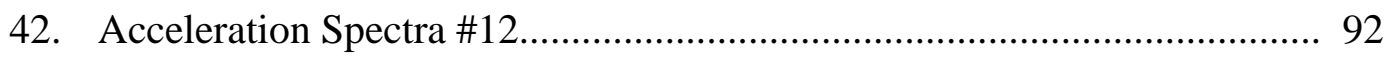

43. Acceleration Spectra \#13.................................................................... 93 


\section{INTRODUCTION}

\section{A. Definition of the Problem}

While extensive research has been conducted on the west coast into the effects of earthquake ground motions on structures, limited research on this subject has been conducted in the Mid-America region which includes Missouri, Illinois, Indiana, Kentucky, Tennessee, and Arkansas. Current researchers have found that more so than of the west coast, earthquakes can cause significant ground motion amplification across Mid-America even in relatively small earthquakes. This amplification, which is mainly due to the contiguous underlying limestone bedrock and the soil structures found in the area, could potentially cause serious damage to structures throughout Mid-America. As bridges are a staple in Mid-America trade and commerce, their damage in an earthquake would cause dire effects. Moreover, it is postulated these effects could result from a relatively small magnitude earthquake. Therefore, the study of ground motion amplification in respect to bridges and bridge supports is necessary to ensure continued trade and commerce in Mid-America. This thesis studies amplification in Kentucky at sites along the Ohio River.

\section{B. Purpose of Research}

It is important to simulate possible effects of earthquakes in this region because if a large or even medium sized earthquake were to occur in this area, significant damage would result. Medium sized earthquakes are also of concern because of the likelihood of 
amplification of seismic waves as they propagate through the regional soil structures. Furthermore, current research suggests that the contiguous limestone bedrock in the area would expand the radius of damage when compounded with the amplification tendencies of the overlying soil structures. The result would be more widespread damage even for smaller earthquakes.

Not only is amplification a Mid-American concern, but the lack of earthquake preparedness is also of concern. Current Mid-American residents have not experienced significant earthquakes in the region during their lifetimes. As a result, many are unaware of the potential for an earthquake or what to do during an earthquake event. Furthermore, many older buildings and structures in the area were not built with earthquake loads in mind. In the event of an earthquake these structures are especially susceptible to damage. Newer buildings however, have earthquake loads accounted for in the design codes. On the other hand, as the hazards associated with the New Madrid seismic zone have been further studied, scientists have increased their estimation of the likelihood of damage resulting from an earthquake, yet many structures have not been retrofitted to account for the increased hazard. The more research is done, the better prepared the region can be if another sizable earthquake occurs.

In an effort to further study the possible effects of earthquakes in the MidAmerican region, the research completed for this thesis studies the effect of site geology in reference to ground motion amplification. Using a computer modeling program, simulations propagated bedrock ground motions up through the overlying soil. These new 'amplified' ground motions were then applied to bridges and bridge support structures to estimate the probable damage from the ground motions. Multiple ground 
motion accelerations were entered into the computer modeling program and then propagated up through the different soil structures. By using a range of commonly estimated ground motion accelerations along with 13 representative soil profiles from along the Ohio River, professionals can use this research as a rapid screening guide to estimate damage to current and future bridges by comparison. In knowing the potential damage in the event of an earthquake, professionals can identify bridges in need of seismic retrofits and then design new bridges to better withstand earthquake effects.

\section{History of Earthquakes in Mid America}

Though there have been no large earthquakes in the Mid-America region in the last century, the area is still seismically active. While there are several active earthquake zones in Mid-America, two of these zones are in close proximity to Kentucky, and therefore, were studied in the subsequent analysis. The first, the New Madrid Fault Zone, runs parallel to the state boundaries between Kentucky, Missouri, Tennessee, and Arkansas. The second, the Wabash Valley Fault Zone, runs parallel to the Wabash River and the boundary between Illinois and Indiana. Both fault zones can be viewed in Figure 1 : 


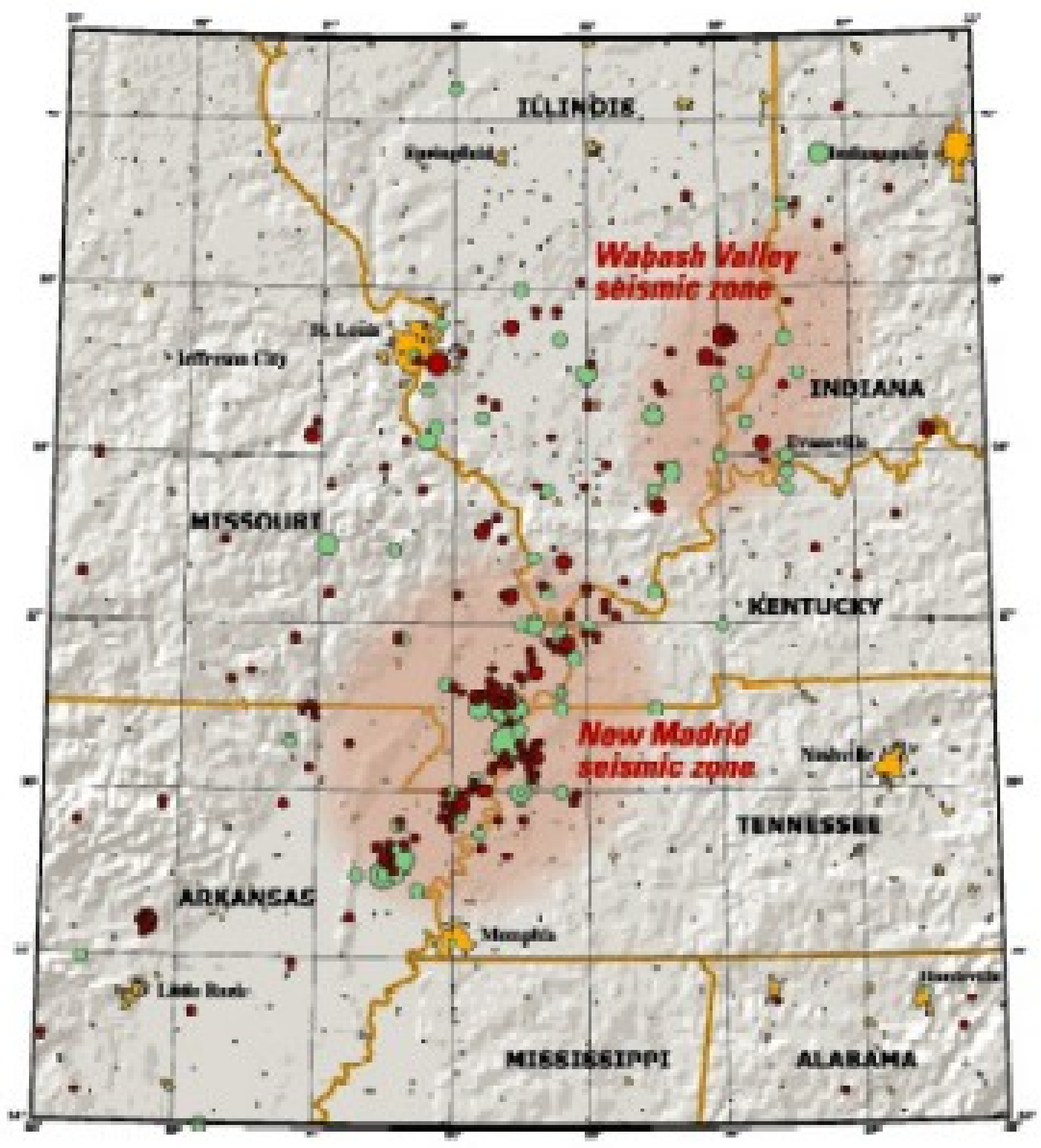

Red circles indicate earthquakes that occurred from 1974 to 2002 with magnitudes larger than 2.5 (University of Memphis). Green circles denote earthquakes that occurred prior to 1974 (USGS Professional Paper 1527). Larger earthquakes are represented by larger circles. From USGS Fact Sheet 131-02, " Earthquake Hazard in the Heart of the Homeland"

FIGURE 1 - Map of the New Madrid and Wabash Valley Seismic Zones

While the Wabash Valley Fault Zone has the potential to create a very damaging earthquake, most of the region's seismic hazards stem from the New Madrid Fault Zone. 
This fault zone produced three separate $8+$ (Richter) or 7+ (Moment) magnitude earthquakes in 1811 and 1812. The exact magnitude of each earthquake is unknown but estimates were made using the Modified Mercalli Intensity Scale and historical records of the events. All three earthquakes could be classified as Mercalli X - XI earthquakes. Earthquakes of this magnitude are considered disastrous to very disastrous and are known to destroy both wooden and masonry structures, bridges, and to bend railways. Historical records after the events also indicated that parts of the ground were permanently warped, and severe landslides and cave-ins resulted. It has been suggested that Reelfoot Lake in Tennessee was formed as a result of these series of earthquakes. Subsidence in the Reelfoot Lake area alone ranged from 1 to 6 meters. In addition, the Mississippi River was forced to change course, creating the Kentucky bend and was even rumored to have "flowed backward." Moreover, the earthquakes were felt as far away as New York City and Boston where "church bells rang." Fortunately, these earthquakes did not result in significant overall damage and there were few fatalities. (Stover and Coffman, 1993)

The outcome of the 1811 and 1812 earthquakes would be quite different if they had happened in modern times. During the early 1800's the Mid-America region was sparsely populated; therefore, damage wouldn't have been as great as compared to a more heavily populated area. If one of these earthquakes occurred during modern times, the resulting damage would be even more severe. Estimates of current researchers show that 8+ magnitude earthquakes, like those in 1811 and 1812, have a recurrence interval of about 500 years. However, a magnitude 6 earthquake has a recurrence interval of only 80 years and may still cause significant damage to bridge structures. (Martin, 2005) 
Therefore it is still necessary to study the effects of the ground motions resulting from earthquakes in this region as applied to the modern day. 


\section{RELATED LITERATURE}

In order to understand how and why earthquakes occur anywhere in the world, not just the Mid-America region, it is important to first understand fundamental principles about the geologic makeup of the earth. This literature review will begin with a description of the geologic makeup of the earth and then relate that description to the theory of plate tectonics. The different types of plate boundaries will be described and how those boundaries produce earthquake energy. This energy is classified by scientists and further described by earthquake intensity and magnitude and the various scales used in the classification of earthquakes. Finally, it will then be possible to proceed to the different types of seismic waves, how these waves are propagated, and how scientists today are researching and analyzing earthquake potential in the Mid-America region.

\section{A. Geologic Makeup of the Earth}

The earth is made up of three basic layers: the center and innermost layer is the core; the middle layer, made of molten hot magma, is the mantle; and the outermost layer is the crust. Figure 2 shows a cutaway view of the earth. In the figure, both the core and the mantle are divided into two separate parts; but for this analysis, both the inner and outer core will be considered the core and the two parts of the mantle will be described in detail later. 


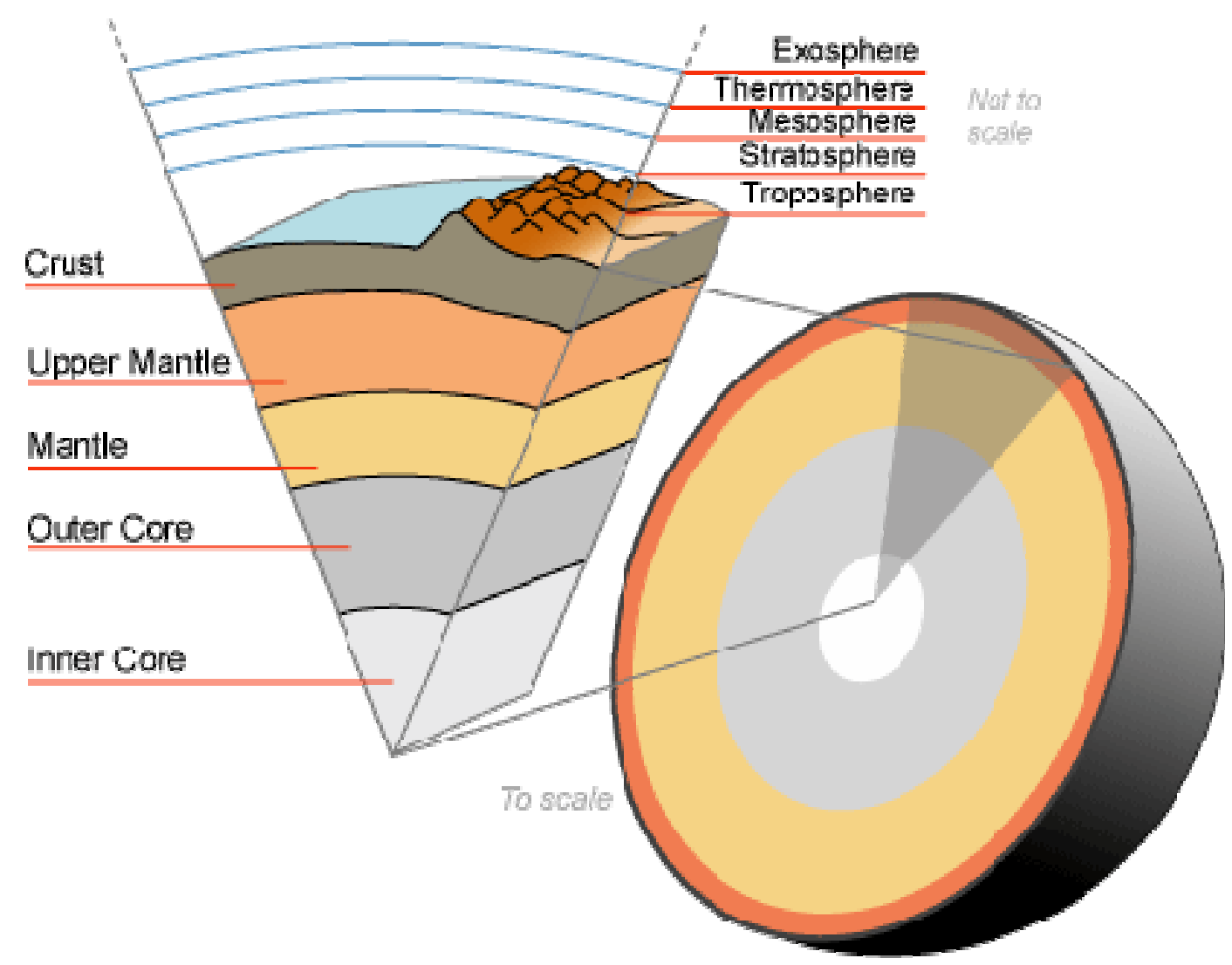

From Wikimedia Public Images

FIGURE 2- Earth Cutaway

\section{B. Plate Tectonics}

The theory of plate tectonics, which helps to explain why earthquakes occur, describes the interactions that occur between the lithosphere (the crust and solidified upper mantle) and the asthenosphere (the mantle). The theory, which is widely accepted among geologists and scientists, states that the lithosphere is not a continuous layer as seen in Figure 2. Instead, it is broken up into large but separate plates over the span of the globe, as seen in Figure 3, that essentially 'float' on top of the asthenosphere. 


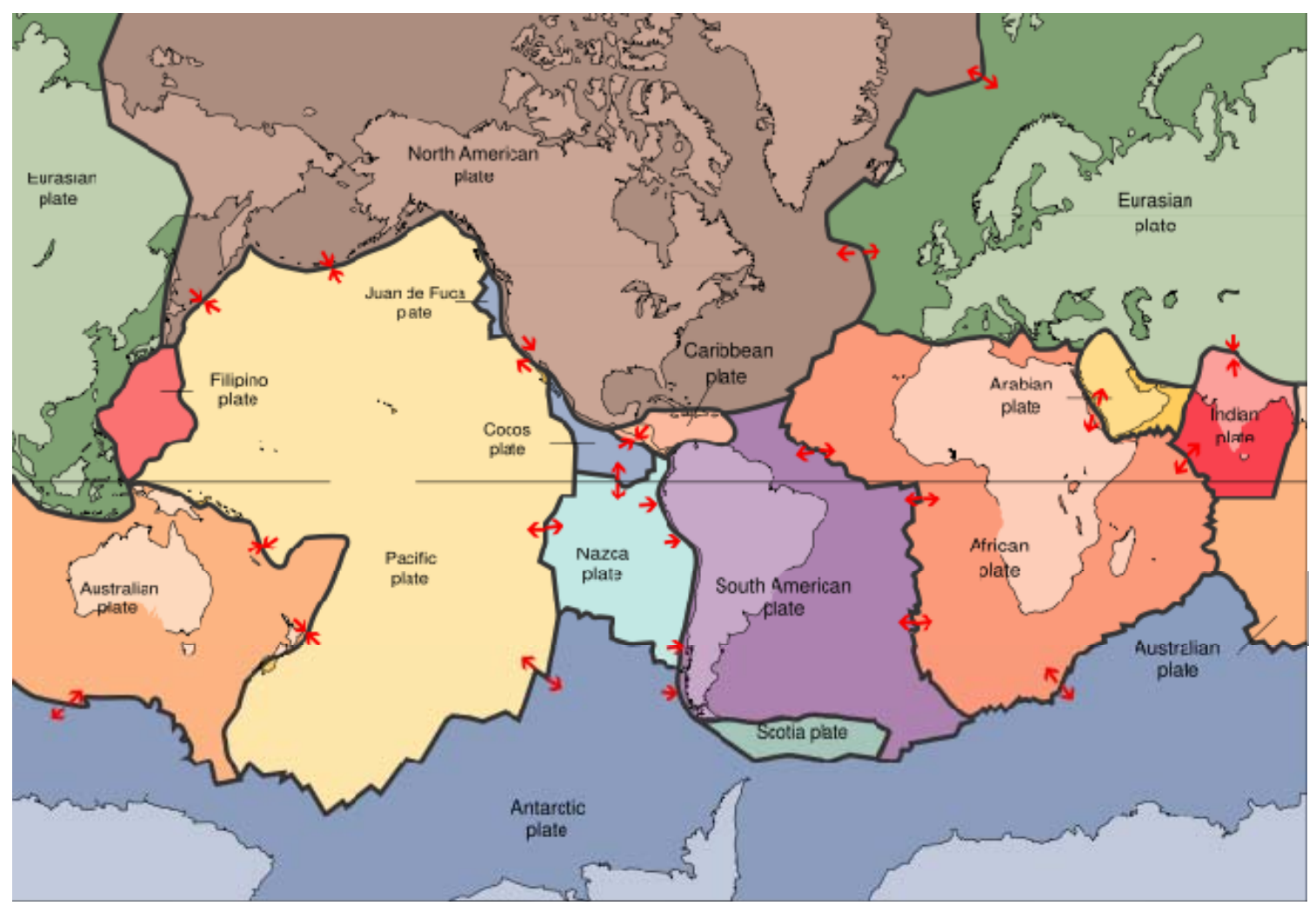

From Wikimedia Public Images

FIGURE 3 - Tectonic Plate Map and Relative Movements

Convection currents from the high-temperature molten magma in the asthenosphere causes plate movements. Due to this movement, interactions between the plates will result in one of three types of plate boundaries: convergent, divergent, or transform boundaries. Each of these boundaries is illustrated in Figure 4 and described in detail following the figure: 


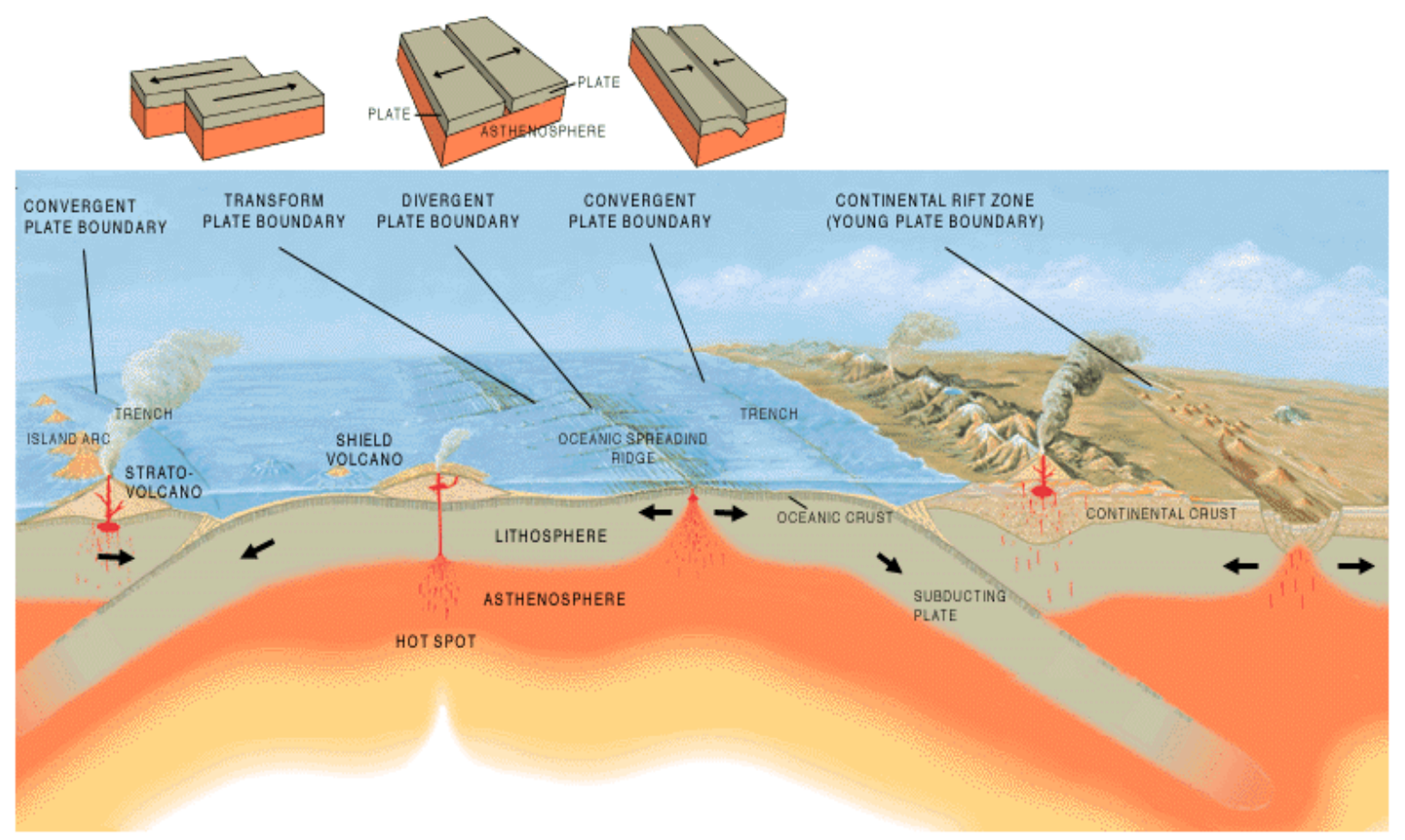

Image courtesy of the U.S. Geological Survey

FIGURE 4 - Tectonic Plate Boundaries

\section{Plate Boundaries}

While each boundary provides the potential to create earthquake movements, the boundaries do have other outcomes depending on how the plates are interacting. Convergent boundaries are formed when two plates move directly toward each other and one slides underneath the other, or the plates meet and both push upward. Convergent boundaries are usually responsible for island arcs, deep oceanic trenches, or in the case of plate collisions: mountain ranges. The Himalayas were created by a convergent boundary of two continental plates in which one did not slide underneath the other. Instead, both plates collided and pushed upward, creating the world's tallest mountain range. 
Divergent boundaries form as two plates move directly away from each other. The boundaries allow for the formation of new crust as molten magma from inside the earth cools as it reaches the surface.

The last boundary, or a transform boundary, occurs when two plates exhibit lateral movement and 'grind' parallel past each other. Transform faults, such as the San Andres in California, form along these boundaries. While they do not usually form any geologic features like the other boundaries, friction makes transform boundaries susceptible to earthquake motion.

As the plates attempt to slide past one another, friction and other forces impede their motion. Earthquakes occur as a result of the dynamic release of stored potential energy from the friction forces and can occur in any of the three boundary types. The earthquake itself is seismic waves released due to the build up of friction with respect to the plate movement. For instance, in a transform boundary the plates move past each other, and friction builds up a potential energy force between the plates. When the friction force is overcome, a sudden displacement occurs; and massive amounts of strain energy are released in the form of seismic waves.

\section{Earthquake Intensity and Magnitude}

Earthquakes around the world are classified by their intensity and/or magnitude. The magnitude, as previously described, is the characterization of the size of an earthquake based on the amount of energy released. Intensity is a measure of the amount of shaking that occurs along with the resulting damage to property. While the magnitude of an earthquake is determinate, the intensity is not a set value. Instead, it varies based on 
the site conditions at the point at which it is measured. Magnitude is the strength of the earthquake, but intensity is a measure of how well that strength can be felt at a given location. In explaining the difference between magnitude and intensity, Charles Richter, the man behind the Richter scale, likened the seismic waves from an earthquake to the broadcast signal waves emitted from a radio station: "Magnitude can be compared to the power output in kilowatts of a broadcasting station. Local intensity ... is then comparable to the signal strength on a receiver at a given locality; in effect, the quality of the signal." (Martin, 2005, pg. 24)

\section{E. Intensity Scales}

Scientists have produced several different scales that describe the measure intensity. The most common, however, is the Mercalli Intensity scale, which was used to estimate the 1811 and 1812 New Madrid earthquakes. The Mercalli Intensity scale has twelve (12) levels of intensity I - XII. The smaller levels describe low intensities that do not cause much damage; as the levels increase, the intensity increases along with the potential for damage. The higher levels of intensity (VI-XII) in the Mercalli Scale and the effect that intensity has on various structures can be seen in Figure 5: 


\section{Strong}

\section{Very}

Strong
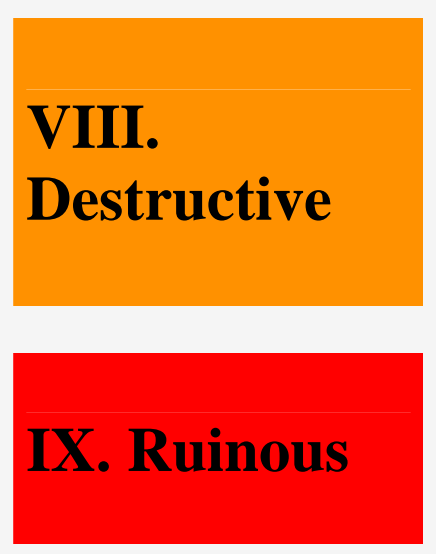

\section{Disastrous}

\section{Very Disastrous}

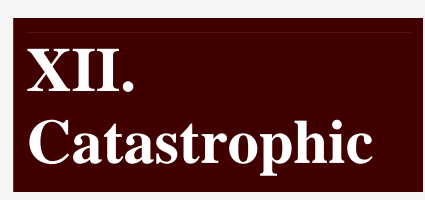

Felt by all. Windows, dishes, glassware broken; a few instances of fallen plaster. Damage slight.

Difficult to stand; damage negligible in building of good design and construction; slight to moderate in well-built ordinary structures; considerable damage in poorly built; some chimneys broken.

Damage slight in specially designed structures; considerable in ordinary substantial buildings with partial collapse. Damage great in poorly built structures. Fall of chimneys, factory stacks, columns, monuments, walls.

Damage considerable in specially designed structures, well designed frame structures thrown out of plumb. Damage great in substantial buildings, with partial collapse. Buildings shifted off foundations.

Some well built wooden structures destroyed; most masonry and frame structures destroyed with foundation. Rails bent.

Few, if any masonry structures remain standing. Bridges destroyed. Rails bent greatly.

Total damage - Almost everything is destroyed. Lines of sight and level distorted. The ground moves in waves or ripples. Large amounts of rock may move.

FIGURE 5 - Mercalli Intensity Scale

\section{F. Magnitude Scales}

As with intensity, there are also various scales used to describe the magnitude of an earthquake. The most easily calculated scale is the moment magnitude scale. Calculations for the moment magnitude scale are based on the total amount of energy 
that's released as a seismic moment in an earthquake event. This moment, (from which the moment magnitude scale gets its name) is an actual moment based on the rupture strength of the material along the fault, the area of the rupture, and the distance of the average slip.

Like most magnitude scales, the moment magnitude scale is logarithmic. In a logarithmic scale a magnitude 8 earthquake is not twice as strong as a magnitude 4 earthquake. Instead, logarithmic scales will increase at faster rates than the normal, base 10, numeric system. For example, a magnitude 7.0 earthquake releases 1000 times the energy of a magnitude 5.0 earthquake, according to the moment magnitude scale.

While the moment magnitude scale is widely used by scientists, the more common scale used to describe magnitude is the Richter scale. A Richter magnitude is calculated using the largest amplitude of the recorded seismic waves at a distance $100 \mathrm{~km}$ from the epicenter. Like moment magnitude, the Richter scale is also logarithmic. Unlike moment magnitude, the Richter scale uses the base 10 number system and each step is a 10 fold increase in energy. For example, a magnitude 8.0 earthquake releases 1000 times more energy than a magnitude 5.0 earthquake on the Richter scale. The Richter magnitude scale calculation is not easily relatable to the properties of the earthquake source. Problems arise for large earthquakes above 8.0; saturation of the wave measurements occurs, and for magnitudes between 8.3-8.5, and the scale will calculate the same magnitude for events that may have different magnitudes. Due to this problem, scientists prefer to calculate magnitude using the moment magnitude scale. (USGS, 2006) 


\section{G. Earthquake Depth}

Despite which magnitude scale is used, the magnitude is relative to the depth of the earthquake. In a typical earthquake event, the focus, or source of the earthquake may occur at a depth of 0-700 km below the surface. Typically, scientists divide the earthquake depth range into 3 zones: shallow $(0-70 \mathrm{~km})$, intermediate $(70-300 \mathrm{~km})$, and deep $(300+\mathrm{km})$. Despite the intermediate and deep classifications, all earthquakes $70 \mathrm{~km}$ and below the surface are considered deep-focus earthquakes. These deep-focus earthquakes tend to have greater magnitudes and cause more damage because seismic waves can travel further than in shallow earthquakes. The exact focus of an earthquake is determined through the use of seismology stations around the world. These stations contain seismometers that are used to record any seismic motions that may occur. The recordings are used to determine the exact focus of an earthquake and to record time histories of the motion. The information gathered through seismometer records can be used to classify earthquakes and in computer modeling programs to analyze the earthquake motions.

\section{H. Intraplate Earthquakes}

Most of the information gathered at these seismology stations records data for earthquakes located along one of the major plate boundaries around the world. The MidAmerica region is not located on any plate boundary, rather it is located in the middle of the North American plate. Therefore, instead of interplate earthquakes found along a plate boundary, Mid-America is likely to be subject to an intraplate earthquake. Why these types of earthquakes occur is truly unknown, but scientists have many theories as to 
the possible causes. One theory suggests that the earth gets fractured in the middle of a plate as the outer edges of the plate pull in tension. These fractures can build up potential energy as the plate itself shifts and moves. A second theory suggests that intraplate faults are "weak spots" in the crust that were caused from the continual heating up and thinning of the crust so that the thickness is reduced. When the crust becomes thinner and thinner, stresses to which these faults are subjected become more concentrated, and are stored as potential energy within the smaller volume of crust. (Martin, 2005)

Another theory suggests that geology is the cause of intraplate earthquakes. In this theory, stress is built and stored by "thermal destabilization" as rock masses with heavy minerals sink into the magma of the mantle. As these rock masses sink, stresses become concentrated in the overlying crust. However, this theory relies on "rock density anomalies" in addition to the thermal process between the crust and the mantle. (Martin, 2005)

While the source of intraplate earthquakes is unclear, scientists do know that intraplate earthquakes occur on a regular basis. In addition to the 1811 / $1812 \mathrm{New}$ Madrid earthquakes, other significant intraplate earthquakes are listed in Table 1 (Martin, 2005):

TABLE I

INTRAPLATE EARTHQUAKES

\begin{tabular}{|l|c|c|}
\hline Location & Year & Magnitude \\
\hline Boston, MA & 1755 & $\approx \mathrm{M} 7.0$ \\
\hline New York City, NY & 1737 & $\approx \mathrm{M} 5.5$ \\
\hline New York City, NY & 1884 & $\approx \mathrm{M} 5.5$ \\
\hline Charleston, SC & 1886 & $\approx \mathrm{M} 6.5-7.3$ \\
\hline
\end{tabular}




\section{Earthquake Energy}

Regardless of whether an earthquake originates from a plate boundary or from an intraplate seismic zone, when an earthquake occurs, four types of seismic waves are emitted; and each affects the resulting ground motion. The four different waves can be segregated into body waves that are able to propagate through the body of a medium, and surface waves that require an interface with the ground surface. Body waves are composed of primary and secondary waves. The $\mathrm{P}$ wave, or primary wave, is the wave with the highest velocity and therefore reaches seismic stations first. P waves are longitudinal waves, meaning the earth media is alternately compressed and dilated along or parallel to the direction of the wave propagation. The second type of wave is the $\mathrm{S}$ wave, or secondary wave. The $\mathrm{S}$ wave is a transverse wave in which materials shear perpendicular to the direction of the wave propagation. The relative movements of both the $\mathrm{P}$ and $\mathrm{S}$ waves are shown in Figure 6: 


\section{Body Waves}

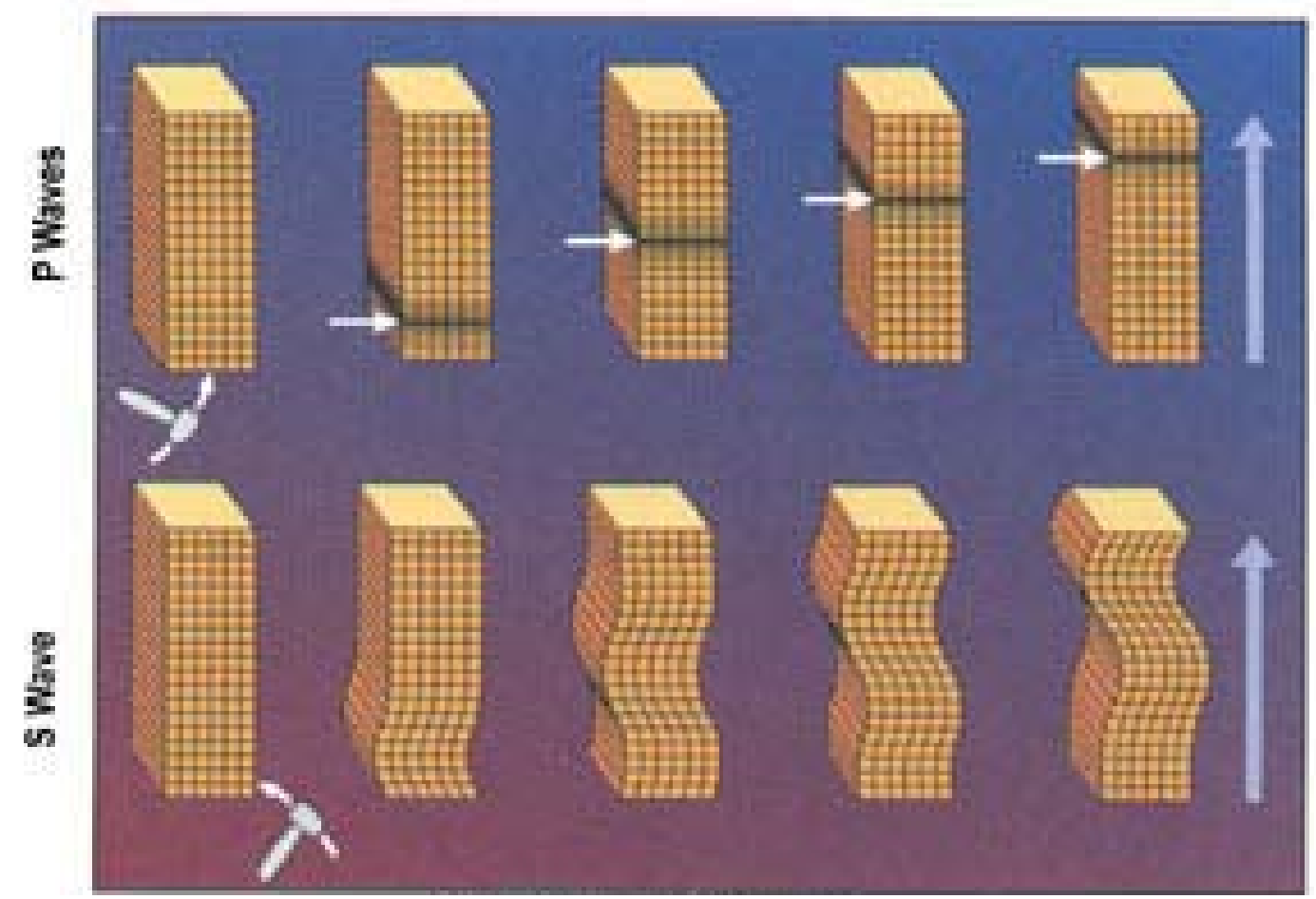

Image courtesy of the U.S. Geological Survey

FIGURE 6 - P and S Body Waves

Surface waves travel more slowly than body waves and at a much lower

frequency. The lower frequencies could cause resonance in buildings and significant structural damage. These surface waves are composed of Love and Rayleigh waves, and behave in much the same way as water waves. In the Love wave, shearing occurs perpendicular to the direction of travel. Rayleigh waves create a ground rolling effect as they propagate parallel to the direction of travel as the particles of earth material move along the trace of a retrograde ellipse. Pictorial images of both the Love and Rayleigh waves are located in Figure 7: 


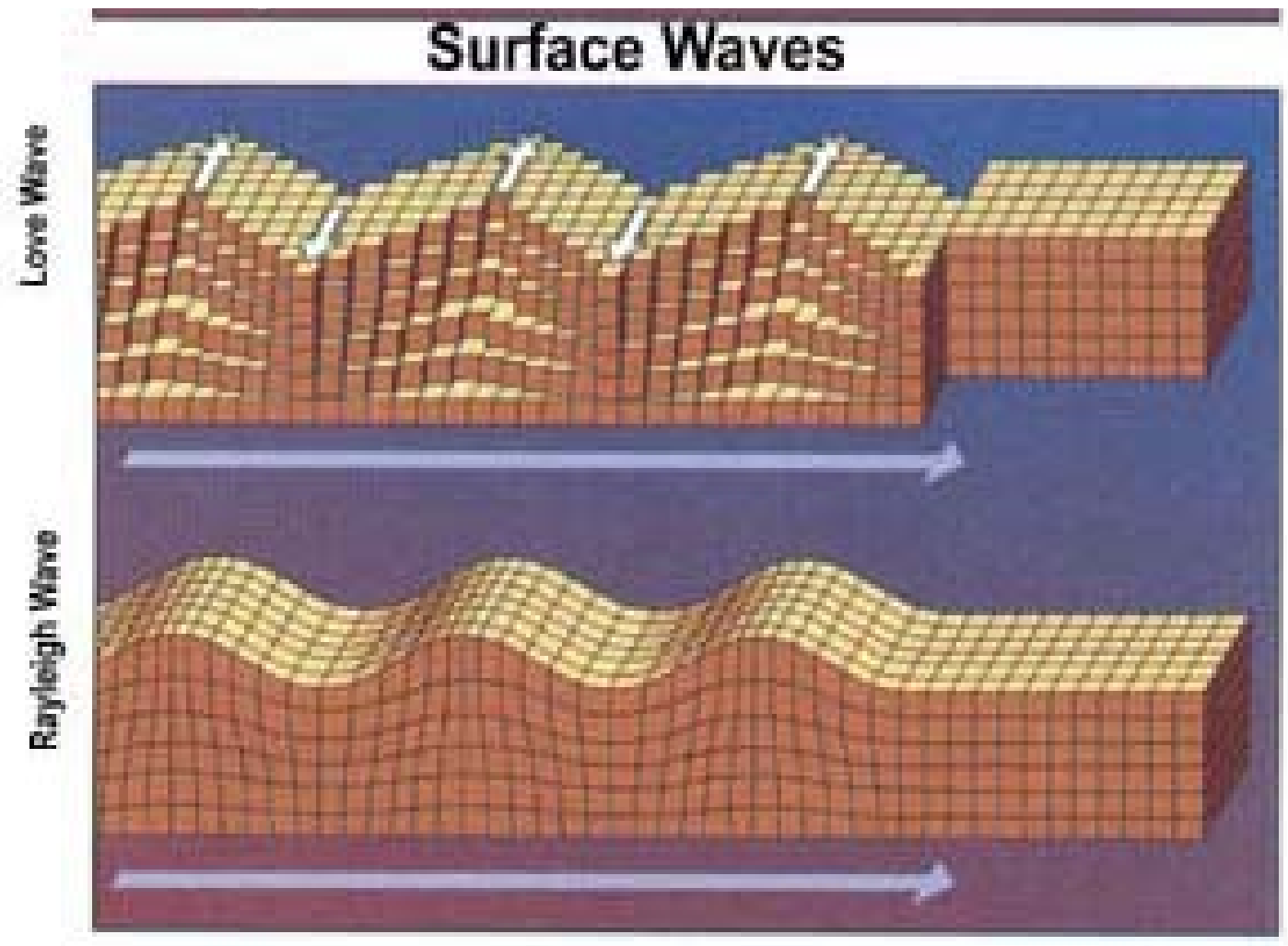

Image courtesy of the U.S. Geological Survey

FIGURE 7 - Love and Rayleigh Surface Waves

\section{J. Earthquake Wave Propagation}

All four seismic waves are recorded at seismology stations concurrently so it can be difficult to accurately model how the waves travel through the ground. Due to this difficulty, scientists tend to simplify the path of the seismic waves. The approach that is usually used tracks the seismic waves in separate steps from the focus as seen in Figure 8: 


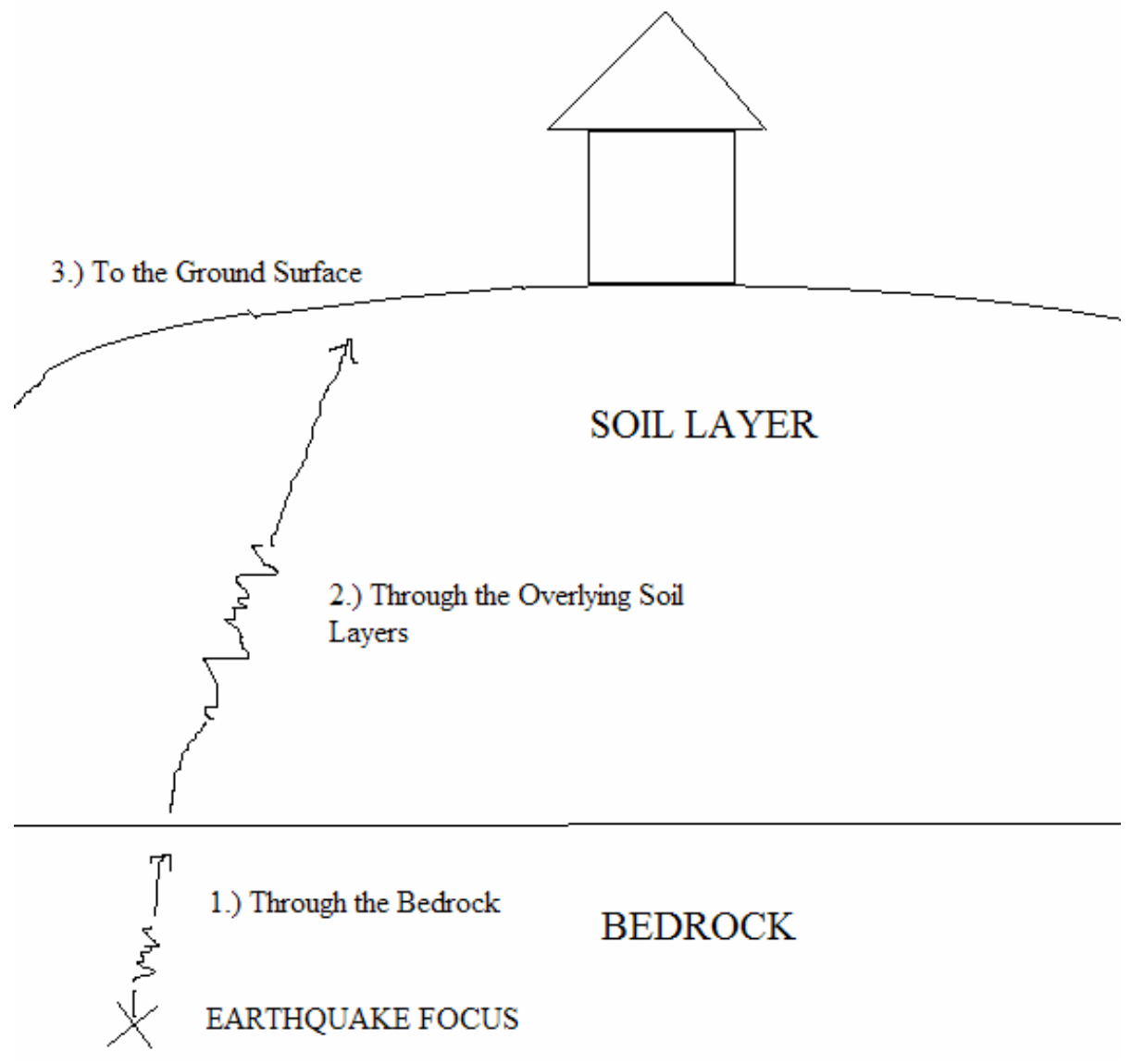

FIGURE 8 - Seismic Wave Path

For a deep focus earthquake, seismic waves will travel through both the mantle and the crust, but the surface waves that reach the ground level do the most damage to structures. Therefore, it is necessary to concentrate on the waves moving through the crust instead of the mantle. As with the earth, the crust can be divided into many layers. Simplified for this study, the two layers that apply are the bedrock and the overlying soil layer. Distinguishing between these two is important because the seismic waves behave quite differently in each layer. The bedrock is hard and dense and the seismic waves will travel faster in this layer than in soil layers. However, the overlying soil layer is usually 
less dense and has varying properties, which can act to amplify or reduce the seismic waves. As a result, the usual practice is to analyze seismic waves in two separate steps: first through the bedrock and then through the overlying soil. Once the seismic wave has reached the ground surface, the displacement, velocity, or acceleration of that wave can be used to estimate the effect of the wave on structures.

When a seismic wave reaches the surface, it can cause many different effects. Near the epicenter the ground surface is likely to displace and cause surface faults. If a building or earthen structure is on top of or part of one of these faults, damage can occur. Farther away from the epicenter, surface Rayleigh and Love waves usually cause the most damage. If the frequency of the surface wave is the same frequency that naturally occurs in the building, the wave will further amplify within the building and the shaking will intensify.

\section{K. Earthquake Hazard Prediction}

In design, engineers try to prevent and account for damage that may occur due to earthquakes. Most building designs incorporate factors to account for earthquake loads, but building codes vary from state to state depending on the determined 'hazard' associated with an earthquake event. This hazard is a relation between population in the area and the estimated severity of shaking for some probability. Figure 9 is the earthquake hazard map developed by the United States Geological Service (USGS). The map below shows the $\% \mathrm{~g}$ acceleration that has a probability of being exceeded in a 50 year period. 


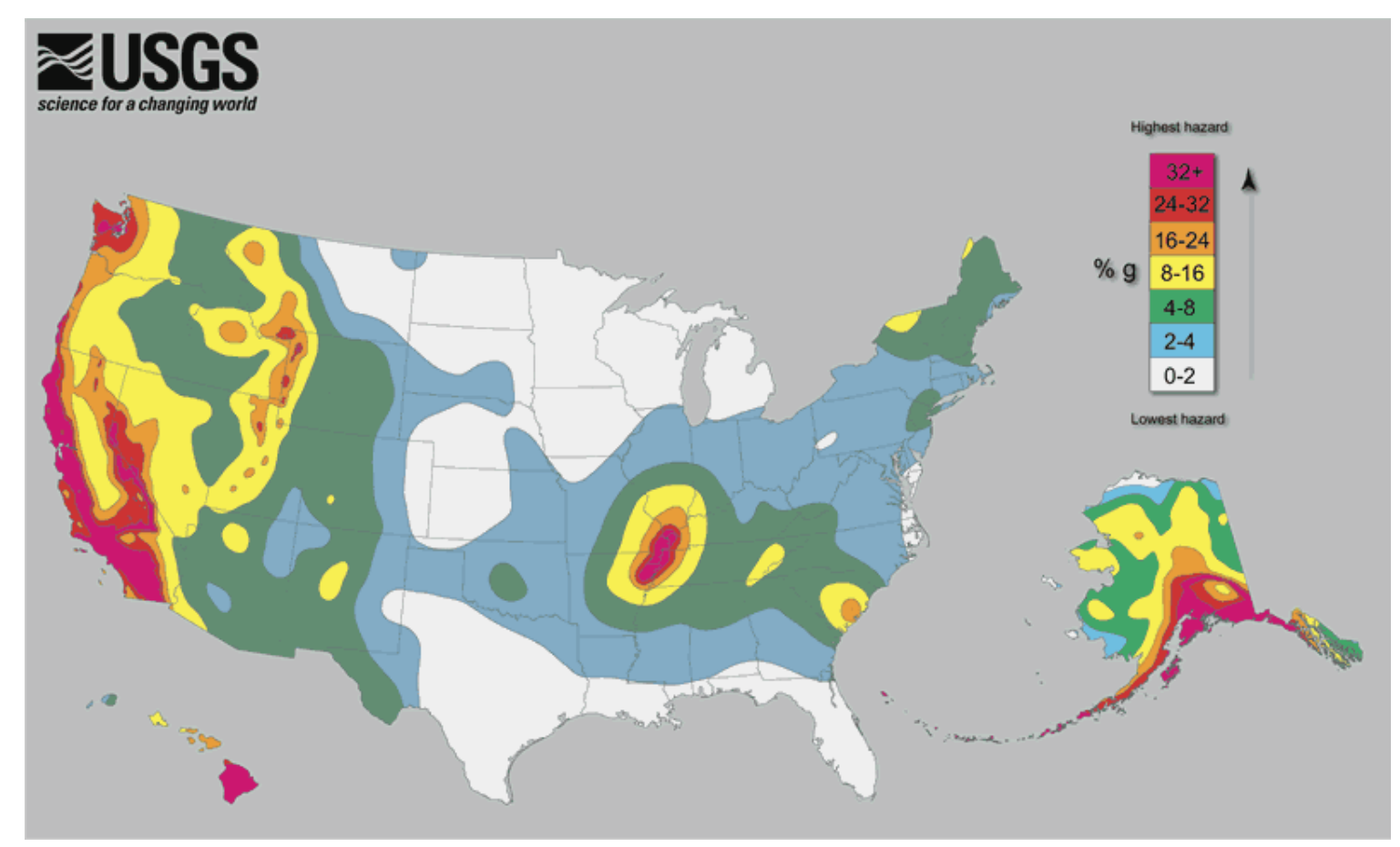

Image courtesy of the U.S. Geological Survey, 2002

FIGURE 9 - USGS Earthquake Hazard Map

In comparison to the research conducted on the San Andres fault in California, a much smaller amount of research has been done in reference to the New Madrid Seismic Zone. However, history has prompted researchers to further investigate the possibility of significant seismic activity in Mid-America. Multiple hazard maps have been created uniquely for the New Madrid and Wabash Valley Seismic Zone. These maps, like those cited previously, estimate hazards as a function of where, how large, and how often an earthquake will occur. In knowing where the most damage is likely to occur, it is possible to focus mitigation efforts into those specific areas.

One of the main problems of the Mid-America region is a lack of earthquake time histories one can use to analyze ground motions. The time histories can be used as input in earthquake simulation programs to help analyze possible seismic wave motions. Yet, 
there have been no significant earthquakes in Mid-America during the time period that scientists have been able to electronically record ground motions for the area. Instead, scientists have been forced to use time histories from other earthquakes around the globe. This has prompted some researchers to create computer simulations of theoretical time histories specifically for this area. Ron Street, of the University of Kentucky, has created two theoretical time histories, both of which were used for analysis in this thesis. The first is for a magnitude 6.5 earthquake which according to Street, has a 50 -year recurrence interval. The second is for a magnitude 7.0 earthquake, which according to Street, has a 500-year recurrence interval. (Street et al, 1996) Aside from these two theoretical time histories, the other time histories used were recorded from actual earthquakes that took place in Canada. In this manner, it was possible to use a range of different time histories that may occur in the Mid-America area. 


\section{PROCEDURE}

The seismic waves emitted from an earthquake are analyzed by researchers in several different steps. First, the displacement, velocity, or acceleration of the seismic waves is analyzed as it travels from the focus of the earthquake through the bedrock to some site a distance away from the epicenter. Next, the waves are analyzed as they propagate up through the soil structure to the ground surface at the specified site. This method is commonly used to account for the different reactions to seismic waves with respect to site geology. Since waves travel at different speeds through the different geologic media, it is more appropriate to break apart the wave path and analyze responses in steps as previously described in Chapter II Section J.

Analysis of wave response for this thesis was also conducted in the broken path manner. Wave responses were analyzed from the focus of an idealized earthquake through the bedrock and then from the bedrock to the surface through 13 different soil columns typical of those found along the Ohio River. Since the geology of the riverbank sites changed in the downstream direction, thirteen (13) typical soil profile sites were established at various locations along the river in order to obtain a representative sample of different soil columns possible. The locations used and the soil profile numbers, which start from the far eastern border of Kentucky and the Ohio River and move west, are shown in Table II: 


\section{TABLE II}

\section{SOIL PROFILE LOCATIONS}

\begin{tabular}{|c|c|}
\hline Soil Profile \# & Location \\
\hline$\# 1$ & Flatwoods, KY \\
\hline$\# 2$ & Maysville, KY \\
\hline$\# 3$ & Newport, KY \\
\hline$\# 4$ & Petersburg, KY \\
\hline$\# 5$ & Madison, IN \\
\hline$\# 6$ & Louisville, KY \\
\hline$\# 7$ & Owensboro, KY \\
\hline$\# 8$ & Henderson, KY \\
\hline$\# 9$ & Henderson, KY \\
\hline$\# 10$ & Uniontown, KY \\
\hline$\# 11$ & Paducah, KY \\
\hline$\# 12$ & Paducah, KY \\
\hline$\# 13$ & Wickliffe, $\mathrm{KY}$ \\
\hline
\end{tabular}

The actual soil layers for Sites 1-11, and 13 were found using a Geological Survey Water-Supply Paper and the Soil Surveys (United States Soil Conservation Service, 1962, 1966, 1967, 1973, 1974, 1976, 1979, 1981, 1986, 1992) for each site location. Profile \#12 was taken from a paper, which conceptualized a ground-water model for a gaseous diffusion plant in Paducah (Jacobs, 1997), and from the Soil Survey for McCracken County (United States Soil Conservation Service, 1976). Two profiles were chosen to represent Paducah because it has such varied and deep soil columns. Paducah is also in close proximity to a possible epicenter of the New Madrid fault zone, and therefore, is more likely to sustain significant damage. The same reasoning was used to justify the use of two soil profiles for Henderson, Kentucky, which is in close proximity to a possible Wabash Valley fault zone epicenter. In addition, research showed that Henderson has varying soil columns on opposite sides of the riverbank, so both columns were analyzed. 
Each soil profile is outlined in a separate table in the Rapid Screening Guide. An example, Soil Profile \#1, is shown in Table III for explanation. The table enumerates the depth, material, strength of material, dry unit weight, and shear wave velocity for each layer. The strengths of the various materials were obtained from the soil surveys or reasonably estimated based on the type of material and regional knowledge. Strength values were given using the friction angle, $\varphi$, or by using the blow count, $\mathrm{N}$. The unit weights, if not found in the research, were also reasonably estimated based on the material and regional knowledge. Shear wave velocity was calculated using an empirical equation in which shear wave velocity is a function of strength, depth, geological epoch, and soil type. (Ohta and Goto, 1978) The material properties were examined in such detail because they would subsequently be needed for use in the modeling program Shake91. Earthquake responses through each soil column were calculated by Shake91 using the soil material parameters of each soil column.

\section{TABLE III}

\section{SOIL PROFILE EXAMPLE- FLATWOODS, KY}

\begin{tabular}{|l|c|c|c|c|}
\hline Depth From Surface & Material & Strength $(\phi)$ & Unit Weight $\boldsymbol{Y}$ (cfs) & $\begin{array}{c}\text { Shear Wave } \\
\text { Velocity (ft/s) }\end{array}$ \\
\hline $0-1^{\prime}$ & Silt Loam & 33 & 100 & 211 \\
\hline $1^{\prime}-2^{\prime}$ & Silt Loam & 33 & 100 & 262 \\
\hline $2^{\prime}-5^{\prime}$ & Silt Loam & 33 & 100 & 311 \\
\hline $5^{\prime}-20^{\prime}$ & Silt / Clay & 33 & 100 & 400 \\
\hline $20^{\prime}-40^{\prime}$ & Sand & $10(\mathrm{~N})$ & 115 & 554 \\
\hline $40^{\prime}-70^{\prime}$ & Gravel & $15(\mathrm{~N})$ & 130 & 910 \\
\hline
\end{tabular}

In order to determine what sort of amplification may occur over the range of the soil column, the peak ground motion from the epicenter to the site through the bedrock would first need to be determined. A number of different ground motion relations could 
be used to find the peak bedrock acceleration, but those given by Toro et al (1997) and Atkinson and Boore (1995) were initially tried in analysis. The Toro et al equation was the equation that was finally chosen:

$$
\begin{aligned}
& \ln Y=C_{1}+C_{2}(M-6)+C_{3}(M-6)^{2}-C_{4} \ln \left(R_{M}\right)-\left(C_{5}-C_{4}\right) \max \left[\ln \left(\frac{R_{M}}{100}\right), 0\right]-C_{6} R_{M} \\
& +\varepsilon_{e}+\varepsilon_{a}, \text { where } R_{M}=\sqrt{R_{j b}{ }^{2}+C_{7}{ }^{2}}
\end{aligned}
$$

In the equation, $\mathrm{Y}$ is the peak bedrock acceleration (in units of $\mathrm{g}$ ), $\mathrm{C}_{1}-\mathrm{C}_{7}$ are modeling constants, $\mathrm{M}$ is the moment magnitude, and $\mathrm{R}_{\mathrm{jb}}$ is the closest horizontal distance to the earthquake rupture. Values to be used for the modeling constants are shown in Table IV:

\section{TABLE IV}

\section{TORO MODELING COEFFICIENTS}

\begin{tabular}{|c|c|c|c|c|c|c|c|}
\hline Freq. & C1 & C2 & C3 & C4 & C5 & C6 & C7 \\
\hline PGA & 2.20 & 0.81 & 0.00 & 1.27 & 1.16 & 0.0021 & 9.3 \\
\hline
\end{tabular}

The epsilon values in the equation were to be used to create boundaries to account for error. They were not used in calculation because the value used was an average value. Therefore, in order to use this equation in analysis, only values of $M$ and $R_{j b}$ would be required. To get these values, the model earthquake magnitudes to be used in Shake91 and the assumed epicenters for these model earthquakes would need to be determined. The epicenters assumed originally were located in New Madrid, Missouri for the New Madrid Seismic Zone and Mt. Vernon, Indiana for the Wabash Valley Seismic Zone. However after calculation of the expected peak bedrock motions and various trial runs of Shake 91, it was decided that the analysis would be more beneficial if a "worst case scenario" was considered. Subsequently, the epicenters for both the 
NMSZ and the WVSZ were moved closer to the Ohio River to Cairo, Illinois and

Evansville, Indiana, respectively. $R_{\mathrm{jb}}$ values were then measured from the epicenters to the location of each soil profile. The distances used in analysis are listed in Table V:

\section{TABLE V}

\section{$\mathrm{R}_{\mathrm{jb}}$ VALUES USED IN ANALYSIS}

\begin{tabular}{|c|c|c|}
\hline Soil Profile \# & NMFZ $(\mathrm{km})$ & WVFZ $(\mathrm{km})$ \\
\hline 1 & 593 & 426 \\
\hline 2 & 509 & 337 \\
\hline 3 & 472 & 293 \\
\hline 4 & 443 & 263 \\
\hline 5 & 385 & 206 \\
\hline 6 & 333 & 160 \\
\hline 7 & 201 & 45 \\
\hline 8 & 169 & 16 \\
\hline 9 & 169 & 16 \\
\hline 10 & 140 & 41 \\
\hline 11 & 49 & 140 \\
\hline 12 & 49 & 140 \\
\hline 13 & 9 & 177 \\
\hline
\end{tabular}

In order to have definitive moment magnitudes to use in the acceleration equation, the following earthquake model events were used (Table VI):

TABLE VI

MODEL EARTHQUAKE EVENTS AND MAGNITUDES

\begin{tabular}{|c|c|c|}
\hline Model Name & Earthquake Event & M \\
\hline Ky50yr & n/a & 6.5 \\
\hline Ky500yr & n/a & 7.0 \\
\hline Les_ebo & Miramichi, New Brunswick 5/6/1982 & 5.9 \\
\hline Standre & Miramichi, New Brunswick 5/6/1982 & 5.9 \\
\hline Mitchlk & Saguenay, Québec 11/25/1988 & 5.7 \\
\hline Lglodge2 & Saguenay, Québec 11/25/1988 & 5.7 \\
\hline
\end{tabular}


The Ky50yr and Ky500yr models were not actual earthquake events but were generated based on the possible earthquake effects for earthquakes at 50 and 500-year recurrence intervals according to Street (Street et al, 1996). The Miramichi and Saguenay earthquake events were chosen because they both occurred in Canada, and the geologic media through which the waves traveled is similar to that found in the Central US. These time-history files were retrieved from the Strongmo Database System. (Columbia University, 2005) The events were each used twice because readings were taken at different distances from the epicenter for each separate model. Overall, 12 different earthquake models were used in Shake91 since the Toro equation is based on distance, the initial peak ground motions had to be considered for distances from both the NMSZ and the WVSZ. The resulting peak bedrock accelerations calculated using the Toro equation are shown in Table VII (all accelerations are expressed in g's):

TABLE VII

INITIAL PEAK GROUND ACCELERATIONS THROUGH BEDROCK

\begin{tabular}{|c|c|c|c|c|c|c|c|c|}
\cline { 2 - 9 } \multicolumn{1}{c|}{} & \multicolumn{4}{c|}{ New Madrid Seismic Zone } & \multicolumn{4}{c|}{ Wabash Valley Seismic Zone } \\
\hline Soil Profile \# & 5.7 & 5.9 & 6.5 & 7.0 & 5.7 & 5.9 & 6.5 & 7.0 \\
\hline 1 & 0.0006 & 0.0009 & 0.0010 & 0.0020 & 0.0010 & 0.0020 & 0.0030 & 0.0040 \\
\hline 2 & 0.0009 & 0.0013 & 0.0020 & 0.0030 & 0.0020 & 0.0030 & 0.0040 & 0.0070 \\
\hline 3 & 0.0010 & 0.0020 & 0.0020 & 0.0040 & 0.0030 & 0.0040 & 0.0060 & 0.0090 \\
\hline 4 & 0.0010 & 0.0020 & 0.0030 & 0.0040 & 0.0030 & 0.0050 & 0.0070 & 0.0110 \\
\hline 5 & 0.0020 & 0.0020 & 0.0030 & 0.0050 & 0.0050 & 0.0070 & 0.0110 & 0.0160 \\
\hline 6 & 0.0020 & 0.0030 & 0.0050 & 0.0070 & 0.0070 & 0.0110 & 0.0160 & 0.0240 \\
\hline 7 & 0.0050 & 0.0080 & 0.0110 & 0.0170 & 0.0420 & 0.0630 & 0.0950 & 0.1430 \\
\hline 8 & 0.0070 & 0.0100 & 0.0150 & 0.0220 & 0.1420 & 0.2130 & 0.3200 & 0.4800 \\
\hline 9 & 0.0070 & 0.0100 & 0.0150 & 0.0220 & 0.1420 & 0.2130 & 0.3200 & 0.4800 \\
\hline 10 & 0.0090 & 0.0130 & 0.0200 & 0.0290 & 0.0480 & 0.0720 & 0.1070 & 0.1610 \\
\hline 11 & 0.0380 & 0.0570 & 0.0850 & 0.1270 & 0.0090 & 0.0130 & 0.0200 & 0.0300 \\
\hline 12 & 0.0380 & 0.0570 & 0.0850 & 0.1270 & 0.0090 & 0.0130 & 0.0200 & 0.0300 \\
\hline 13 & 0.2270 & 0.3400 & 0.5100 & 0.7640 & 0.0060 & 0.0090 & 0.0140 & 0.0210 \\
\hline
\end{tabular}


The aforementioned data were compiled into input files that were used by Shake91 to simulate the propagation of the initial ground motions at the bedrock up to the surface of the soil in each of the 13 different soil profiles along the Ohio River. A table of the peak ground accelerations at the soil surface is located in the Results and Discussion of Results section (Chapter IV Section A) of this thesis, and acceleration vs. period(log) graphs can be viewed in Appendix I.

While it is beneficial to examine the effects of each separate initial bedrock acceleration on each soil profile, it is not possible to accurately compare the simulated motions for each profile unless the same initial bedrock acceleration is input into Shake91. With the exception of Soil Profiles 8, 9, and 13 in which the epicenter and the soil profile were within $20 \mathrm{~km}$ of each other, most profiles showed initial accelerations between $0.005-0.015 \mathrm{~g}$. Therefore, accelerations of $0.005 \mathrm{~g}, 0.010 \mathrm{~g}$, and $0.015 \mathrm{~g}$ were input into Shake91 to create a probable range in which a common acceleration would lie. In addition, the acceleration 0.100 was also run and included in analysis to try and incorporate the possible accelerations for sites that may be located very close to the epicenter of an earthquake.

Once each of the four accelerations were run in Shake91, tripartite graphs with the previous 'ranges' of accelerations were created. These graphs 'averaged' the pseudo velocities produced by all 12 earthquakes into a 'range' of four initial bedrock accelerations and for each soil profile. These 13 average range pseudo velocity graphs for each soil profile can be found in the Rapid Screening Guide (Chapter V). Each of the graphs created for this 'range' of initial accelerations is to be used with damping coefficients to create elastic design spectra to analyze the possible damage effects to 
bridges and bridge supports. The exact procedure for the creation of the elastic design spectra can also be found in the Rapid Screening Guide (Chapter V). 


\section{RESULTS AND EVALUATION OF RESULTS}

This research assessed ground motion response simulated by Shake91 using two separate formats. The first analysis investigated ground motion amplification effects at specific locations from “medium” sized earthquake events likely to affect bridges in Kentucky along the Ohio River. This assessment compared bedrock motions to ground surface motions to identify earthquake events that were likely to cause significant ground motion amplification. The second analysis investigated the relationship between site geology and ground motion response. This investigation compared the soil profile responses from earthquake events scaled to typical acceleration values to create a more idealized, average ‘range’ velocity response spectrums for various earthquake magnitudes. This chapter will describe the procedures and analysis used, as well as the results.

\section{A. Ground Motion Amplification}

To assess the effects of differing earthquake events on ground motion response, Shake91 was run using 156 different approximated bedrock accelerations. These bedrock accelerations provided idealized responses at each of the 13 typical soil profiles sites for six different earthquake events from two different epicenters. The responses were then used to investigate the possibility of ground motion amplification at each of the 13 different sites. 
Table VIII lists each peak ground acceleration for the motions generated using initial accelerations calculated from Toro. Period vs. pseudo acceleration graphs of every earthquake motion can be found for each soil profile in Appendix I. (It should be noted that the ky500yr time history for Soil Profile \#13 would not run properly in Shake91, therefore peak ground accelerations could not be determined for this soil profile).

TABLE VIII

PEAK GROUND ACCELERATIONS (g) FROM SHAKE

\begin{tabular}{|c|c|c|c|c|c|c|}
\cline { 2 - 7 } \multicolumn{1}{c|}{ Soil Profile } & \multicolumn{2}{|c|}{$k y 50 y r-6.5$} & \multicolumn{2}{c|}{ ky500yr - 7.0 } & \multicolumn{2}{c|}{ lglodge2 -5.7} \\
\cline { 2 - 7 } \multicolumn{1}{c|}{} & NMSZ & WVSZ & NMSZ & WVSZ & NMSZ & WVSZ \\
\hline 1 & 0.00433 & 0.01174 & 0.00705 & 0.01342 & 0.00172 & 0.00172 \\
\hline 2 & 0.00600 & 0.01156 & 0.00875 & 0.01621 & 0.00137 & 0.00268 \\
\hline 3 & 0.00769 & 0.01629 & 0.01410 & 0.02297 & 0.00174 & 0.00496 \\
\hline 4 & 0.01194 & 0.02533 & 0.01731 & 0.03867 & 0.00201 & 0.00588 \\
\hline 5 & 0.01243 & 0.02789 & 0.01809 & 0.03288 & 0.00398 & 0.00959 \\
\hline 6 & 0.01869 & 0.03976 & 0.02193 & 0.04478 & 0.00347 & 0.01179 \\
\hline 7 & 0.02008 & 0.10772 & 0.03204 & 0.09772 & 0.00593 & 0.00163 \\
\hline 8 & 0.04309 & 0.30398 & 0.04521 & 0.25326 & 0.01137 & 0.16744 \\
\hline 9 & 0.05886 & 0.58548 & 0.06451 & 0.72467 & 0.015 & 0.19725 \\
\hline 10 & 0.04111 & 0.17683 & 0.05223 & 0.18243 & 0.01396 & 0.06687 \\
\hline 11 & 0.08616 & 0.02972 & 0.09767 & 0.04218 & 0.03753 & 0.00972 \\
\hline 12 & 0.08331 & 0.03178 & 0.10468 & 0.04471 & 0.03218 & 0.00814 \\
\hline 13 & 0.09553 & 0.02220 & n/a & n/a & 0.17219 & 0.00688 \\
\hline
\end{tabular}

\begin{tabular}{|c|c|c|c|c|c|c|}
\cline { 2 - 7 } \multicolumn{1}{c|}{ Soil Profile } & \multicolumn{2}{c|}{ standre-5.9 } & \multicolumn{2}{c|}{ mitchlk-5.7 } & \multicolumn{2}{c|}{ les_ebo-5.9 } \\
\cline { 2 - 7 } \multicolumn{1}{c|}{} & NMSZ & WVSZ & NMSZ & WVSZ & NMSZ & WVSZ \\
\hline 1 & 0.00325 & 0.00613 & 0.00269 & 0.00269 & 0.00472 & 0.00877 \\
\hline 2 & 0.00258 & 0.00703 & 0.00285 & 0.00526 & 0.00306 & 0.00836 \\
\hline 3 & 0.00611 & 0.01117 & 0.00242 & 0.00639 & 0.00668 & 0.0117 \\
\hline 4 & 0.00771 & 0.01566 & 0.00329 & 0.01014 & 0.00883 & 0.01901 \\
\hline 5 & 0.00844 & 0.02259 & 0.00486 & 0.01157 & 0.00596 & 0.02041 \\
\hline 6 & 0.01054 & 0.03249 & 0.00499 & 0.01845 & 0.00965 & 0.02909 \\
\hline 7 & 0.01595 & 0.09162 & 0.00948 & 0.06374 & 0.01642 & 0.08315 \\
\hline 8 & 0.03011 & 0.24424 & 0.01628 & 0.16615 & 0.026 & 0.25584 \\
\hline 9 & 0.04539 & 0.46006 & 0.02451 & 0.21053 & 0.03394 & 0.51319 \\
\hline 10 & 0.03054 & 0.11014 & 0.01827 & 0.07096 & 0.03127 & 0.14511 \\
\hline 11 & 0.07379 & 0.02694 & 0.04856 & 0.01476 & 0.07083 & 0.02435 \\
\hline 12 & 0.07981 & 0.02513 & 0.05467 & 0.01395 & 0.07357 & 0.02566 \\
\hline 13 & 0.24464 & 0.01579 & 0.1729 & 0.00928 & 0.33787 & 0.02094 \\
\hline
\end{tabular}


Again, it can be seen that for "medium" sized earthquakes likely to affect the Ohio River structures within Kentucky, most of the accelerations were within a 0.005$0.030 \mathrm{~g}$ range. This range is slightly greater than the initial peak bedrock accelerations because in most cases, the soil layers worked to amplify the seismic waves as they traveled through the soil column. The amount of amplification was determined by taking a ratio of the peak ground accelerations divided by the initial peak rock accelerations. Table IX shows the amplification $/$ deamplification factor at the initial condition (time $=0$ sec) of each earthquake motion. The motions with factors greater than one show that the seismic waves were amplified by the soil, while the motions with factors between 0.0 0.99 were deamplified. Factors in the table equal to one indicated that the seismic waves were neither amplified nor deamplified by the soil structure and remained constant. It should be noted that the amplification factors were rounded and for factors equal to 0.0 , the amplification factor was so small that the number rounded to 0.0 .

\section{TABLE IX}

\section{AMPLIFICATION FACTORS FOR SOIL PROFILES}

\begin{tabular}{|c|c|c|c|c|c|c|}
\hline \multirow[t]{2}{*}{$\begin{array}{l}\text { Soil } \\
\text { Profile }\end{array}$} & \multicolumn{2}{|c|}{ ky50yr - 6.5} & \multicolumn{2}{|c|}{ ky500yr - 7.0} & \multicolumn{2}{|c|}{ Iglodge2 -5.7 } \\
\hline & NMSZ & WVSZ & NMSZ & WVSZ & NMSZ & WVSZ \\
\hline 1 & 4.3 & 3.9 & 3.5 & 3.4 & 2.9 & 1.7 \\
\hline 2 & 3.0 & 2.9 & 2.9 & 2.3 & 1.5 & 1.3 \\
\hline 3 & 3.8 & 2.7 & 3.5 & 2.6 & 1.7 & 1.7 \\
\hline 4 & 4.0 & 3.6 & 4.3 & 3.5 & 2.0 & 2.0 \\
\hline 5 & 4.1 & 2.5 & 3.6 & 2.1 & 2.0 & 1.9 \\
\hline 6 & 3.7 & 2.5 & 3.1 & 1.9 & 1.7 & 1.7 \\
\hline 7 & 1.8 & 1.1 & 1.9 & 0.7 & 1.2 & 0.0 \\
\hline 8 & 2.9 & 0.9 & 2.1 & 0.5 & 1.6 & 1.2 \\
\hline 9 & 3.9 & 1.8 & 2.9 & 1.5 & 2.1 & 1.4 \\
\hline 10 & 2.1 & 1.7 & 1.8 & 1.1 & 1.6 & 1.4 \\
\hline 11 & 1.0 & 1.5 & 0.8 & 1.4 & 1.0 & 1.1 \\
\hline 12 & 1.0 & 1.6 & 0.8 & 1.5 & 0.8 & 0.9 \\
\hline 13 & 0.2 & 1.6 & $\mathrm{n} / \mathrm{a}$ & $\mathrm{n} / \mathrm{a}$ & 0.8 & 1.1 \\
\hline
\end{tabular}




\begin{tabular}{l|c|c|c|c|c|c|}
\cline { 2 - 7 } \multicolumn{1}{c|}{$\begin{array}{l}\text { Soil } \\
\text { Profile }\end{array}$} & \multicolumn{2}{|c|}{ standre - 5.9 } & \multicolumn{2}{c|}{ Mitchlk - 5.7 } & \multicolumn{2}{c|}{ les_ebo - 5.9 } \\
\cline { 2 - 7 } \multicolumn{1}{c|}{} & NMSZ & WVSZ & NMSZ & WVSZ & NMSZ & WVSZ \\
\hline 1 & 3.6 & 3.1 & 4.5 & 2.7 & 5.2 & 4.4 \\
\hline 2 & 2.0 & 2.3 & 3.2 & 2.6 & 2.4 & 2.8 \\
\hline 3 & 3.1 & 2.8 & 2.4 & 2.1 & 3.3 & 2.9 \\
\hline 4 & 3.9 & 3.1 & 3.3 & 3.4 & 4.4 & 3.8 \\
\hline 5 & 4.2 & 3.2 & 2.4 & 2.3 & 3.0 & 2.9 \\
\hline 6 & 3.5 & 3.0 & 2.5 & 2.6 & 3.2 & 2.6 \\
\hline 7 & 2.0 & 1.5 & 1.9 & 1.5 & 2.1 & 1.3 \\
\hline 8 & 3.0 & 1.1 & 2.3 & 1.2 & 2.6 & 1.2 \\
\hline 9 & 4.5 & 2.2 & 3.5 & 1.5 & 3.4 & 2.4 \\
\hline 10 & 2.3 & 1.5 & 2.0 & 1.5 & 2.4 & 2.0 \\
\hline 11 & 1.3 & 2.1 & 1.3 & 1.6 & 1.2 & 1.9 \\
\hline 12 & 1.4 & 1.9 & 1.4 & 1.6 & 1.3 & 2.0 \\
\hline 13 & 0.7 & 1.8 & 0.8 & 1.5 & 1.0 & 2.3 \\
\hline
\end{tabular}

The general trend with the amplification factors is that they are higher for those soil profiles that are farther away from the epicenter of the earthquake. For instance, some of the highest amplification factors come from Soil Profile \#1 which is $593 \mathrm{~km}$ from the New Madrid epicenter and $426 \mathrm{~km}$ from the Wabash Valley epicenter. The profiles which are extremely close to the epicenter, such as Profiles \#8 and \#9 in Henderson for the Wabash Valley epicenter, or Profile \#13 in Wickliffe, for a New Madrid epicenter, show small amplifications and dampening tendencies. It should be noted that greater amplification seems to occur, relatively, for those earthquakes with smaller magnitudes. For instance, Soil Profile \#10 shows greater amplification factors for the 5.7 and 5.9 earthquakes than it does for the 6.5 and the 7.0 earthquakes. Both of these trends are significant. If wave amplification is more likely to occur at greater distances for smaller magnitude earthquakes then a greater radius is more likely to be affected in the event of an earthquake. Worse, those smaller earthquakes, which have smaller recurrence intervals, are also more likely to amplify. However, these amplification factors are valid for the initial condition only. As time in an earthquake 
progresses, the amplification factor will change since the pseudo acceleration is constantly changing.

\section{B. Effect of Site Geology on Ground Motion Response}

In addition to assessing the effects of earthquake location, the effects of varying earthquake input motions were also studied. "Typical” earthquake input records for the Kentucky area were scaled to selected values so that the soil amplification effects could be assessed without needing to account for differing earthquake locations.

Within the Kentucky study area, most earthquake events reviewed generated a $0.005-0.015 \mathrm{~g}$ bedrock acceleration range. However, larger earthquake events that were relatively close to the soil profile locations produced much larger initial bedrock accelerations, therefore an estimation of $0.100 \mathrm{~g}$ was used to try and incorporate larger earthquakes into this study. In the end, the accelerations $0.005,0.010,0.015$, and 0.100 were used as input in Shake91 to create an average range ground motion response for possible earthquake events in the Ohio Valley area. These responses were then used to create average range velocity response spectra for estimation of structural responses at each typical soil profile. Figure 10 is an example of a tripartite graph for pseudo acceleration versus period as found by Shake91 for each soil profile at initial accelerations $0.005,0.010,0.015$, and 0.100 . Graphs for each of the 13 soil profiles can be found in Chapter V: Rapid Screening Guide. 


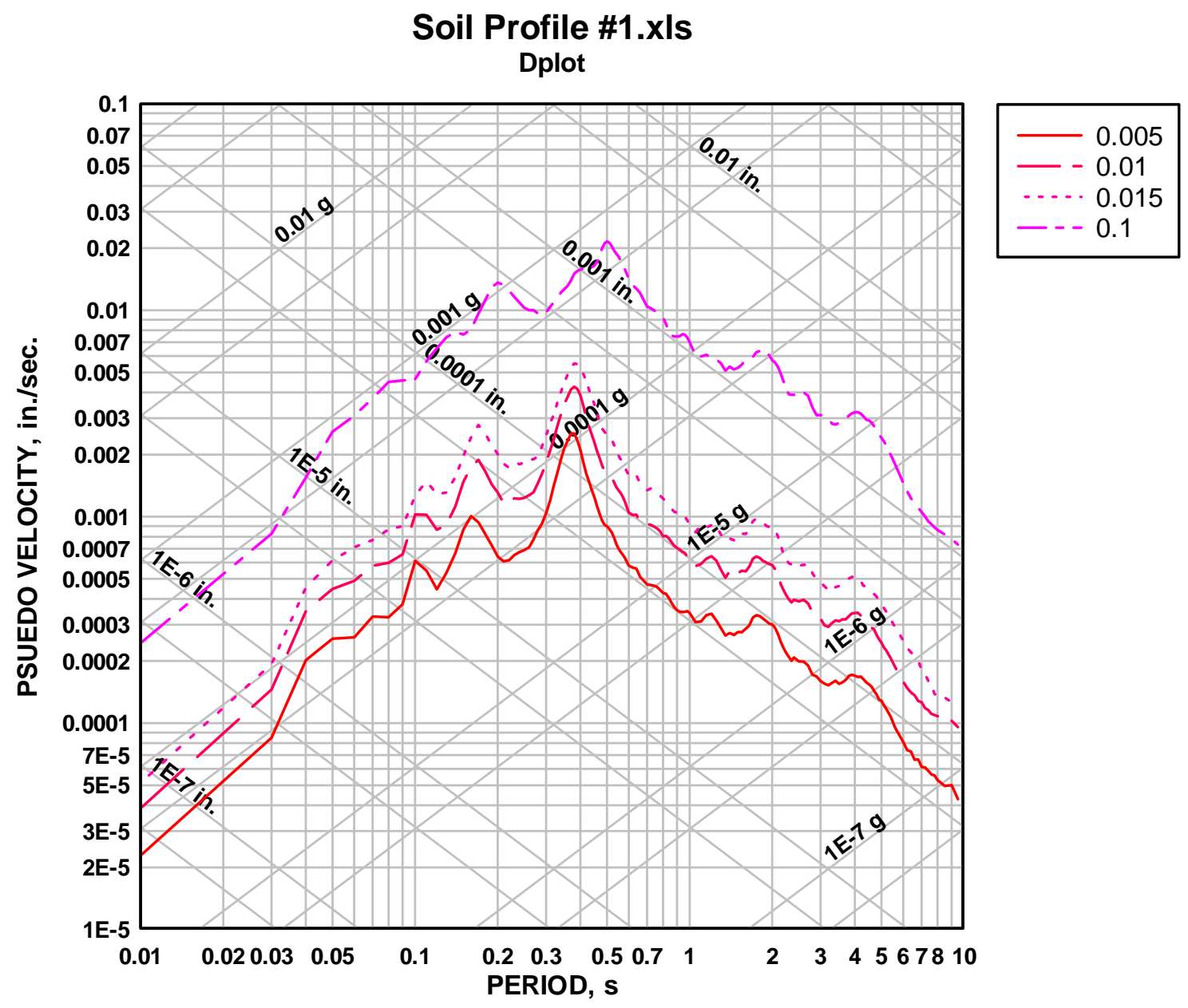

FIGURE 10 - Example Pseudo Velocity Spectrum

The average range acceleration inputs could be used in Shake91 for the creation of response spectra as shown above, but the analysis also provides an opportunity to determine the effect of site geology on ground motion responses. In order to examine the effect of site geology on ground motion responses, each of the 13 generated acceleration spectra need to be compared directly. Figure 11 is a compilation of all 13 soil profiles each with initial peak bedrock accelerations equal to 0.005. As can be seen in Figure 10, increasing the initial bedrock acceleration does not change the shape of the time history; instead it moves the same general shape up on the graph. Therefore, it would be accurate 
to compare soil profile acceleration spectra, as long as the initial bedrock acceleration was the same for each soil profile.

Soil Profile Comparison - Acceleration Spectra

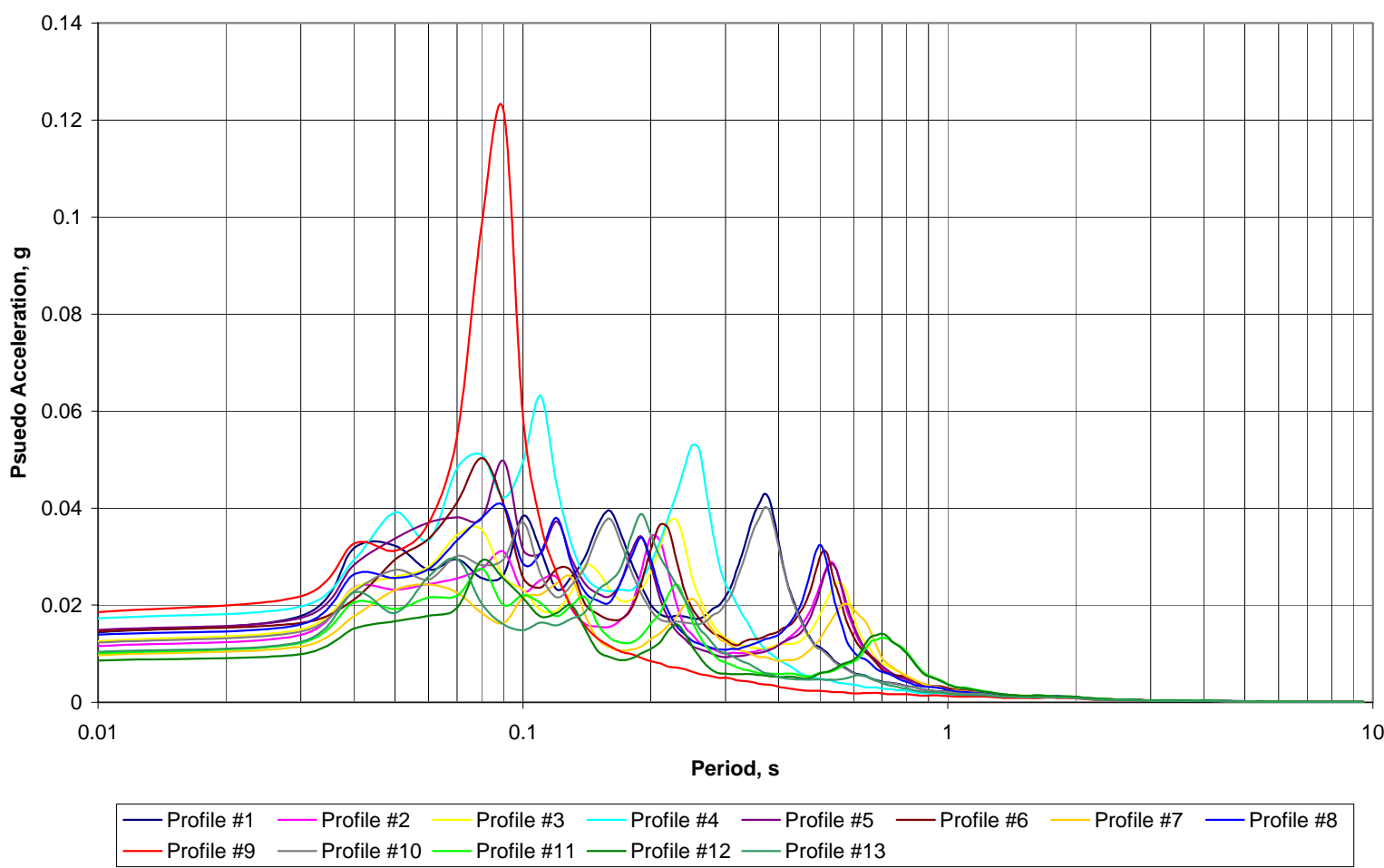

FIGURE 11- Soil Profile Comparison for a Peak Bedrock Acceleration $=0.005$

By comparing the acceleration spectra from the soil profiles, it is possible to compare the effects of site geology. From the graph (Figure 11), it can be seen that most of the spectra are relatively the same from $0-0.03$ of a second and after 1 second. They do, however, differ significantly in the range of periods between 0.03 and 1 second. The significant peaks for the various soil profiles occur at $0.09,0.11,0.2,0.25,0.4,0.5$, and 0.7 seconds. 
The first peak at 0.09 is for Soil Profile \#9. In this profile about 5 feet of silt/clay overlies about 110 feet of sand which is on top of some gravel. The extremely large sand layer causes this peak; and it can be seen that afterward, there are no other peaks and the acceleration steadily declines since the wave penetrated the sand layer so rapidly.

In relation to the previous trend, it was found that the soil profiles with large clay layers at the top of the soil structure correlated with time histories that had peaks at a much later period. For example, Profile \#3 and Profile \#6 both had peaks at 0.5 second. Profile \#3 consisted of a 55 foot silt/clay layer on top of a 54 foot gravel layer. Profile \#6 had a 24 foot clay layer on top of 86 feet of sand and gravel. While it was not possible to find an exact correlation between the soil structure and the peak period, the various peaks represented in the period between 0.03 and 1 second are likely due to the varying amounts of clay vs. sand within the soil structures. The structures, such as Profile \#9, that were mostly sand developed high peaks with early periods. On the other hand, those structures with large surficial clay layers had peaks at varying, but later, periods.

In addition, it can also be seen that Profile \#'s 11, 12, and 13 had peak values much later than all the other profiles, at a period of 0.7 second. This trend has two possible explanations. First, those three profiles not only contain significantly large upper clay layers but they also contain additional clay layers deep within the soil structure. In addition, the soil profiles which are located in the Paducah area have many alternating soil layers; and the depth to bedrock, in general, is greater than for the other profiles. Profile \#12 for instance shows 222 feet to bedrock.

In light of the aforementioned trends, it is important to consider the soil structures when using the rapid screening guide. Special attention should be paid to those soil 
structures with large clay or sand layers, those structures with deep clay layers, and those structures where the bedrock is very deep. 


\section{RAPID SCREENING GUIDE}

This rapid screening guide may be used to create design spectra and to compare those created spectra to idealized models of ground acceleration for the Ohio River Valley area. Through rapid screening, engineers will be able to quickly assess current or future bridge sites and the possible effects of earthquakes at those sites. Knowledge of the possible effects of an earthquake event will help engineers to properly mitigate or prevent possible future problems. Mitigation and prevention is especially important in the Ohio River Valley area due to the overlying soil structure's natural susceptibility to amplification. Since this amplification makes the area more vulnerable to smaller magnitude earthquakes, proper mitigation and planning is necessary.

In order to properly use the screening guide the following procedure must be used:

1.) Select appropriate typical soil profile comparable to site

2.) Estimate initial bedrock acceleration range for site based on earthquake event and location.

3.) Select velocity response spectra corresponding to appropriate soil profile

4.) Create design spectrum from peak acceleration, velocity, displacement and natural damping ratio of structure.

5.) Estimate damage through comparison of design spectrum and response spectrum.

\section{A. Selecting Appropriate Soil Profile}

Thirteen (13) typical soil profiles were used in this research and each can subsequently be used to create design spectrum estimations. Soil profiles can be chosen 
based on location or geology. Design soil profiles used were taken from actual soil profiles along the Ohio River in 11 different locations. Locations of the profiles as found in Table II are re-listed for convenience in Table X below:

\section{TABLE X}

SOIL PROFILE LOCATIONS

\begin{tabular}{|c|c|}
\hline Soil Profile \# & Location \\
\hline$\# 1$ & Flatwoods, KY \\
\hline$\# 2$ & Maysville, KY \\
\hline$\# 3$ & Newport, KY \\
\hline$\# 4$ & Petersburg, KY \\
\hline$\# 5$ & Madison, IN \\
\hline$\# 6$ & Louisville, KY \\
\hline$\# 7$ & Owensboro, KY \\
\hline$\# 8$ & Henderson, KY \\
\hline$\# 9$ & Henderson, KY \\
\hline$\# 10$ & Uniontown, KY \\
\hline$\# 11$ & Paducah, KY \\
\hline$\# 12$ & Paducah, KY \\
\hline$\# 13$ & Wickliffe, $\mathrm{KY}$ \\
\hline
\end{tabular}

Soil profiles should be chosen based on nearest location if soil structure is unknown. Otherwise, it is best to choose a soil profile based on the specific geology of the site. It is important to note that the conditions in which geology is the most pertinent are for those sites with large ratios of clay to sand or vice versa and those soil profiles with deeply embedded clay layers. Moreover, the soil profiles used in this research use typical unit strengths and dry unit weights for different soil types in the Ohio Valley region. It is not advisable to use these typical soil profiles as a substitute for soil columns with soil parameters widely varying from Tables XI through XXIII. The idealized models generated for comparison are dependent on the soil parameters, and substitution 
in this manner would result in an inaccurate analysis. All of the 13 typical soil profiles are listed in the Tables XI through XXIII:

TABLE XI

SOIL PROFILE \#1- FLATWOODS, KY

\begin{tabular}{|l|c|c|c|c|}
\hline Depth From Surface & Material & Strength $(\phi)$ & Unit Weight $\boldsymbol{Y}$ (cfs) & $\begin{array}{c}\text { Shear Wave } \\
\text { Velocity (ft/s) }\end{array}$ \\
\hline $0-1^{\prime}$ & Silt Loam & 33 & 100 & 210.86 \\
\hline $1^{\prime}-2^{\prime}$ & Silt Loam & 33 & 100 & 262.38 \\
\hline $2^{\prime}-5^{\prime}$ & Silt Loam & 33 & 100 & 310.57 \\
\hline $5^{\prime}-20^{\prime}$ & Silt / Clay & 33 & 100 & 400.11 \\
\hline $20^{\prime}-40^{\prime}$ & Sand & $10(\mathrm{~N})$ & 115 & 554.03 \\
\hline $40^{\prime}-70^{\prime}$ & Gravel & $15(\mathrm{~N})$ & 130 & 910.00 \\
\hline
\end{tabular}

TABLE XII

SOIL PROFILE \#2- MAYSVILLE, KY

\begin{tabular}{|l|c|c|c|c|}
\hline Depth From Surface & Material & Strength $(\phi)$ & Unit Weight $\mathbf{Y}$ (cfs) & $\begin{array}{c}\text { Shear Wave } \\
\text { Velocity (ft/s) }\end{array}$ \\
\hline $0-1^{\prime}$ & Silt Loam & 33 & 100 & 210.86 \\
\hline $1^{\prime}-4^{\prime}$ & Silty Clay Loam & 33 & 100 & 298.22 \\
\hline $4^{\prime}-7^{\prime}$ & Fine Sand Loam & 34 & 107 & 402.71 \\
\hline $7^{\prime}-35^{\prime}$ & Silt / Clay & 34 & 107 & 455.47 \\
\hline $35^{\prime}-78^{\prime}$ & Sand & $10(\mathrm{~N})$ & 115 & 628.41 \\
\hline $78^{\prime}-81^{\prime}$ & Gravel & $15(\mathrm{~N})$ & 130 & 979.23 \\
\hline
\end{tabular}

\section{TABLE XIII}

SOIL PROFILE \#3- NEWPORT, KY

\begin{tabular}{|l|c|c|c|c|}
\hline Depth From Surface & Material & Strength $(\phi)$ & Unit Weight $\boldsymbol{Y}$ (cfs) & $\begin{array}{c}\text { Shear Wave } \\
\text { Velocity (ft/s) }\end{array}$ \\
\hline $0^{\prime}-1^{\prime}$ & silt loam & 33 & 100 & 210.86 \\
\hline $1^{\prime}-4^{\prime}$ & silty clay loam & 33 & 100 & 298.22 \\
\hline $4^{\prime}-6^{\prime}$ & silt loam & 33 & 100 & 333.42 \\
\hline $6^{\prime}-55^{\prime}$ & silt / clay & 33 & 100 & 490.59 \\
\hline $55^{\prime}-109^{\prime}$ & gravel & $15(\mathrm{~N})$ & 130 & 985.28 \\
\hline
\end{tabular}




\section{TABLE XIV}

SOIL PROFILE \#4- PETERSBURG, KY

\begin{tabular}{|l|c|c|c|c|}
\hline Depth From Surface & Material & Strength $(\phi)$ & Unit Weight $\boldsymbol{Y}$ (cfs) & $\begin{array}{c}\text { Shear Wave } \\
\text { Velocity (ft/s) }\end{array}$ \\
\hline $0^{\prime}-1^{\prime}$ & Silt Loam & 33 & 100 & 210.86 \\
\hline $1^{\prime}-4^{\prime}$ & Silty Clay Loam & 33 & 100 & 298.22 \\
\hline $4^{\prime}-6^{\prime}$ & Silt Loam & 33 & 100 & 333.42 \\
\hline $6^{\prime}-55^{\prime}$ & Silt / Clay & 33 & 100 & 490.59 \\
\hline $55^{\prime}-70^{\prime}$ & Gravel & $15(\mathrm{~N})$ & 130 & 933.45 \\
\hline $70^{\prime}-113^{\prime}$ & Sand & $10(\mathrm{~N})$ & 115 & 691.69 \\
\hline $113^{\prime}-123^{\prime}$ & Gravel & $15(\mathrm{~N})$ & 130 & 1059.29 \\
\hline
\end{tabular}

TABLE XV

SOIL PROFILE \#5- MADISON, IN

\begin{tabular}{|l|c|c|c|c|}
\hline Depth From Surface & Material & Strength $(\phi)$ & Unit Weight Y (cfs) & $\begin{array}{c}\text { Shear Wave } \\
\text { Velocity (ft/s) }\end{array}$ \\
\hline $0^{\prime}-1^{\prime}$ & Silt Loam & 33 & 100 & 210.86 \\
\hline $1^{\prime}-3^{\prime}$ & Silty Clay Loam & 34 & 107 & 285.26 \\
\hline $3^{\prime}-5^{\prime}$ & Fine Sandy Loam & 33 & 112 & 348.05 \\
\hline $5^{\prime}-6^{\prime}$ & Very Fine Sand & 36 & 124 & 402.71 \\
\hline $6^{\prime}-15^{\prime}$ & Silt / Clay & 33 & 100 & 396.79 \\
\hline $15^{\prime}-27^{\prime}$ & Gravel & $15(\mathrm{~N})$ & 130 & 751.33 \\
\hline $27^{\prime}-75^{\prime}$ & Sand & $10(\mathrm{~N})$ & 115 & 615.73 \\
\hline $75^{\prime}-95^{\prime}$ & Gravel & $15(\mathrm{~N})$ & 130 & 992.36 \\
\hline
\end{tabular}

\section{TABLE XVI}

SOIL PROFILE \#6- LOUISVILLE, KY

\begin{tabular}{|l|c|c|c|c|}
\hline Depth From Surface & Material & Strength $(\phi)$ & Unit Weight Y (cfs) & $\begin{array}{c}\text { Shear Wave } \\
\text { Velocity (ft/s) }\end{array}$ \\
\hline $0-4^{\prime}$ & Silty Clay Loam & 33 & 100 & 285.26 \\
\hline $4^{\prime}-5^{\prime}$ & Silt Loam & 33 & 99 & 326.50 \\
\hline $5^{\prime}-24^{\prime}$ & Silt / Clay & 33 & 99 & 423.11 \\
\hline $24^{\prime}-80^{\prime}$ & Gravel & $15(\mathrm{~N})$ & 130 & 899.90 \\
\hline $80^{\prime}-90^{\prime}$ & Sand & $10(\mathrm{~N})$ & 115 & 681.62 \\
\hline $90^{\prime}-110^{\prime}$ & Gravel & $15(\mathrm{~N})$ & 130 & 1024.97 \\
\hline
\end{tabular}


TABLE XVII

SOIL PROFILE \#7- OWENSBORO, KY

\begin{tabular}{|l|c|c|c|c|}
\hline Depth From Surface & Material & Strength $(\phi)$ & Unit Weight $\boldsymbol{Y}$ (cfs) & $\begin{array}{c}\text { Shear Wave } \\
\text { Velocity (ft/s) }\end{array}$ \\
\hline $0^{\prime}-1^{\prime}$ & Silt Loam & 33 & 105 & 210.86 \\
\hline $1^{\prime}-2^{\prime}$ & Silt Loam & 33 & 102 & 262.38 \\
\hline $2^{\prime}-5^{\prime}$ & Silt Loam & 33 & 103 & 310.57 \\
\hline $5^{\prime}-40^{\prime}$ & Silt / Clay & 33 & 100 & 461.77 \\
\hline $40^{\prime}-65^{\prime}$ & Gravel & $15(\mathrm{~N})$ & 130 & 901.62 \\
\hline $65^{\prime}-78^{\prime}$ & Sand & $10(\mathrm{~N})$ & 115 & 658.56 \\
\hline $78^{\prime}-85^{\prime}$ & Silt / Clay & 33 & 100 & 596.57 \\
\hline $85^{\prime}-105^{\prime}$ & Sand & $10(\mathrm{~N})$ & 115 & 696.88 \\
\hline $105^{\prime}-110^{\prime}$ & Gravel & $15(\mathrm{~N})$ & 130 & 1039.82 \\
\hline
\end{tabular}

TABLE XVIII

SOIL PROFILE \#8- HENDERSON, KY 1

\begin{tabular}{|l|c|c|c|c|}
\hline Depth From Surface & Material & Strength $(\phi)$ & Unit Weight $\boldsymbol{Y}(\mathbf{c f s})$ & $\begin{array}{c}\text { Shear Wave } \\
\text { Velocity (ft/s) }\end{array}$ \\
\hline $0-4^{\prime}$ & Silt Loam & 33 & 100 & 277.84 \\
\hline $4^{\prime}-43^{\prime}$ & Silt / Clay & 33 & 100 & 465.78 \\
\hline $43^{\prime}-60^{\prime}$ & Sand & $10(\mathrm{~N})$ & 115 & 616.93 \\
\hline $60^{\prime}-85^{\prime}$ & Gravel & $15(\mathrm{~N})$ & 130 & 961.43 \\
\hline
\end{tabular}

TABLE XIX

SOIL PROFILE \# 9- HENDERSON, KY 2

\begin{tabular}{|l|c|c|c|c|}
\hline Depth From Surface & Material & Strength $(\phi)$ & Unit Weight $\boldsymbol{Y}$ (cfs) & $\begin{array}{c}\text { Shear Wave } \\
\text { Velocity (ft/s) }\end{array}$ \\
\hline $0-5^{\prime}$ & Silt Loam & 33 & 100 & 290.46 \\
\hline $5^{\prime}-110^{\prime}$ & Sand & $10(\mathrm{~N})$ & 115 & 630.61 \\
\hline $110^{\prime}-113^{\prime}$ & Gravel & $15(\mathrm{~N})$ & 130 & 1047.41 \\
\hline
\end{tabular}


TABLE XX

SOIL PROFILE \#10- UNIONTOWN, KY

\begin{tabular}{|l|c|c|c|c|}
\hline Depth From Surface & Material & Strength $(\phi)$ & Unit Weight $\boldsymbol{Y}$ (cfs) & $\begin{array}{c}\text { Shear Wave } \\
\text { Velocity (ft/s) }\end{array}$ \\
\hline $0-5^{\prime}$ & Silty Clay Loam & 33 & 100 & 298.22 \\
\hline $5^{\prime}-25^{\prime}$ & Silt / Clay & 33 & 100 & 425.97 \\
\hline $25^{\prime}-40^{\prime}$ & Sand & $10(\mathrm{~N})$ & 115 & 562.93 \\
\hline $40^{\prime}-70^{\prime}$ & Gravel & $15(\mathrm{~N})$ & 130 & 910.00 \\
\hline
\end{tabular}

\section{TABLE XXI}

SOIL PROFILE \#11- PADUCAH, KY 1

\begin{tabular}{|l|c|c|c|c|}
\hline Depth From Surface & Material & Strength $(\phi)$ & Unit Weight $\boldsymbol{Y}(\mathbf{c f s})$ & $\begin{array}{c}\text { Shear Wave } \\
\text { Velocity (ft/s) }\end{array}$ \\
\hline $0-3^{\prime}$ & Silty Clay Loam & 33 & 100 & 269.39 \\
\hline $3^{\prime}-4^{\prime}$ & Silty Clay Loam & 33 & 100 & 318.87 \\
\hline $4^{\prime}-7^{\prime}$ & Silty Clay Loam & 33 & 100 & 348.88 \\
\hline $7^{\prime}-9^{\prime}$ & Silty Clay Loam & 33 & 100 & 375.89 \\
\hline $9^{\prime}-33^{\prime}$ & Sand & $10(\mathrm{~N})$ & 115 & 516.07 \\
\hline $33^{\prime}-68^{\prime}$ & Gravel & $15(\mathrm{~N})$ & 130 & 894.67 \\
\hline $68^{\prime}-105^{\prime}$ & Silt / Clay & 33 & 100 & 603.68 \\
\hline $105-110^{\prime}$ & Sand & $10(\mathrm{~N})$ & 115 & 710.89 \\
\hline
\end{tabular}

TABLE XXII

SOIL PROFILE \#12- PADUCAH, KY 2

\begin{tabular}{|l|c|c|c|c|}
\hline Depth From Surface & Material & Strength $(\phi)$ & Unit Weight Y (cfs) & $\begin{array}{c}\text { Shear Wave } \\
\text { Velocity (ft/s) }\end{array}$ \\
\hline $0-3^{\prime}$ & Silty Clay Loam & 33 & 100 & 269.39 \\
\hline $3^{\prime}-4^{\prime}$ & Silty Clay Loam & 33 & 100 & 318.87 \\
\hline $4^{\prime}-7^{\prime}$ & Silty Clay Loam & 33 & 100 & 348.88 \\
\hline $7^{\prime}-10^{\prime}$ & Silty Clay Loam & 33 & 100 & 380.45 \\
\hline $10^{\prime}-50$ & Gravel & $15(\mathrm{~N})$ & 130 & 806.60 \\
\hline $50^{\prime}-61^{\prime}$ & Sand & $10(\mathrm{~N})$ & 115 & 626.18 \\
\hline $61^{\prime}-95^{\prime}$ & Gravel & $15(\mathrm{~N})$ & 130 & 975.52 \\
\hline $95^{\prime}-118^{\prime}$ & Silt / Clay & 33 & 100 & 629.20 \\
\hline $118^{\prime}-220^{\prime}$ & Sand & $10(\mathrm{~N})$ & 115 & 728.82 \\
\hline $220^{\prime}-222^{\prime}$ & Gravel & $15(\mathrm{~N})$ & 130 & 1200.17 \\
\hline
\end{tabular}


from the epicenter produced larger initial bedrock accelerations. For these cases, the $0.100 \mathrm{~g}$ initial bedrock acceleration line on the response spectrum graph should be used for comparison. Therefore, if the distance from an assumed epicenter is known, it is recommended that an estimated range of the initial acceleration be calculated. This estimated range will better determine where on the response spectrum graph the response at the investigated site will fall. Estimations may also be made using the initial bedrock accelerations calculated for each of the 13 profiles. Tables for each profile can be found in Appendix II.

\section{C. $\underline{\text { Response Spectrum Graphs }}$}

After the initial bedrock acceleration range and the appropriate soil profile model are determined, a design spectrum can be created for comparison to the previously generated response spectrum graph. It is best if the design spectrum is drawn directly on the response spectrum graph. Differences in the estimated time-histories of the design and response spectrum are more pronounced in direct comparison. The velocity response spectra for each separate soil profile at various initial bedrock accelerations are shown in the following Figures 12-24: 


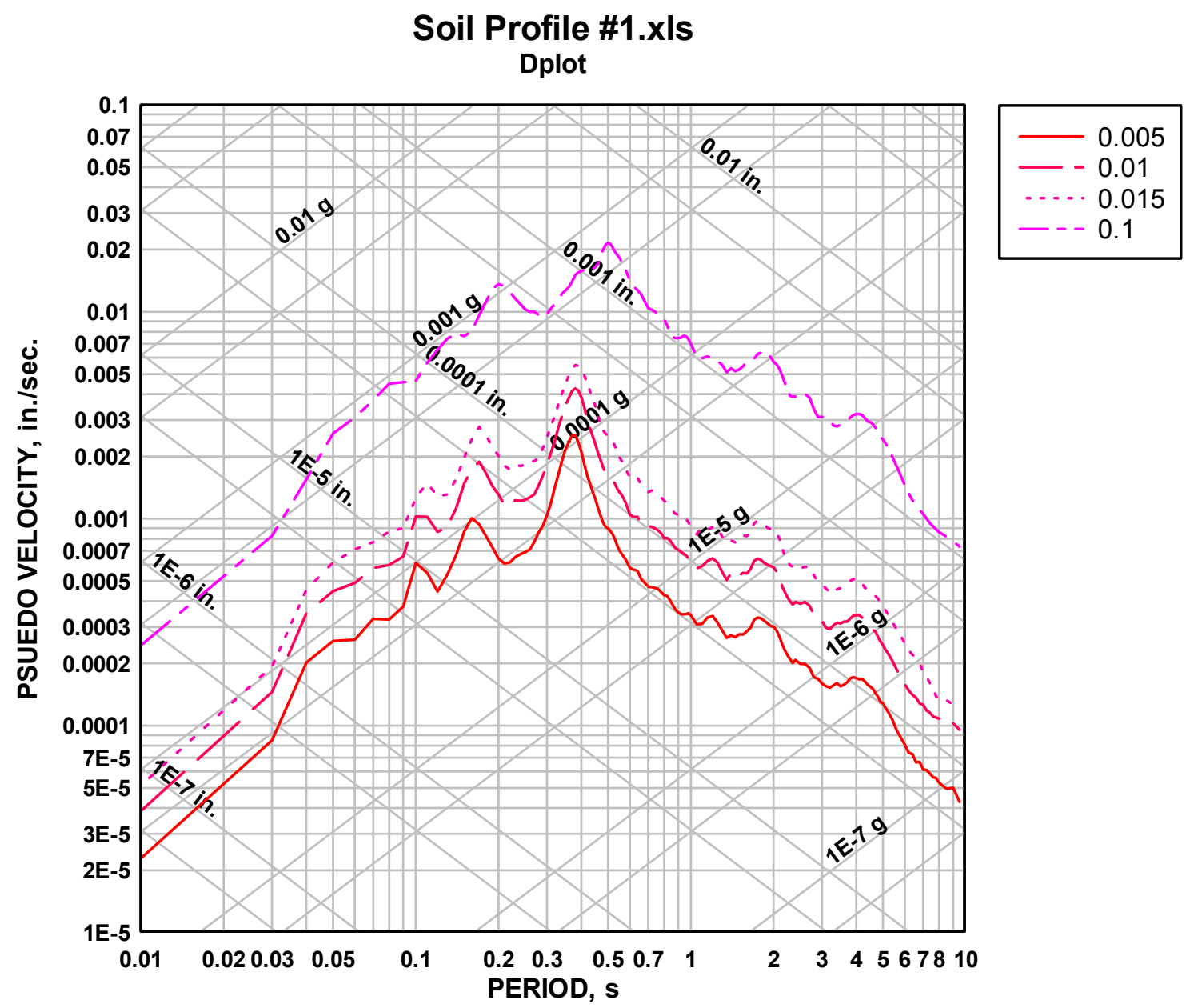

FIGURE 12- Pseudo Velocity Spectrum for Soil Profile \#1 
TABLE XXIII

SOIL PROFILE \#13- WICKLIFFE, KY

\begin{tabular}{|l|c|c|c|c|}
\hline Depth From Surface & Material & Strength $(\phi)$ & Unit Weight Y (cfs) & $\begin{array}{c}\text { Shear Wave } \\
\text { Velocity (ft/s) }\end{array}$ \\
\hline $0-3^{\prime}$ & Silty Clay Loam & 33 & 100 & 269.39 \\
\hline $3^{\prime}-4^{\prime}$ & Silty Clay Loam & 33 & 100 & 318.87 \\
\hline $4^{\prime}-7^{\prime}$ & Silty Clay Loam & 33 & 100 & 348.88 \\
\hline $7^{\prime}-9^{\prime}$ & Silty Clay Loam & 33 & 100 & 375.89 \\
\hline $9^{\prime}-19^{\prime}$ & Silt / Clay & 33 & 100 & 420.17 \\
\hline $19^{\prime}-28^{\prime}$ & Gravel & $15(\mathrm{~N})$ & 130 & 768.34 \\
\hline $28^{\prime}-66^{\prime}$ & Silt / Clay & 33 & 100 & 534.67 \\
\hline $66^{\prime}-87^{\prime}$ & Gravel & $15(\mathrm{~N})$ & 130 & 971.75 \\
\hline $87^{\prime}-106^{\prime}$ & Sand & $10(\mathrm{~N})$ & 115 & 699.05 \\
\hline
\end{tabular}

\section{B. Initial Bedrock Acceleration}

Once the soil profile is chosen, the range of initial bedrock acceleration of the specific site will need to be calculated or estimated. This acceleration range will be used in the response spectrum graphs to better determine where on the graph the actual acceleration response for the site will occur. Bedrock accelerations used to generate the response spectrum graphs were calculated using the Toro equation (Toro et al, 1997):

$$
\begin{aligned}
& \ln Y=C_{1}+C_{2}(M-6)+C_{3}(M-6)^{2}-C_{4} \ln \left(R_{M}\right)-\left(C_{5}-C_{4}\right) \max \left[\ln \left(\frac{R_{M}}{100}\right), 0\right]-C_{6} R_{M} \\
& +\varepsilon_{e}+\varepsilon_{a}, \quad \text { where } R_{M}=\sqrt{R_{j b}{ }^{2}+C_{7}{ }^{2}}
\end{aligned}
$$

The Toro equation generates accelerations as a function of distance from the site to the epicenter and the magnitude of the earthquake. Each spectrum includes a response of the earthquake ground acceleration using an initial bedrock acceleration input of 0.005 , $0.010,0.015$, and $0.100 \mathrm{~g}$. In the initial analysis of the possible bedrock accelerations, the $0.005-0.015 \mathrm{~g}$ range included most of the calculated accelerations for magnitude 5.0-6.5 earthquakes that were located more than $50 \mathrm{~km}$ from the epicenter. The higher magnitude earthquakes (7.0 region) and the sites which were located less than $50 \mathrm{~km}$ 


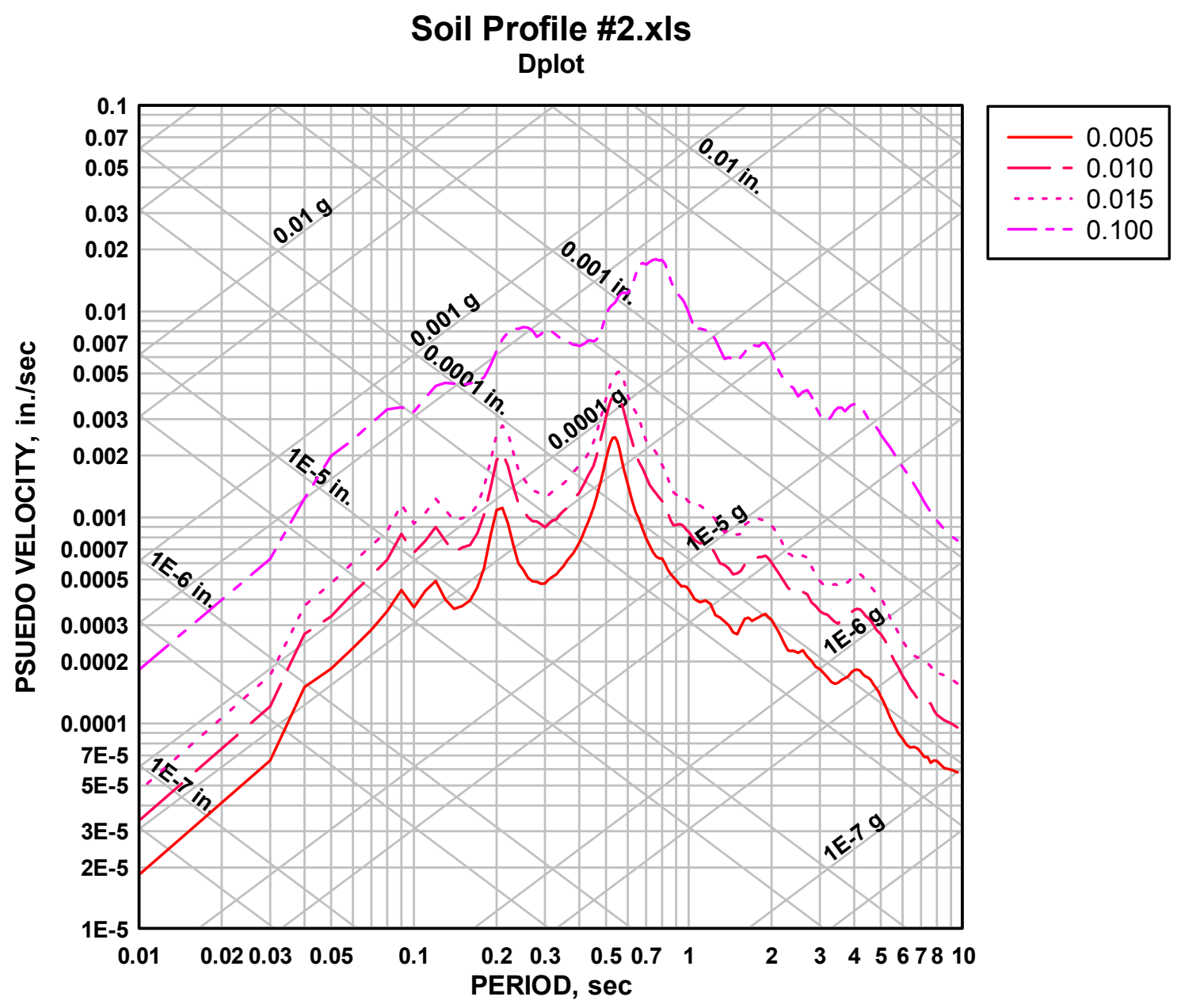

FIGURE 13- Pseudo Velocity Spectrum for Soil Profile \#2 


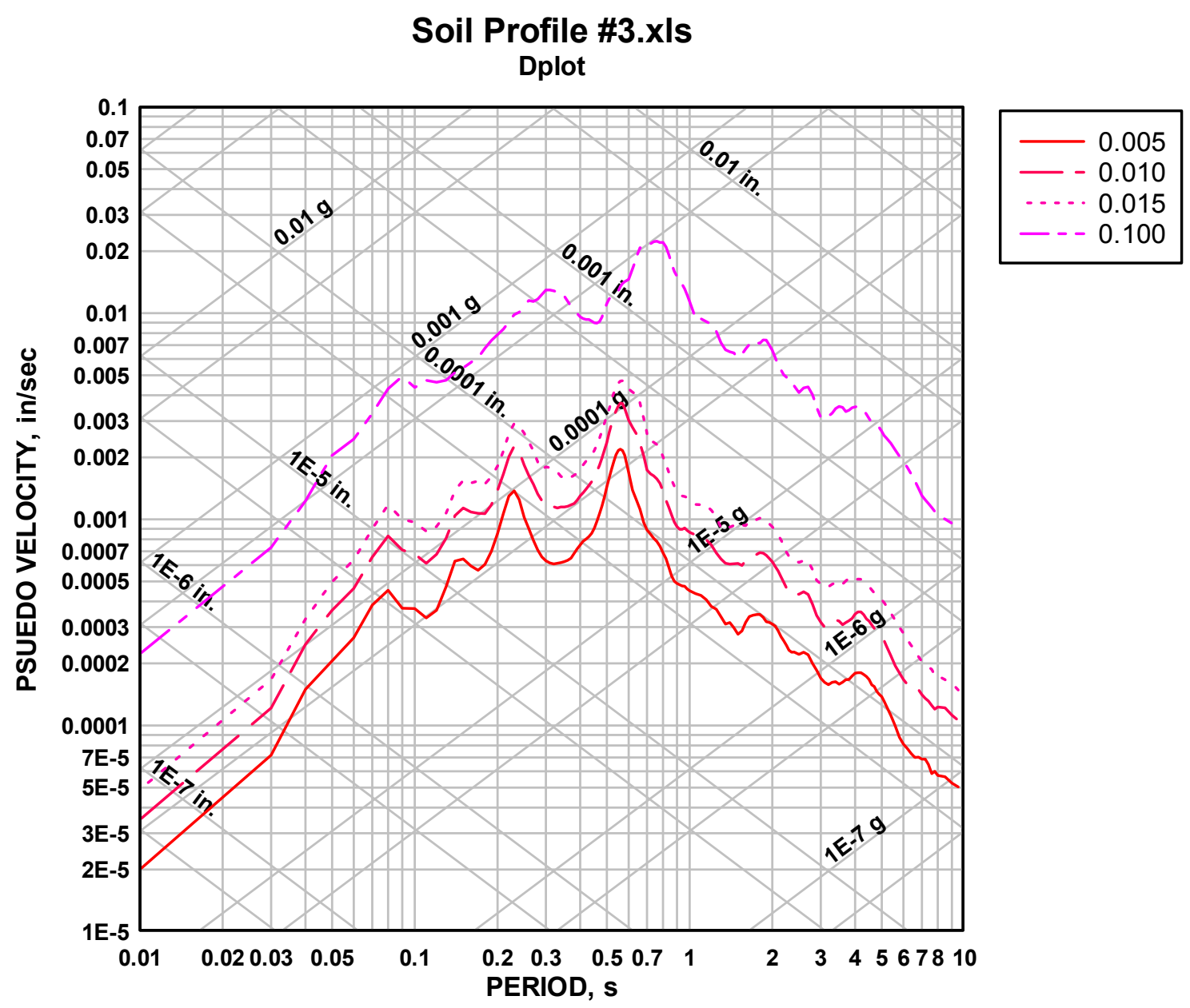

FIGURE 14- Pseudo Velocity Spectrum for Soil Profile \#3 


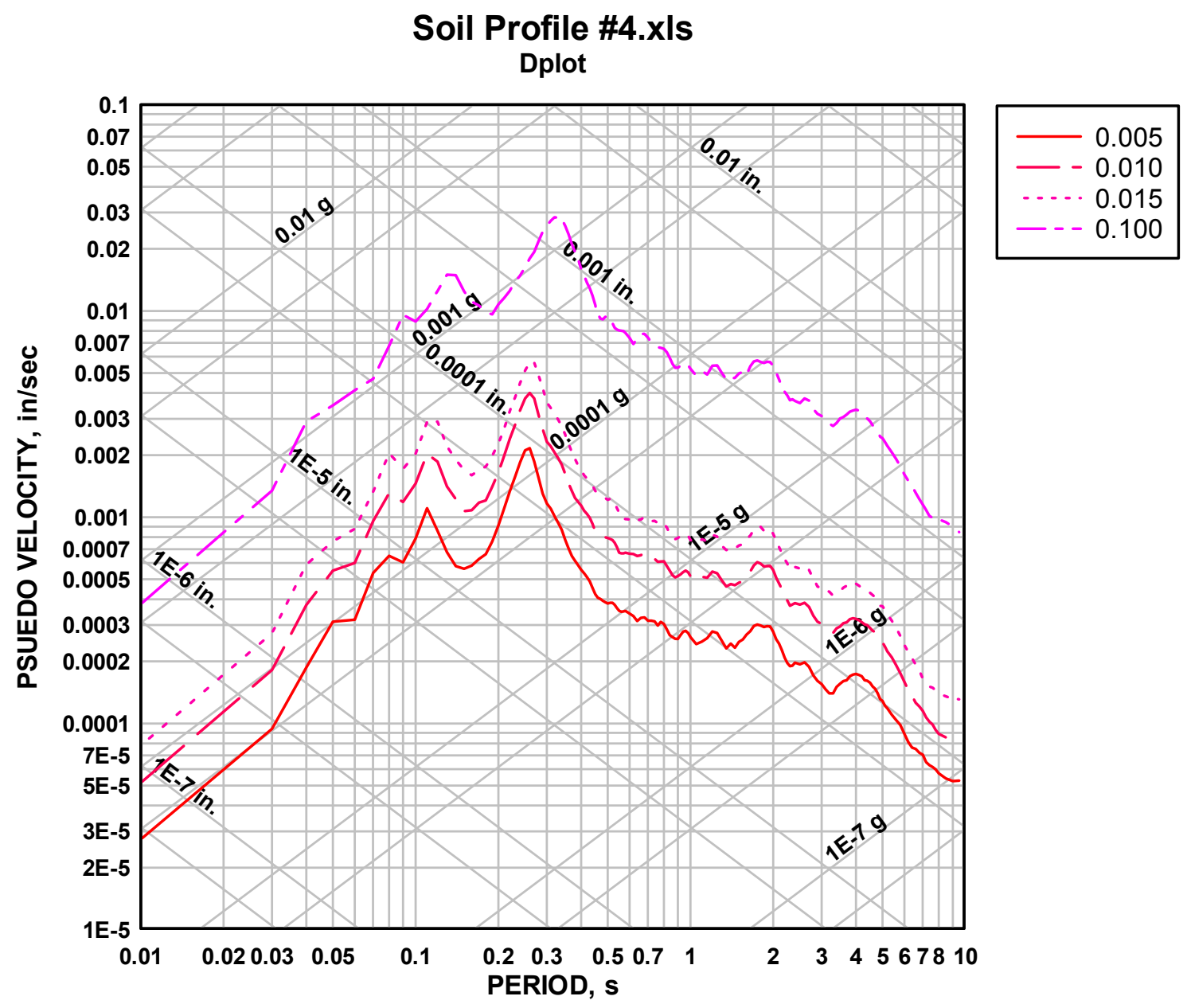

FIGURE 15- Pseudo Velocity Spectrum for Soil Profile \#4 


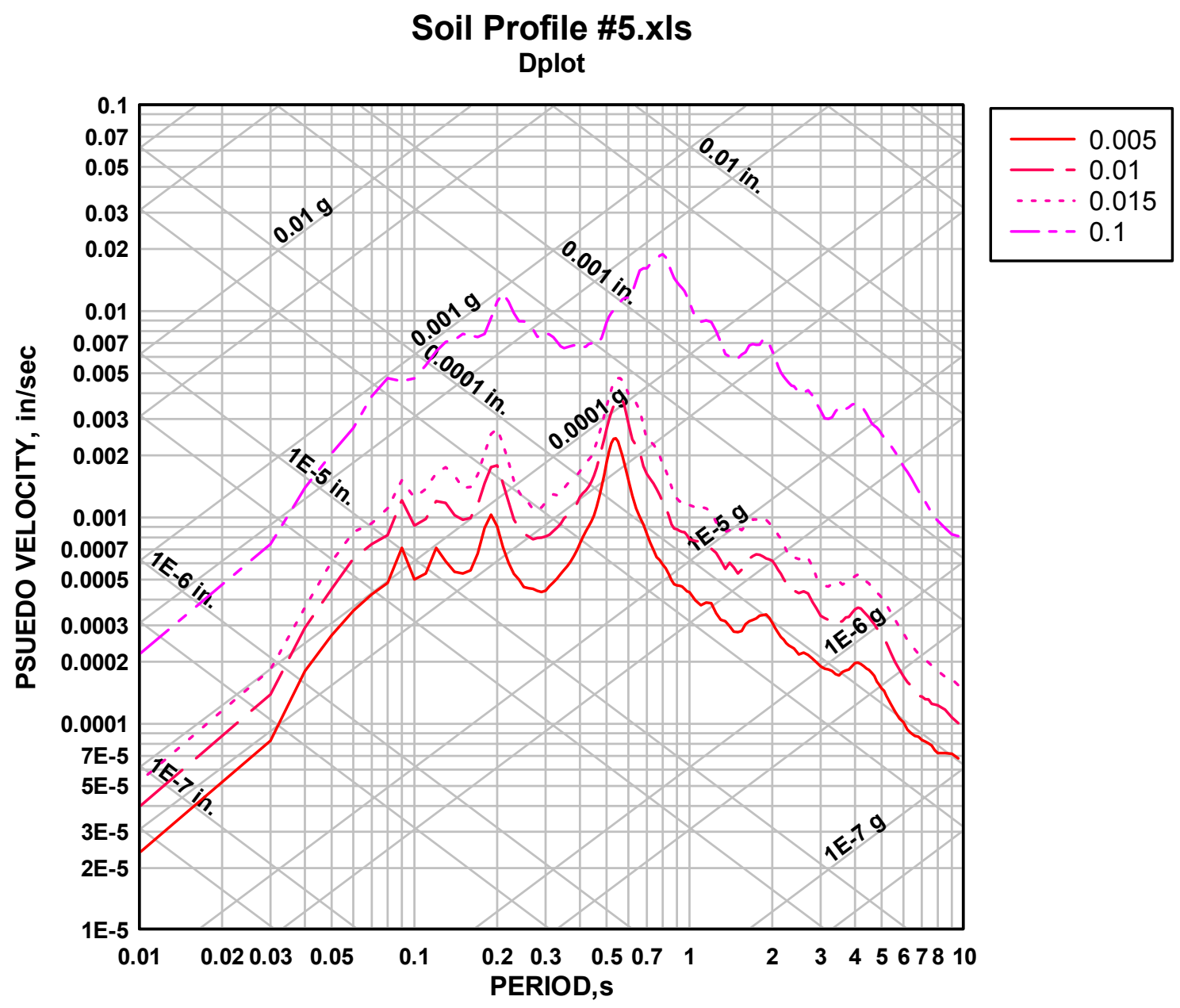

FIGURE 16- Pseudo Velocity Spectrum for Soil Profile \#5 


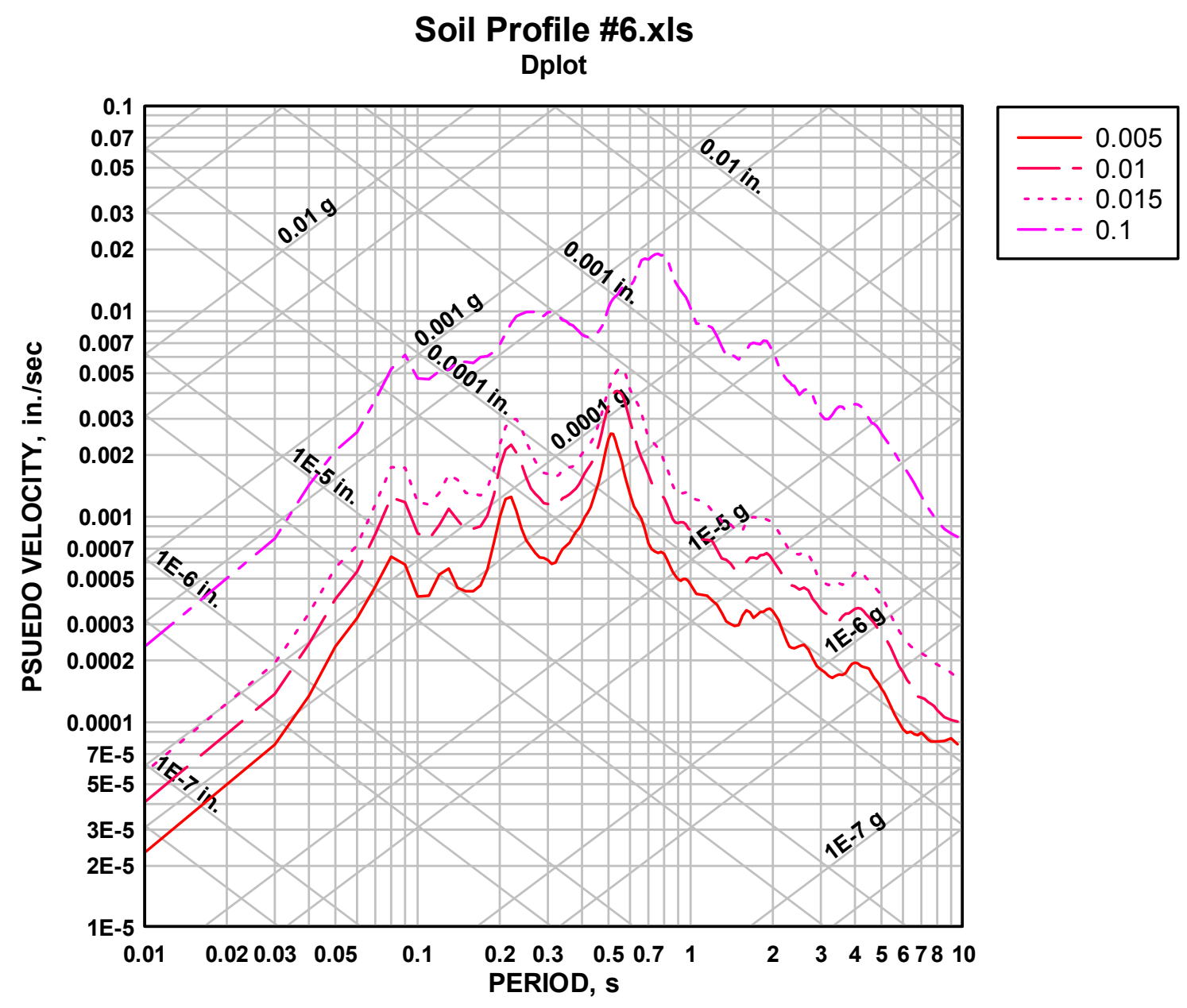

FIGURE 17- Pseudo Velocity Spectrum for Soil Profile \#6 


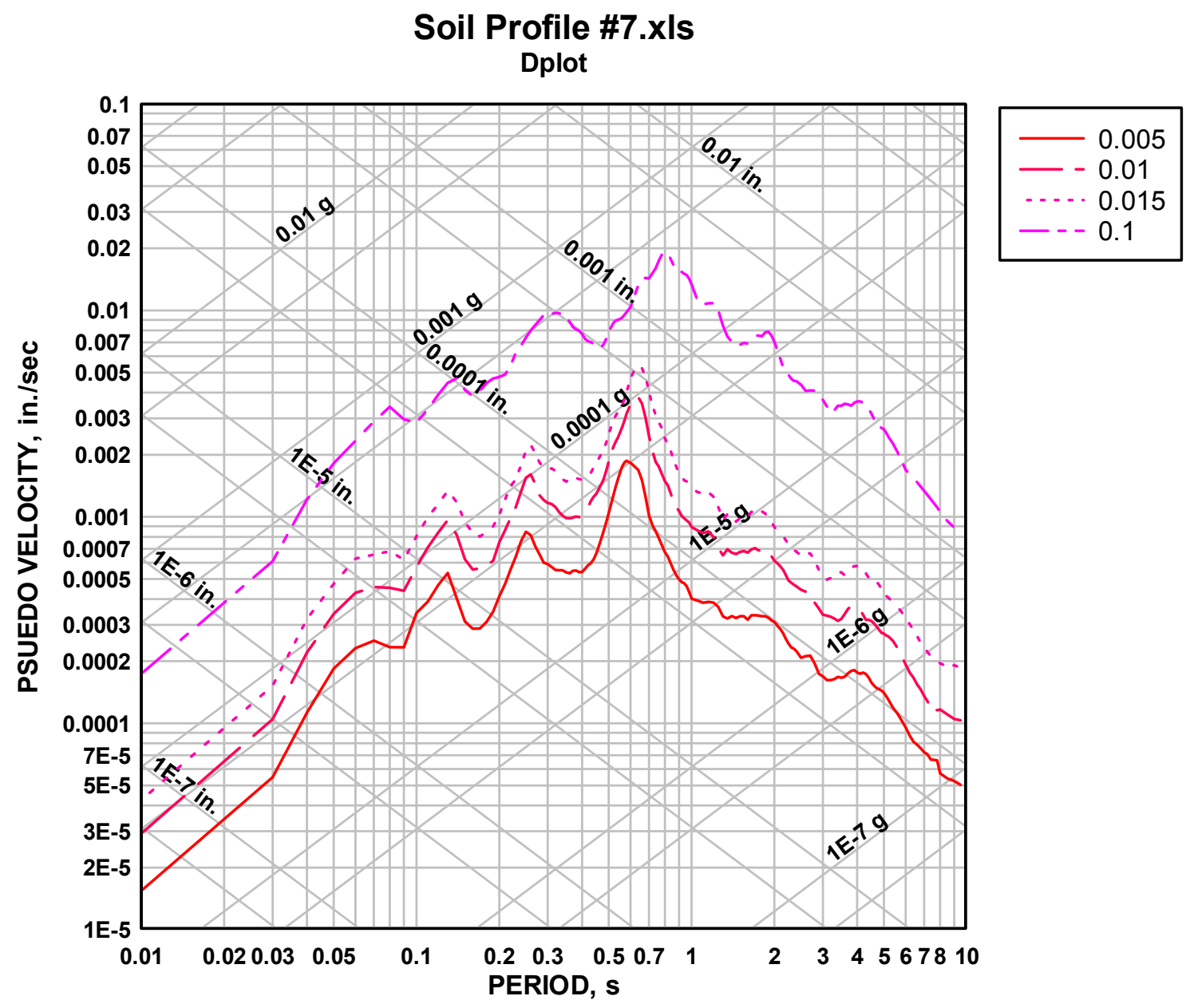

FIGURE 18- Pseudo Velocity Spectrum for Soil Profile \#7 


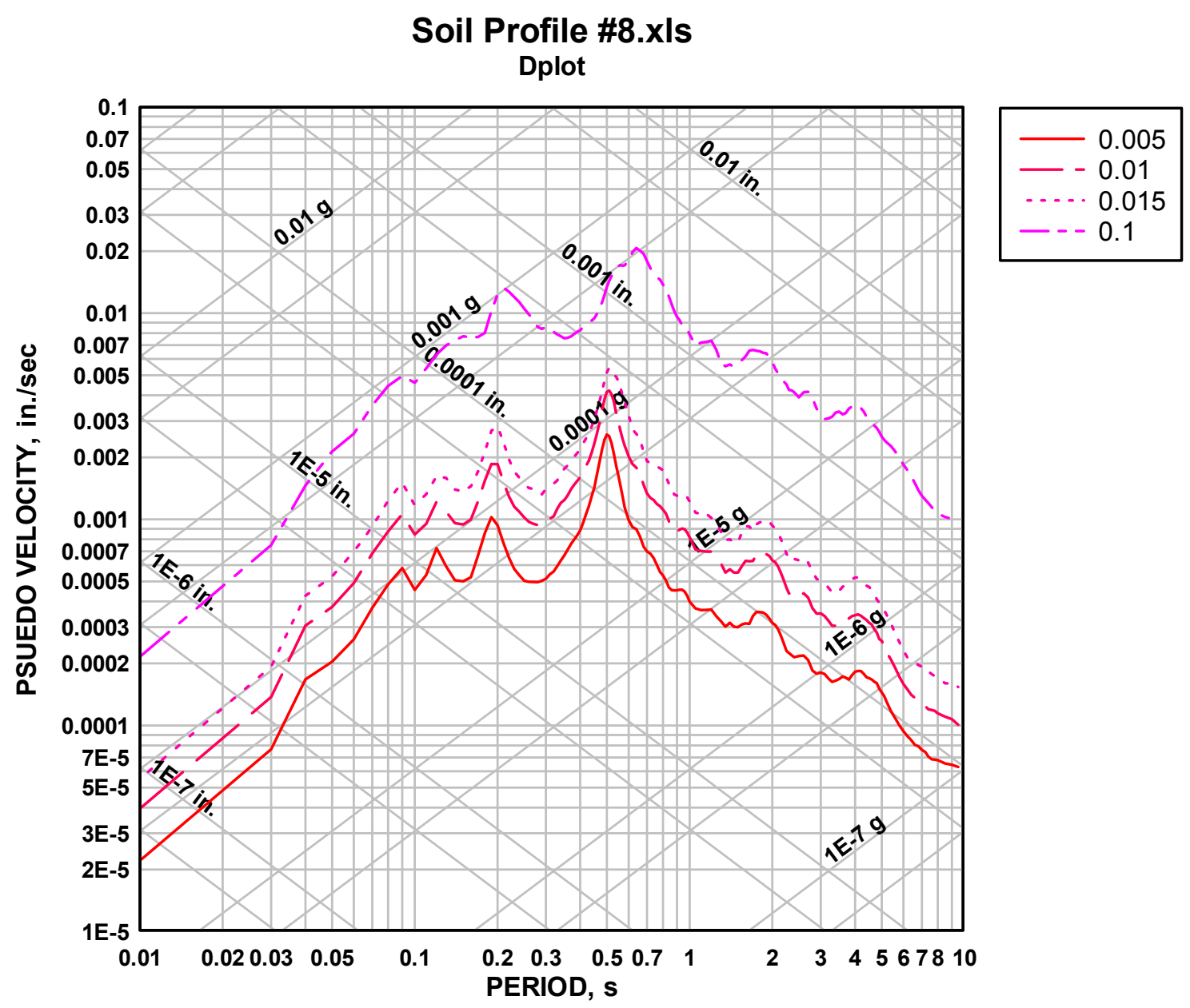

FIGURE 19- Pseudo Velocity Spectrum for Soil Profile \#8 


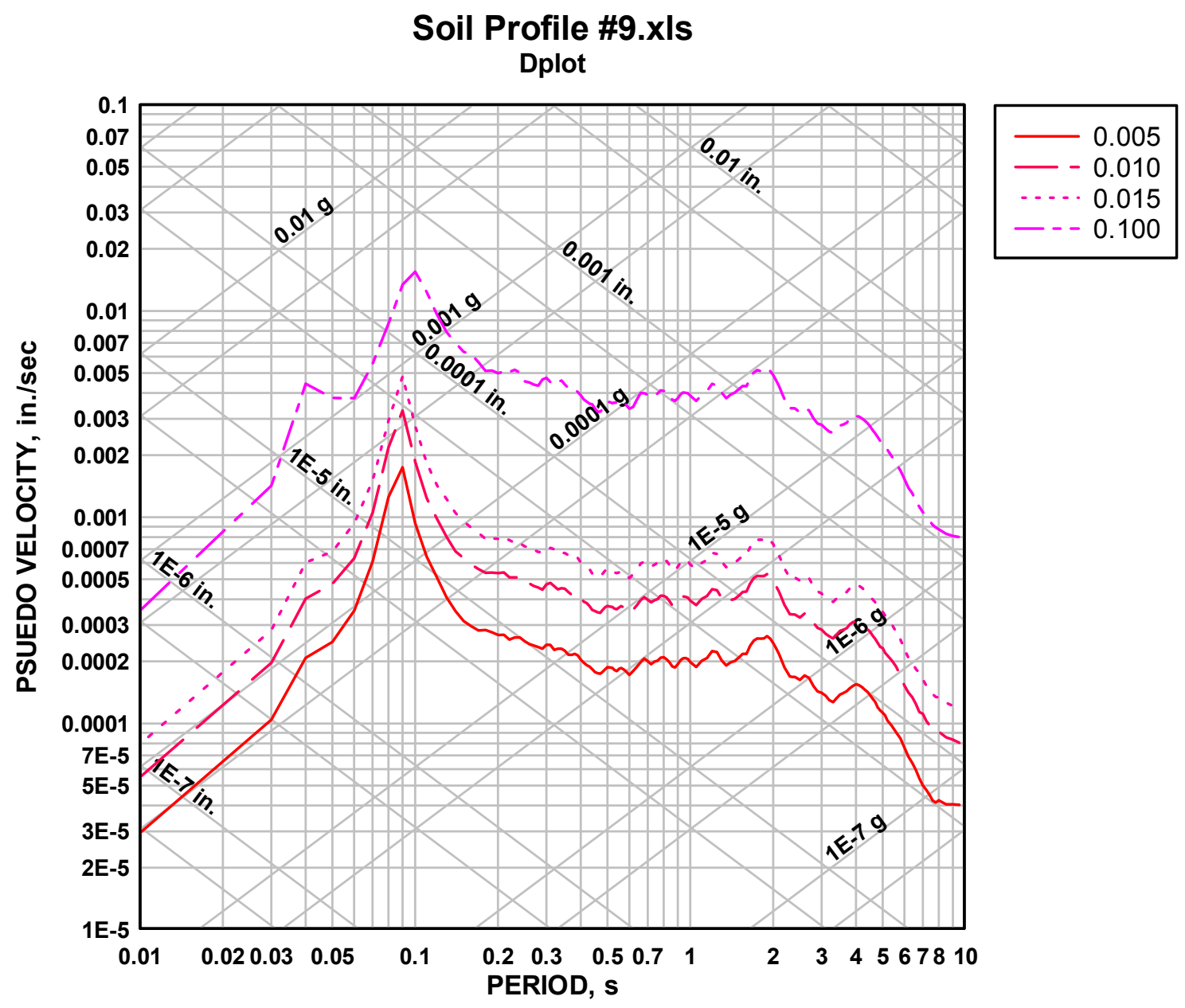

FIGURE 20- Pseudo Velocity Spectrum for Soil Profile \#9 


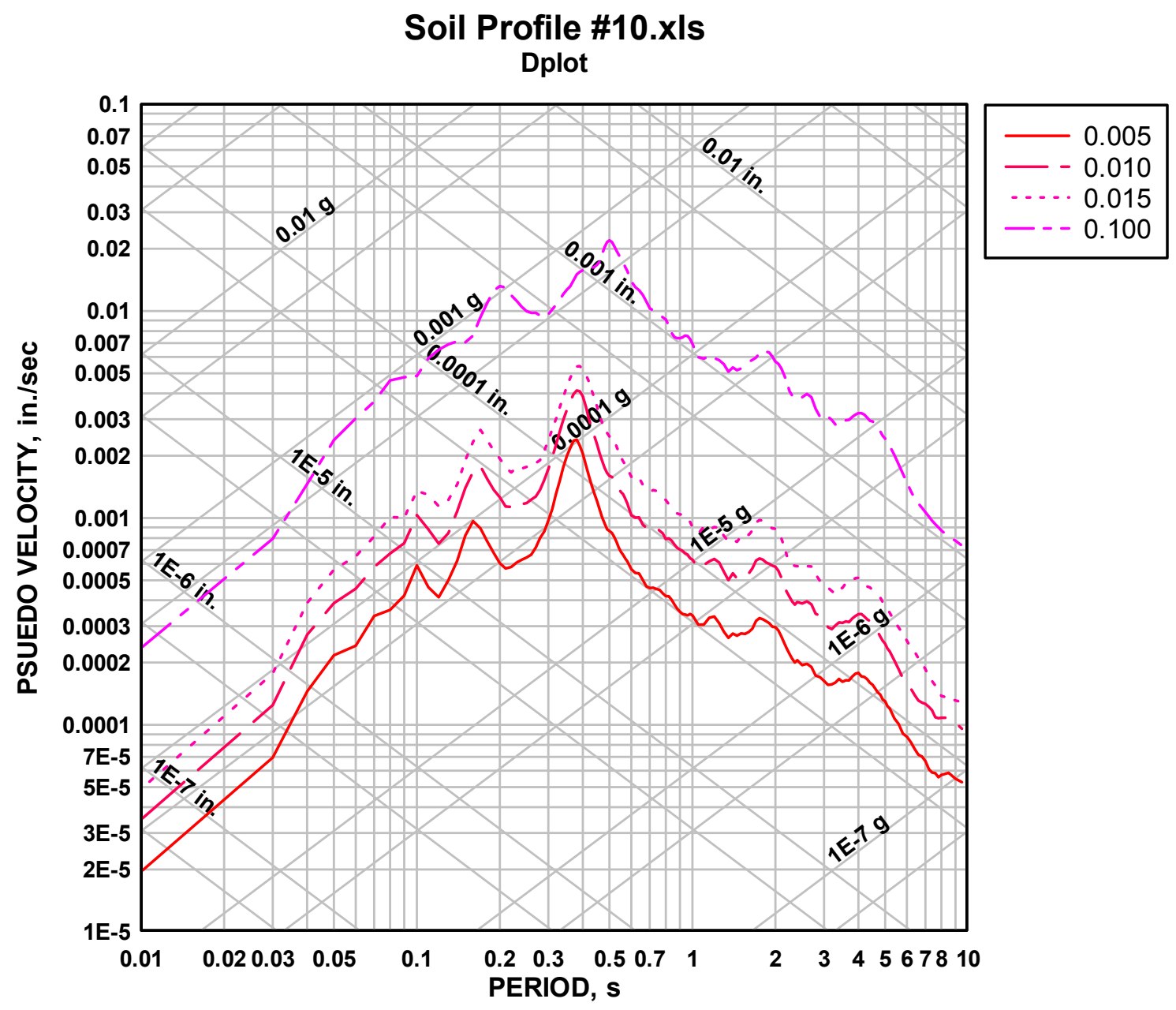

FIGURE 21- Pseudo Velocity Spectrum for Soil Profile \#10 


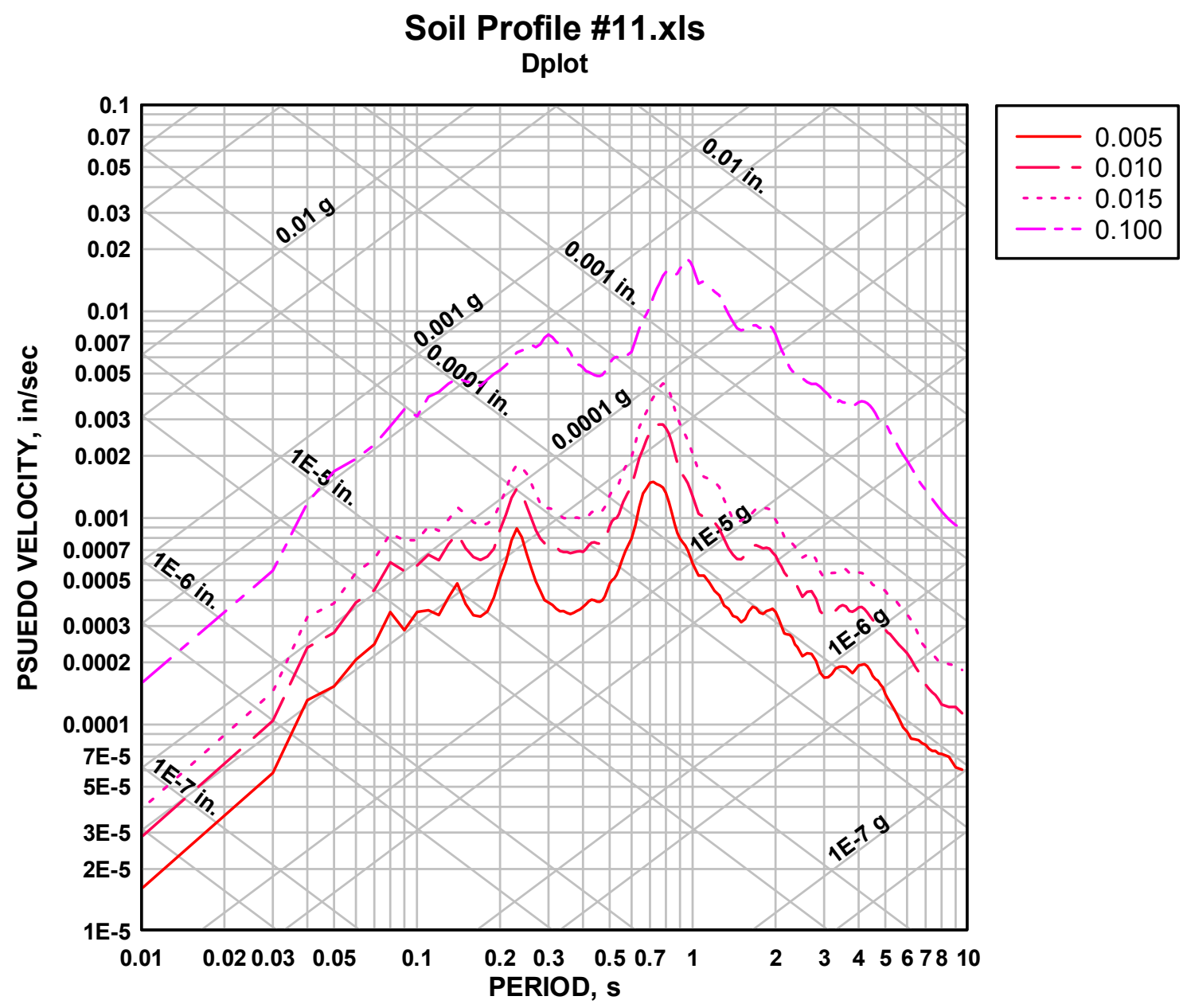

FIGURE 22- Pseudo Velocity Spectrum for Soil Profile \#11 


\section{Soil Profile \#12.xIs}

Dplot

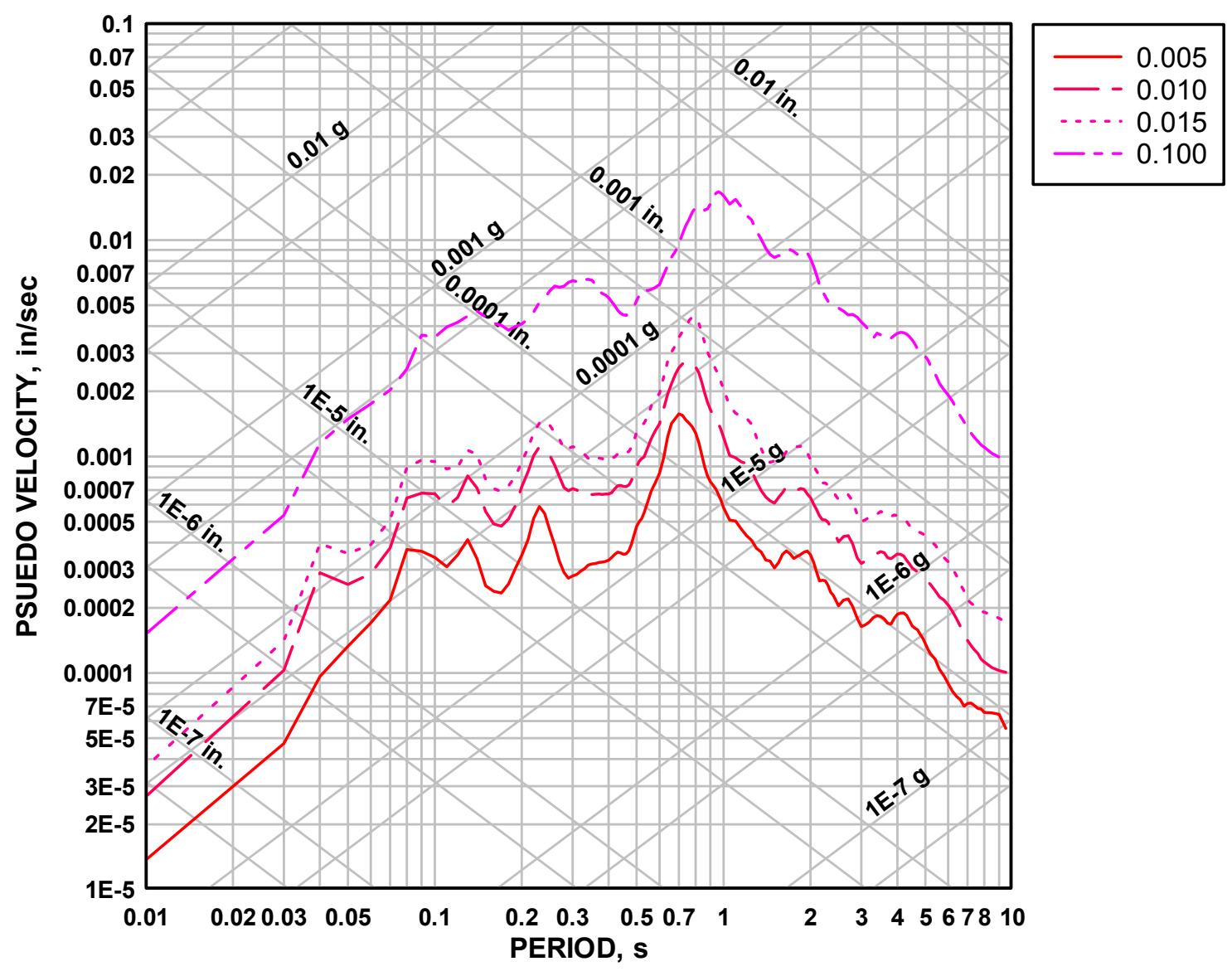

FIGURE 23- Pseudo Velocity Spectrum for Soil Profile \#12 


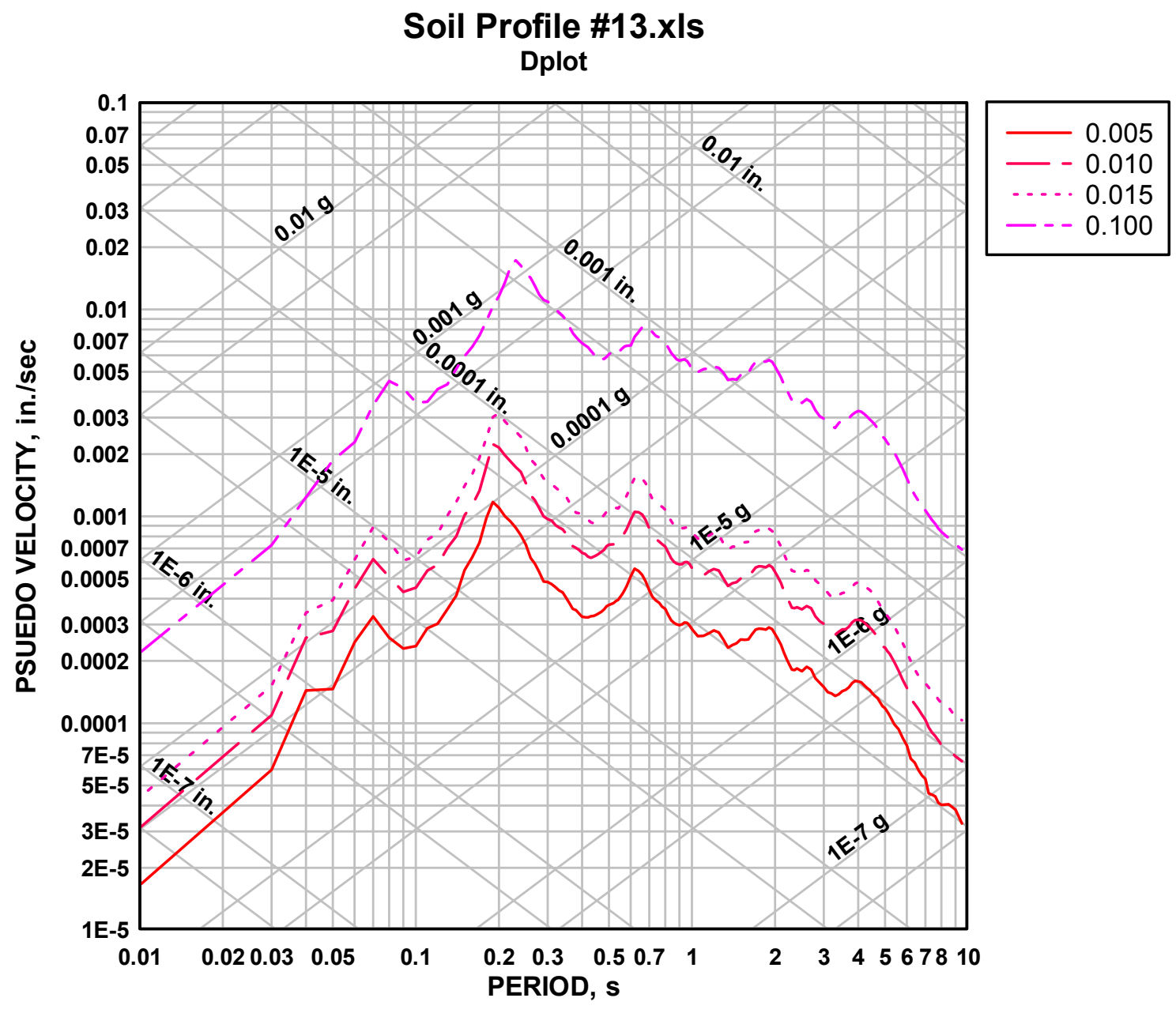

FIGURE 24- Pseudo Velocity Spectrum for Soil Profile \#13

\section{Design Spectrum}

The design spectra to be created on the response spectra are representative of the $50 \%$ nonexceedance probability, or median value of a spectral acceleration, and the $84.1 \%$ nonexceedence probability, or the mean plus one standard deviation value. As outlined in Chapter 6 of Dynamics of Structures (Chopra, 2001), design spectra should be created using the following procedure:

1.) Plot the peak ground acceleration ( $\left.u^{\prime \prime}\right)$, velocity ( $\left.u^{\prime}\right)$, and displacement $(u)$ for the design ground motion.

2.) Obtain $\alpha_{A}, \alpha_{V}$, and $\alpha_{D}$ values for the selected $\xi$ value from the tables below: 
TABLE XXIV

AMPLIFICATION RATIOS

\begin{tabular}{|c|c|c|c|c|c|c|}
\hline \multirow{2}{*}{ Damping, $\xi(\%)$} & \multicolumn{4}{|c|}{${ }^{2}$} & \multicolumn{3}{c|}{ One Sigma (84.1th } \\
\cline { 2 - 7 } & $\alpha_{\mathrm{A}}$ & $\mathrm{\alpha}_{\mathrm{V}}$ & $\mathrm{\alpha}_{\mathrm{D}}$ & $\mathrm{\alpha}_{\mathrm{A}}$ & $\mathrm{\alpha}_{\mathrm{V}}$ & $\mathrm{\alpha}_{\mathrm{D}}$ \\
\hline 1 & 3.21 & 2.31 & 1.82 & 4.38 & 3.38 & 2.73 \\
\hline 2 & 2.74 & 2.03 & 1.63 & 3.66 & 2.92 & 2.42 \\
\hline 5 & 2.12 & 1.65 & 1.39 & 2.71 & 2.30 & 2.01 \\
\hline 10 & 1.64 & 1.37 & 1.20 & 1.99 & 1.84 & 1.69 \\
\hline 20 & 1.17 & 1.08 & 1.01 & 1.26 & 1.37 & 1.38 \\
\hline
\end{tabular}

\begin{tabular}{|c|c|c|}
\hline & Median $\left(50^{\text {th }}\right.$ percentile $)$ & $\begin{array}{c}\text { One Sigma (84.1th } \\
\text { Percentile) }\end{array}$ \\
\hline$\alpha_{A}$ & $3.21-0.68 \ln \xi$ & $4.38-1.04 \ln \xi$ \\
\hline$\alpha_{V}$ & $2.31-0.41 \ln \xi$ & $3.38-0.67 \ln \xi$ \\
\hline$\alpha_{D}$ & $1.82-0.27 \ln \xi$ & $2.73-0.45 \ln \xi$ \\
\hline
\end{tabular}

(Chopra, 2001)

Steps 3-6 should be done twice: once using $\alpha_{A}, \alpha_{V}$, and $\alpha_{D}$ values for the $50^{\text {th }}$ percentile and again using $\alpha_{A}, \alpha_{V}$, and $\alpha_{D}$ values for the 84.1 th percentile.

3.) Multiply the peak ground acceleration, $u$ ', by the amplification factor, $\alpha_{\mathrm{A}}$, to create the straight line portion $b-c$ beginning at a period of $1 / 8 \mathrm{sec}$ as seen in Figure 25: 


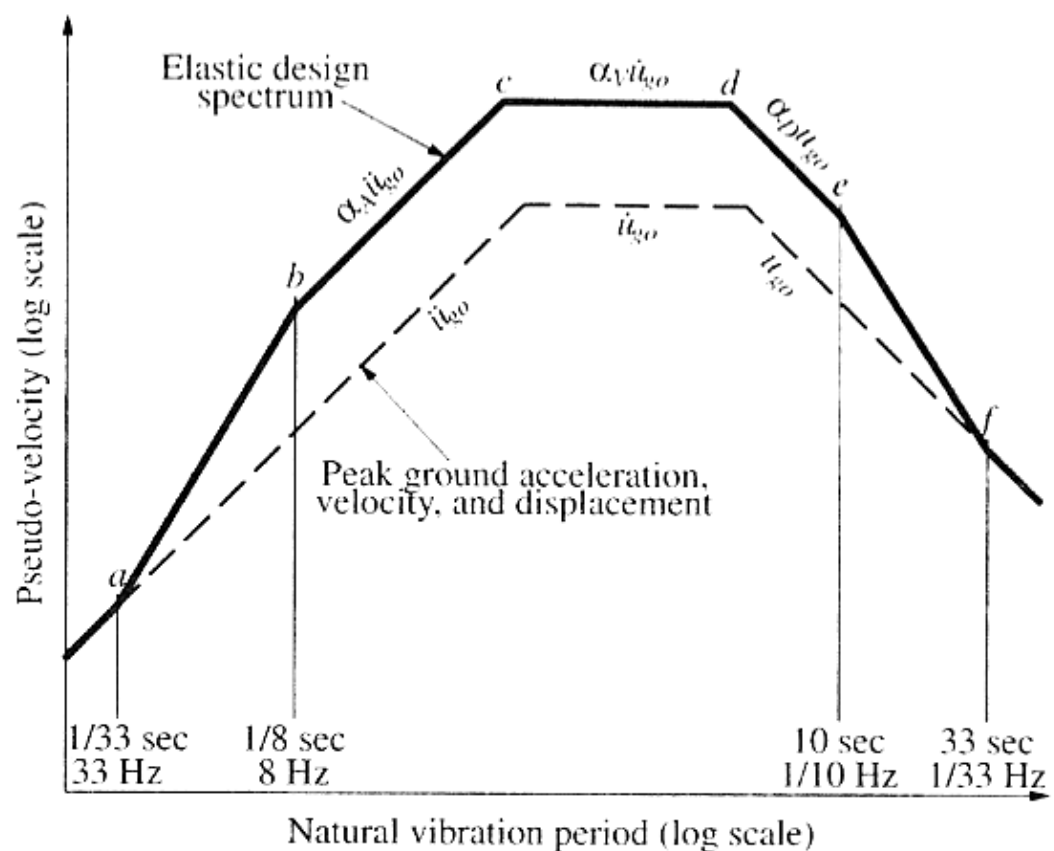

FIGURE 25 - Construction of Elastic Design Spectrum

The straight line portion $b$-c represents a constant value of pseudo acceleration $A$.

4.) Multiply the peak ground velocity, $u^{\prime}$, by the amplification factor to create the straight line portion $c$ - $d$ in Figure 25 to represent a constant value of pseudo velocity $V$.

5.) Multiply the peak ground displacement $u$ by the amplification factor to create the straight line portion $d-e$ in Figure 25 to represent a constant value of displacement $D$.

6.) For periods shorter than $1 / 33 \mathrm{sec}, A=u$ ', and $a-b$ is a straight line transition between the previously calculated values at $1 / 33 \mathrm{sec}$ and $1 / 8 \mathrm{sec}$.

The line $e-f$ seen in Figure 25 was not calculated because the response spectrum created for comparison showed significant decline after a period of 1 second. Therefore, investigation into the response after 10 seconds did not appear warranted. An example of the design spectrum creation process is outlined in Section E for further clarification. 


\section{E. Example}

Assume a design spectrum comparison is desired for a bridge site in Louisville, Kentucky, for a soil column that is 100 feet deep with soil column consisting respectively of 35 feet of clay/silt, 40 feet of sand, 20 feet of clay, and 5 feet of gravel. The design ground motions and damping ratio are as follows: $\mathrm{u}=0.0001 \mathrm{in}, \mathrm{u}^{\prime}=0.0015 \mathrm{in} / \mathrm{sec}, \mathrm{u}{ }^{\prime}=$

$0.00008 \mathrm{~g}$ 's, and $\xi=5 \%$. (It should be noted that these design ground motions are very low when compared to design values for most bridge structures. The values were chosen to provide an illustration for the process of drawing a design spectrum.) An earthquake response at the site is required for an earthquake in the $6.0-6.5$ range, $345 \mathrm{~km}$ from the New Madrid Seismic Zone. The following steps, as previously outlined in Chapter V Section D are necessary for completion of a design spectrum:

1.) Selecting the Appropriate Soil Profile

The bridge site is located in Louisville which is the location of Profile \#6. On the other hand, the soil column is 100 feet deep with a deeply embedded clay layer. Therefore it is more advisable to use Soil Profile \# 11 because it has strata more similar to the site specific soil column.

2.) Estimate initial bedrock acceleration range for site based on earthquake event and location.

The response desired is for an earthquake 6.0-6.5 range from the New Madrid Seismic Zone. Initial bedrock accelerations can be calculated using the Toro Equation or can be estimated using the charts in Appendix II. 


\section{Using the Toro Equation:}

From the initial information: $\mathrm{R}_{\mathrm{jb}}=345 \mathrm{~km}$ and $\mathrm{M}=6.0$ and 6.5

$\mathrm{C}$ coefficients are obtained from TABLE IV at the peak ground acceleration (PGA)

TABLE VI

TORO MODELING COEFFICIENTS

\begin{tabular}{|c|c|c|c|c|c|c|c|}
\hline Freq. & C1 & C2 & C3 & C4 & C5 & C6 & C7 \\
\hline PGA & 2.20 & 0.81 & 0.00 & 1.27 & 1.16 & 0.0021 & 9.3 \\
\hline
\end{tabular}

Therefore, using these values and the Toro equation:

$\ln Y=C_{1}+C_{2}(M-6)+C_{3}(M-6)^{2}-C_{4} \ln \left(R_{M}\right)-\left(C_{5}-C_{4}\right) \max \left[\ln \left(\frac{R_{M}}{100}\right), 0\right]-C_{6} R_{M}$

$+\varepsilon_{e}+\varepsilon_{a}, \quad$ where $R_{M}=\sqrt{R_{j b}^{2}+C_{7}^{2}}$

The peak bedrock acceleration at $\mathrm{M}=6.0$ is calculated as follows:

$$
\begin{aligned}
& \ln Y=2.20+0.81(6.0-6)+0.00(6.0-6)^{2}-1.27 \ln \left(\sqrt{345^{2}+9.3^{2}}\right) \\
& -(1.16-1.27) \max \left[\ln \left(\frac{\sqrt{345^{2}+9.3^{2}}}{100}, 0\right)\right]-0.0021\left(\sqrt{345^{2}+9.3^{2}}\right)
\end{aligned}
$$

Here $\mathrm{Y}=0.0029$

The peak bedrock acceleration for $\mathrm{M}=6.5$ would be calculated in the same manner. In the case of $\mathrm{M}=6.5$, the peak bedrock acceleration $\mathrm{Y}=0.0045$

If the $\mathrm{R}_{\mathrm{jb}}$ value was unknown, or the exact calculation of the acceleration was not necessary, the acceleration could be estimated using the tables in Appendix II. Tables should be selected as a function of distance and magnitude. The Appendix 
II tables provide the following peak bedrock accelerations for a site located in Louisville.

\begin{tabular}{|l|l|}
\hline Magnitude & Accel. Y \\
\hline 6.0 & 0.0032 \\
\hline 6.5 & 0.0048 \\
\hline
\end{tabular}

3.) Select velocity response spectra corresponding to the appropriate soil profile.

In agreement with both the calculated Toro equation and the tabulated values, the initial bedrock acceleration is approximately $0.005 \mathrm{~g}$. Therefore, when using the velocity response spectra for Soil Profile \#11 (Figure 22), the design spectrum should be compared to the lowest line $(0.005)$ in the graph to estimate the response for a magnitude 6.0-6.5 earthquake at the specified distance of $345 \mathrm{~km}$.

4.) Create a design spectrum from peak acceleration, velocity, displacement and natural damping ratio of the structure using amplification factors from Table XXIV.

The design spectrum should be drawn directly on top of the velocity response spectrum of Soil Profile \#11 using the method previously described in Chapter V Section D.

Plot the design acceleration, velocity and displacement ground motions on the graph $\left(\mathrm{u}=0 . \mathrm{sec}\right.$, and u' $001 \mathrm{in}, \mathrm{u}^{\prime}=0.0015 \mathrm{in} /=0.00008 \mathrm{~g}$ 's $)$ as shown in Figure 26: 


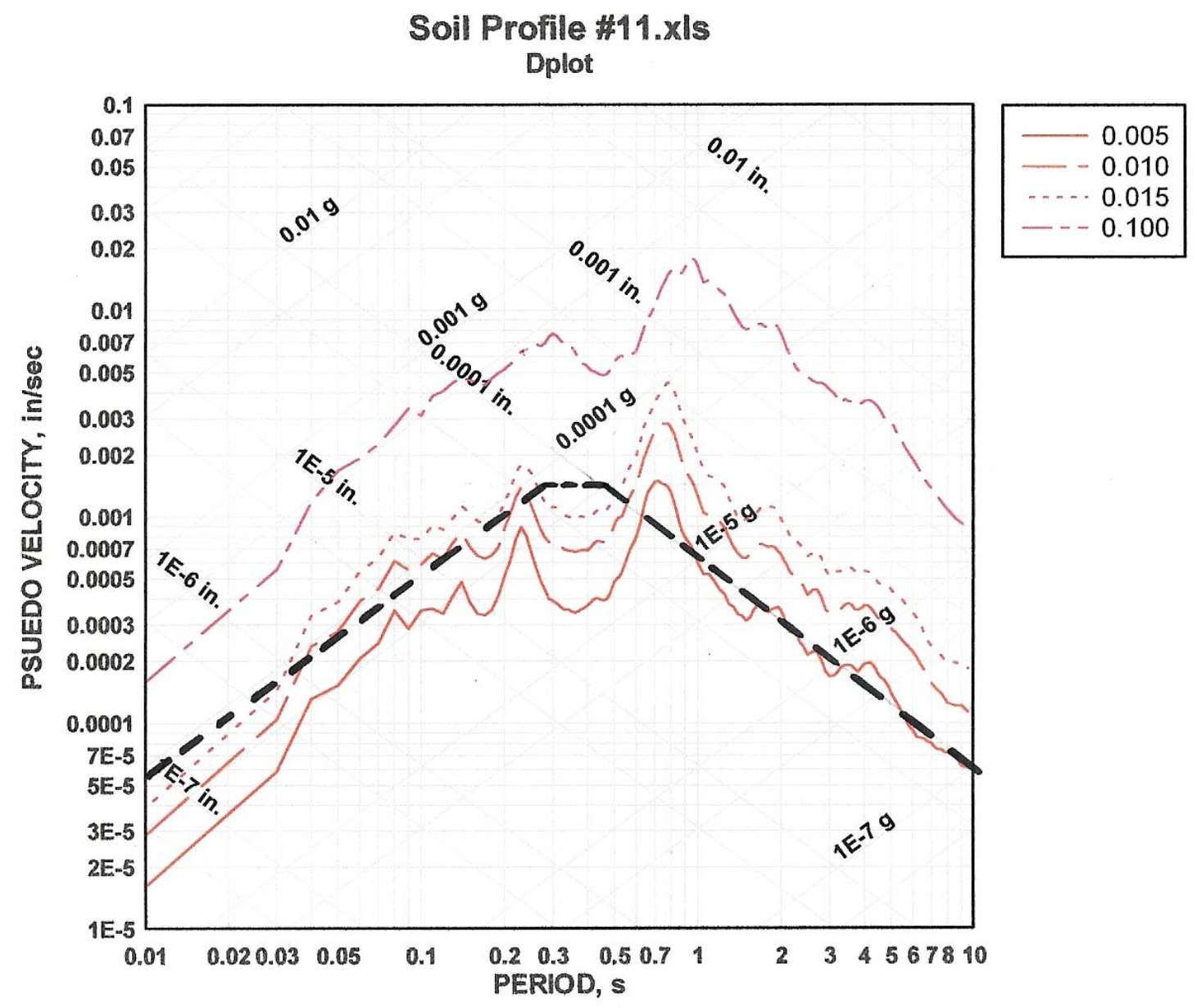

FIGURE 26 - Plot Design Ground Motions

After the known ground motions are plotted, the amplification factors for the design spectra will need to be applied to these ground motion values. Ground motion values of acceleration, velocity, and displacement will be multiplied by $\alpha_{A}, \alpha_{V}$, and $\alpha_{D}$, respectively. These alpha values may be obtained from TABLE XXIV in reference to the corresponding damping value of $5 \%$ given in the problem statement. The design motions will have two sets of alpha values applied: one for $50 \%$ nonexceedence probability and the other for a $84.1 \%$ nonexceedence probability. The design ground motion values, the alpha values, and the resulting amplification factors for both nonexceedence probabilities can be found in Table XXV: 
TABLE XXV

AMPLIFICATION CALCULATIONS FOR DESIGN SPECTRUM

\begin{tabular}{|c|c|c|c|c|c|c|c|}
\hline $\begin{array}{l}\text { Ground } \\
\text { Motion }\end{array}$ & $\begin{array}{l}\text { Design } \\
\text { Value }\end{array}$ & $\begin{array}{c}\text { Alpha } \\
50 \%\end{array}$ & $\begin{array}{l}\text { Amp. } \\
50 \%\end{array}$ & $\begin{array}{l}\text { Ground } \\
\text { Motion }\end{array}$ & $\begin{array}{l}\text { Design } \\
\text { Value }\end{array}$ & $\begin{array}{l}\text { Alpha } \\
84.1 \%\end{array}$ & $\begin{array}{l}\text { Amp. } \\
84.1 \%\end{array}$ \\
\hline & & 212 & & & & 3.66 & \\
\hline & & & & & & 2. & \\
\hline Dis & 0.0001 & 1.39 & 0.00013 & Displacement & 0.0001 & 2.42 & 0.00024 \\
\hline
\end{tabular}

Next, the amplification values for $50 \%$ nonexceedence should be plotted on the velocity response spectrum with the acceleration beginning at a period of $1 / 8 \mathrm{sec}$. (See the blue line in Figure 27) 


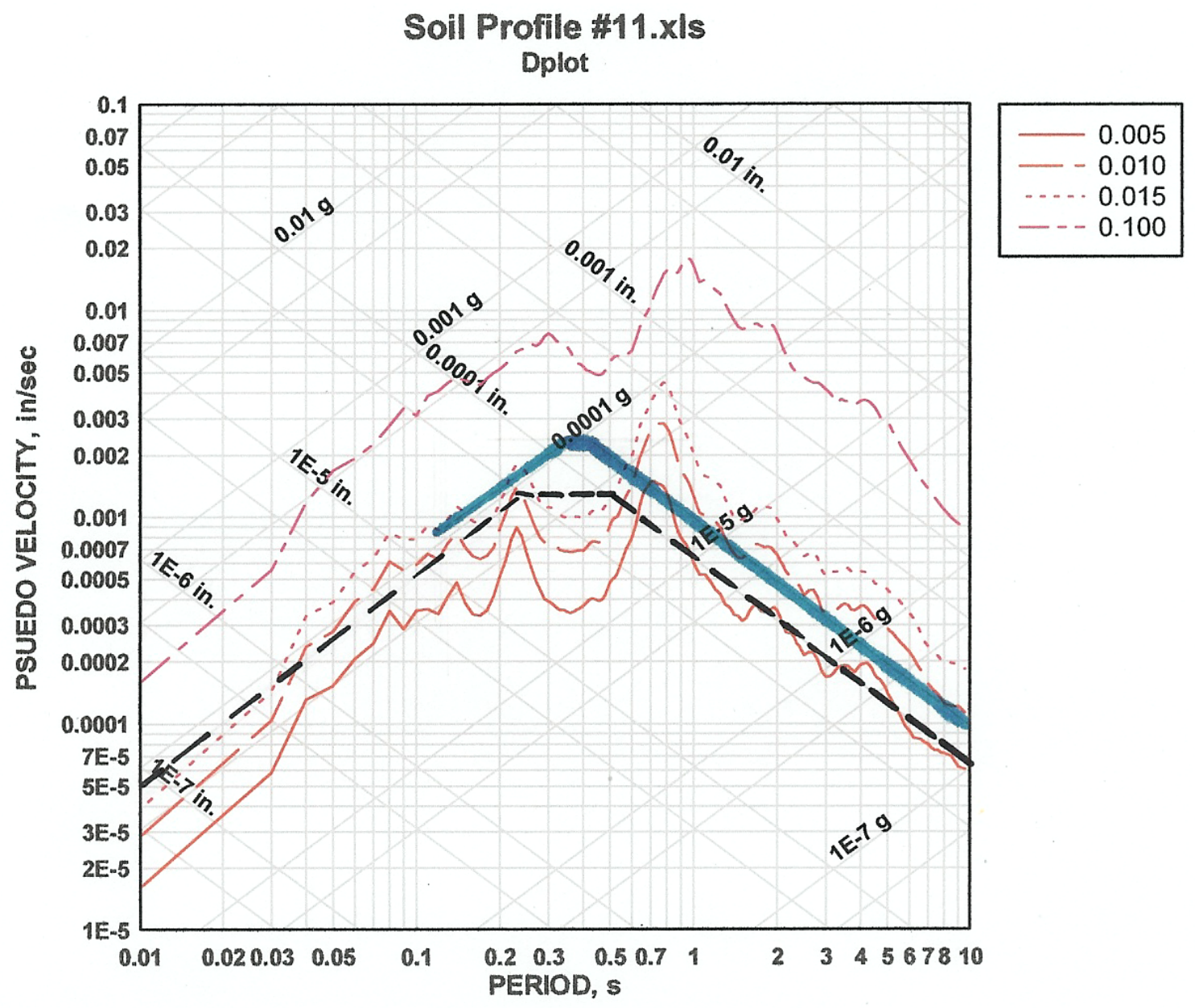

FIGURE 27 - Plot of 50\% Nonexceedence Amplification Values

Next, plot the line $a-b$ as described in the original instructions. The line should connect the design acceleration at a period of $1 / 33 \mathrm{sec}$ to the amplification acceleration at a period $=1 / 8 \mathrm{sec}$. (See the pink line in Figure 28.) 


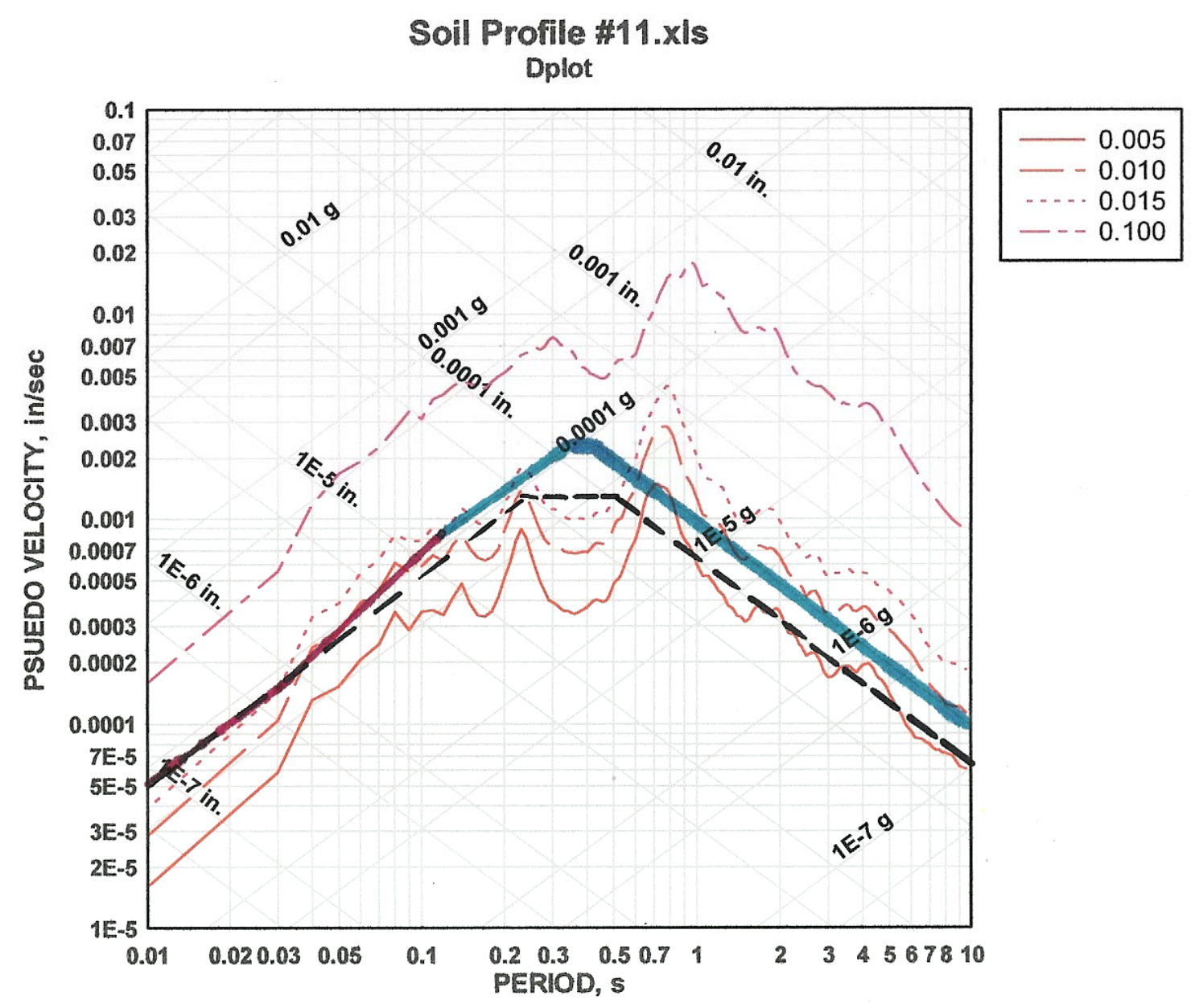

FIGURE 28 - Plot of completed 50\% Design Spectrum

Repeat the process of plotting the amplification values for the $84.1 \%$ nonexceedence probability. (See the green line in Figure 29.) 


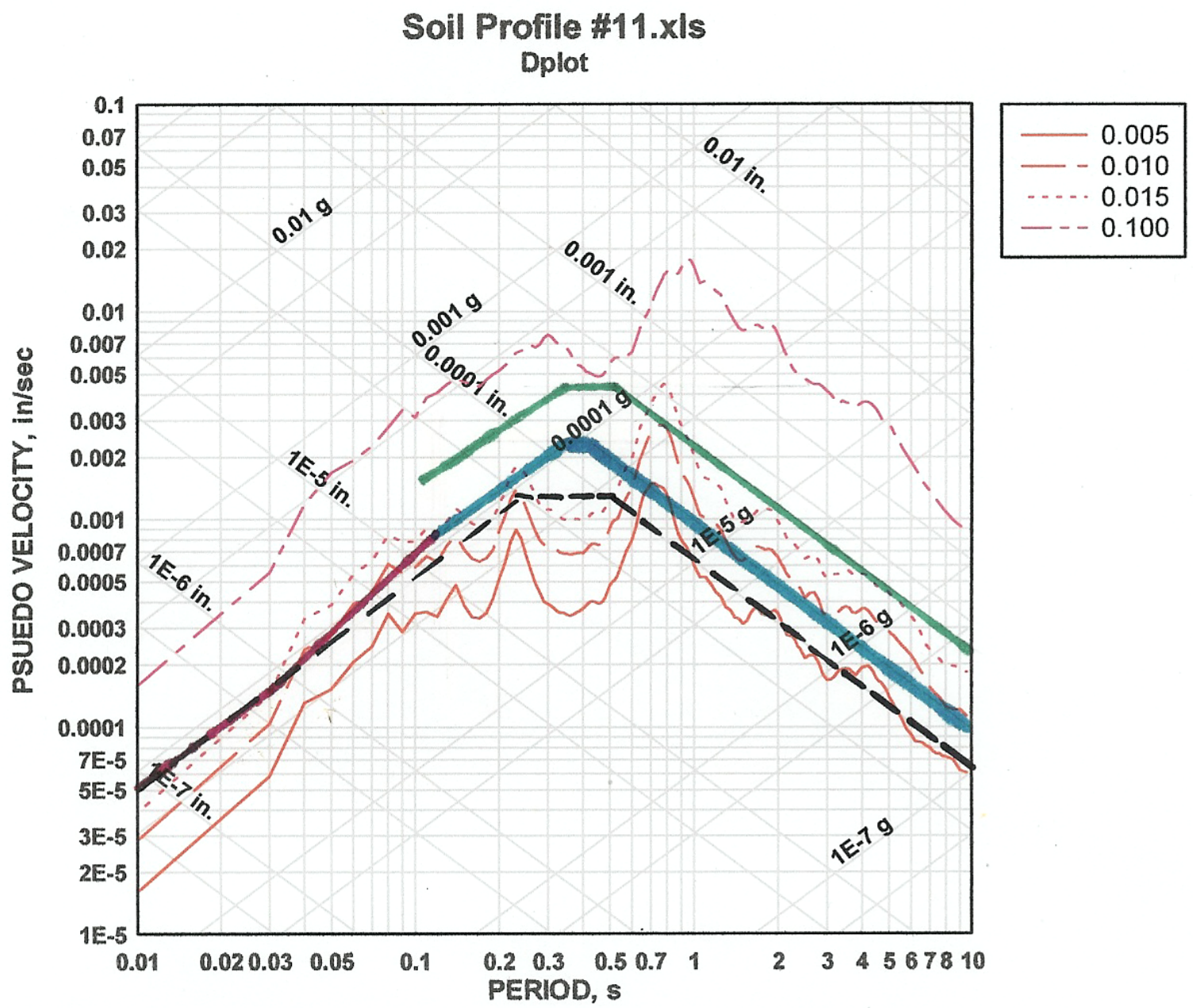

FIGURE 29 - Plot of $84.1 \%$ Nonexceedence Amplification Values

Repeat the process of plotting the connecting line a-b for the $84.1 \%$ nonexceedence probability. (See the upper pink line in Figure 30.) 


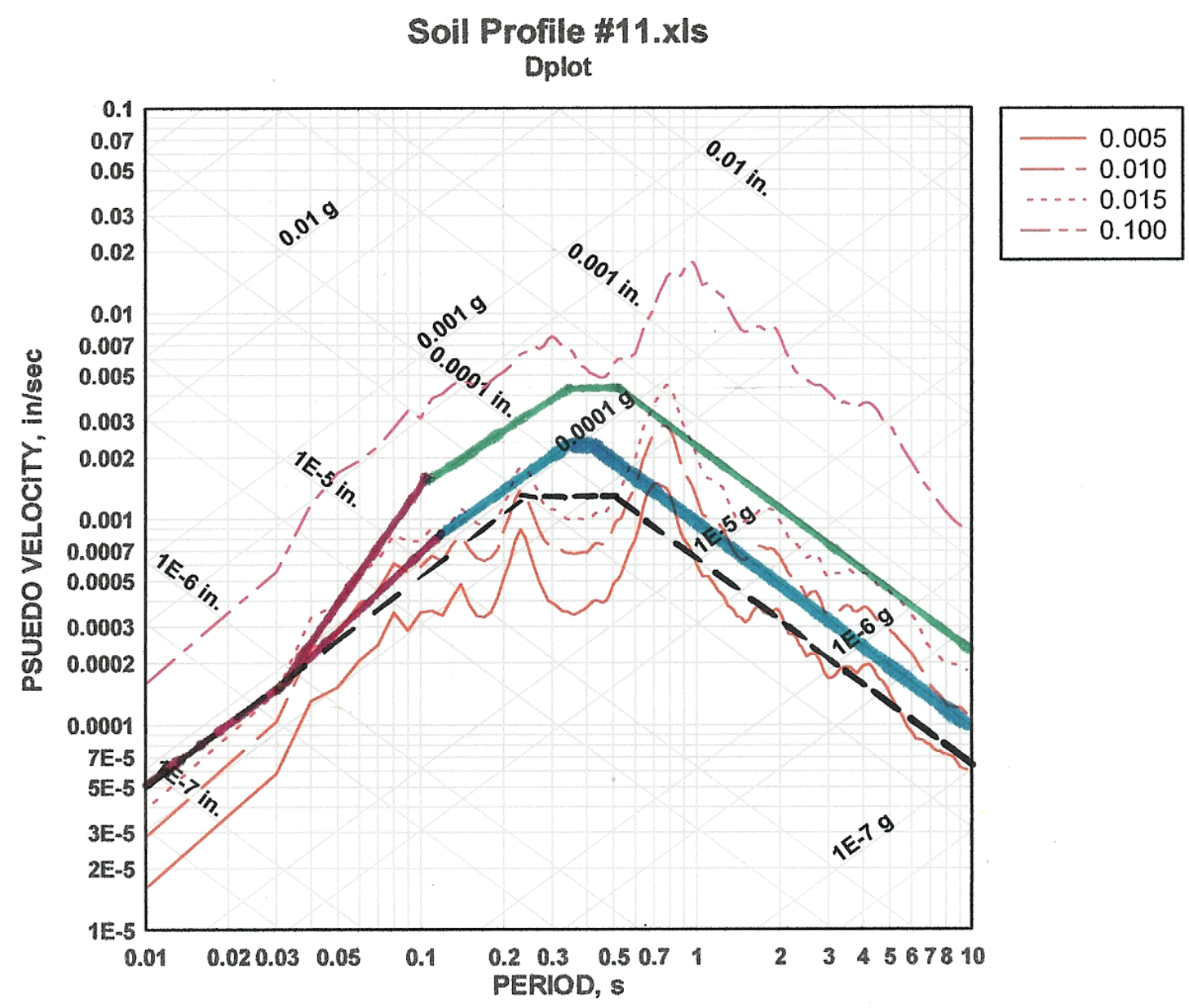

Figure 30 - Plot of completed 50\% and 84.1\% Design Spectrum

\section{F. Damage Estimation}

The completed design spectrum, like the one in Figure 30, should be used in comparison to the appropriate soil profile response spectrum on which it was drawn. Comparison of the estimated response and the design spectra should provide an adequate idea if the earthquake response at a site will exceed the ground motion design values for the calculated mean and one standard deviation values of amplification. For instance, in Figure 30 it can be seen that for an initial bedrock acceleration response values for 0.005 , 0.010 and 0.015 generally fall within or near one standard deviation of the original design 
spectrum. Therefore, damage is possible but not likely for these lower values of bedrock acceleration. Conversely, the 0.100 initial bedrock acceleration earthquake response ground motion values exceed those calculated for two standard deviations. Therefore, damage is likely a result of an earthquake with this initial bedrock acceleration. 


\section{CONCULSIONS AND RECOMMENDATIONS}

While more research into the effects of medium and large magnitude earthquakes in the Mid-America region should be conducted, the original intent to specifically study ground amplification of bedrock motions in the Ohio Valley area has been achieved. From the previous analysis, it is apparent that earthquakes in the magnitude range of 5.06.5 would not cause significant damage in the Ohio Valley region. While amplification within the soil column does appear to occur, the ground motions reaching the soil column through the bedrock are already so diminished that amplification does not increase the ground motion to a value that could cause significant damage. The bedrock accelerations reaching the sites are only significant for sites near the epicenter of the earthquake event. While those sites could experience damage, the evidence presented in this analysis shows that damage for sites farther away from the epicenter is not likely.

Despite the lack of damage found to occur in the Mid-America region, the analysis still provides interesting conclusions that can be used in further research. In the analysis of the 13 typical soil columns, conclusions can be made regarding the amplification of seismic waves within the soil column, and the varying time-history responses with respect to soil column geology.

\section{A. Conclusions}

The following conclusions were made as a result of the research completed in reference to the amplification of seismic waves within soil columns: 
1.) Amplification of the initial bedrock acceleration as compared to the peak ground acceleration at the soil surface occurred in most of the soil columns studied.

2.) Most of the soil columns that did not show amplification were located within $50 \mathrm{~km}$ of the epicenter.

3.) Amplification factors were larger for those soil columns located farther away from the epicenter than soil columns located near the epicenter.

The conclusions above support the notion that Mid-America should be just as concerned about medium sized earthquakes as very large earthquakes. However, the energy propagated through the soil columns could be amplified, but not enough to cause damage. In addition to conclusions about amplification, the research also allows for the drawing of the following conclusions about the response with respect to soil column geology:

1.) As shown in the response spectra, peak values of pseudo acceleration were dependent on the clay to sand ratio.

2.) Soil columns with large sand layers and relatively no clay produced responses with large initial acceleration peaks that then steadily declined.

3.) Soil columns with large surficial clay layers produced responses with acceleration peaks located at a later time period than those soil columns that consisted mainly of sand.

4.) Soil columns with deeply embedded clay layers produced responses with small acceleration peaks much later in the time period.

\section{B. Recommendations}

The current analysis used in this thesis, while valid, uses generalizations and estimations. If these generalizations and assumptions were to be broken down and studied further, perhaps a more accurate estimation of site response could be obtained. Future improvements to the concluded research include the use of different epicenters for 
analysis, the use of other bedrock attenuation theories, the use of different computer analysis programs, and possibly further separation of earthquake events.

In this analysis only two different epicenters were used to estimate the initial peak bedrock motion values. Perhaps in the future, multiple epicenters could be used and studied for both the New Madrid and the Wabash Valley Fault Zones, to see if the location of the epicenter and the distance to the site are major variables in determining the response spectrum of a site. Variation to the results found could occur by using other attenuation theories besides Toro, such as the Atkinson and Boore (1995) theory which was studied but not used in this analysis. Various different computer analysis programs besides Shake91 also could be used to determine if the response spectra generated are significantly different from those generated in this analysis. Any of these differences in procedure could prove to significantly change the outcome from the results in this analysis.

If earthquake events were further separated, a more refined estimation of the response spectra could be acquired for specific sites. In this analysis, the response spectra created were averages of six different earthquake time-histories with four different magnitudes ranging from 5.7-7.0. In the future, more detailed analysis could be conducted by creating response spectra for more specific ranges of magnitude and using more time-histories. Also, narrower ranges of initial bedrock values could also be used. If this thesis were repeated, the author would consider adding an additional range of initial bedrock values between the $0.015 \mathrm{~g}$ and $0.100 \mathrm{~g}$ range. This addition would help to further encompass the possible accelerations calculated by those using the rapid screening guide. 


\section{Future Areas of Research}

To further investigate amplification and the response of other life-line structures in Mid-America, future research could branch out to investigate such structures as retaining walls, pipelines or roadway fills and approaches. Separate analysis would be required for each of these structures. It would not be accurate to estimate damage for these structures using this analysis because seismic waves affect these structures at ground depths other than the ground surface. 


\section{LIST OF REFERENCES}

Atkinson, G.M. and Boore, D.M. 1995. Ground Motion Relations for Eastern North America. Bulletin of the Seismological Society of America 85:17-30.

Chopra, Anil K. 2001. Dynamics of Structures, $2^{\text {nd }}$ Edition. Prentice Hall Publishing Company. Chp 6: 197-245.

Coffman, Jerry L. and Stover, Carl W. "USGS earthquake Hazards Program: 1811 1812 earthquakes in the New Madrid Seismic Zone”. Internet Source, 15 October 2003. available from http://wwwneic.cr.usgs.gov/neis/eq_depot/usa/18111812.html. accessed 30 April 2006.

Columbia University. 2005. Strongmo Database System. Internet Source. Available from http://www.ldeo.columbia.edu/res/data/nceer/strongmo.html; accessed 14 Oct 2005, 16 Oct 2005, 17 Oct. 2005.

Idriss, I. M. and Sun, J. I. 1992. User's Manual for Shake91. University of California. Davis, California.

Jacobs EM Team. 1997. Ground-water Conceptual Model for the Paducah Gaseous Diffusion Plant, Paducah, Kentucky. Kevil, KY: For United States Department of Energy Environmental Restoration Division. Contract DE-AC05-93OR22028.

Martin, James R. 2005. Geotechnical Earthquake Engineering in the Central and eastern US: Seismic Issues in Kentucky. Proceedings of the Kentucky Geotechnical Engineering Group Seismic Seminar (Frankfort, KY), 1:4-15.

Ohta, Y and Goto, N. 1978. Emperical Shear Wave Velocity Equations in Terms of Characteristic Soil Indexes. Earthquake Engineering and Structural Dynamics 6:167-187.

Shake91. 1991. University of California. Davis, California.

Street, R., Wang, Z., Harik, I.E., Allen, D.L. and Griffin, J.J. 1996. Source Zones, Recurrence Rates and Time Histories for Earthquake Affecting Kentucky, KTC96-4, Kentucky Transportation Center, March, 187 pp. 
Toro et al. 1997. Model of Strong Ground Motions from earthquakes in Central and Eastern North America: Best Estimates and Uncertainties. Seismological Research Letters 68:41-57.

United States Geological Survey. “The Richter Magnitude Scale.” Internet Source. 7 March, 2006. Available at http://earthquake.usgs.gov/learning/topics/richter.php; accessed 24 March 2006.

United States Soil Conservation Service. 1976. Soil Survey of Ballard and McCracken Counties, Kentucky. Washington: US Government Printing Office.

United States Soil Conservation Service. 1973. Soil Survey of Boone, Kenton, and Campbell Counties, Kentucky. Washington: US Government Printing Office.

United States Soil Conservation Service. 1979. Soil Survey of Boyd and Greenup Counties, Kentucky. Washington: US Government Printing Office.

United States Soil Conservation Service. 1974. Soil Survey of Daviess County, Kentucky. Washington: US Government Printing Office.

United States Soil Conservation Service. 1967. Soil Survey of Henderson County, Kentucky. Washington: US Government Printing Office.

United States Soil Conservation Service. 1992. Soil Survey of Henry and Trimble Counties, Kentucky. Washington: US Government Printing Office.

United States Soil Conservation Service. 1966. Soil Survey of Jefferson County, Kentucky. Washington: US Government Printing Office.

United States Soil Conservation Service. 1986. Soil Survey of Mason County, Kentucky. Washington: US Government Printing Office.

United States Soil Conservation Service. 1981. Soil Survey of Union and Webster Counties, Kentucky. Washington: US Government Printing Office.

Walker, E.H. 1957. The Deep Channel and Alluvial Deposits of the Ohio Valley in Kentucky. Geological Survey Water-Supply paper 1411. 


\section{APPENDIX I}

\section{SOIL PROFILE ACCELERATION SPECTRA}

Note I: The following graphs represent the acceleration spectra for 12 different earthquake events with 12 different initial accelerations for each soil profile. It is not advisable to use these acceleration spectra to create design spectra.

Note II: For all graphs period is expressed in units of seconds and spectral acceleration is expressed in g's. 
Soil Profile \#1

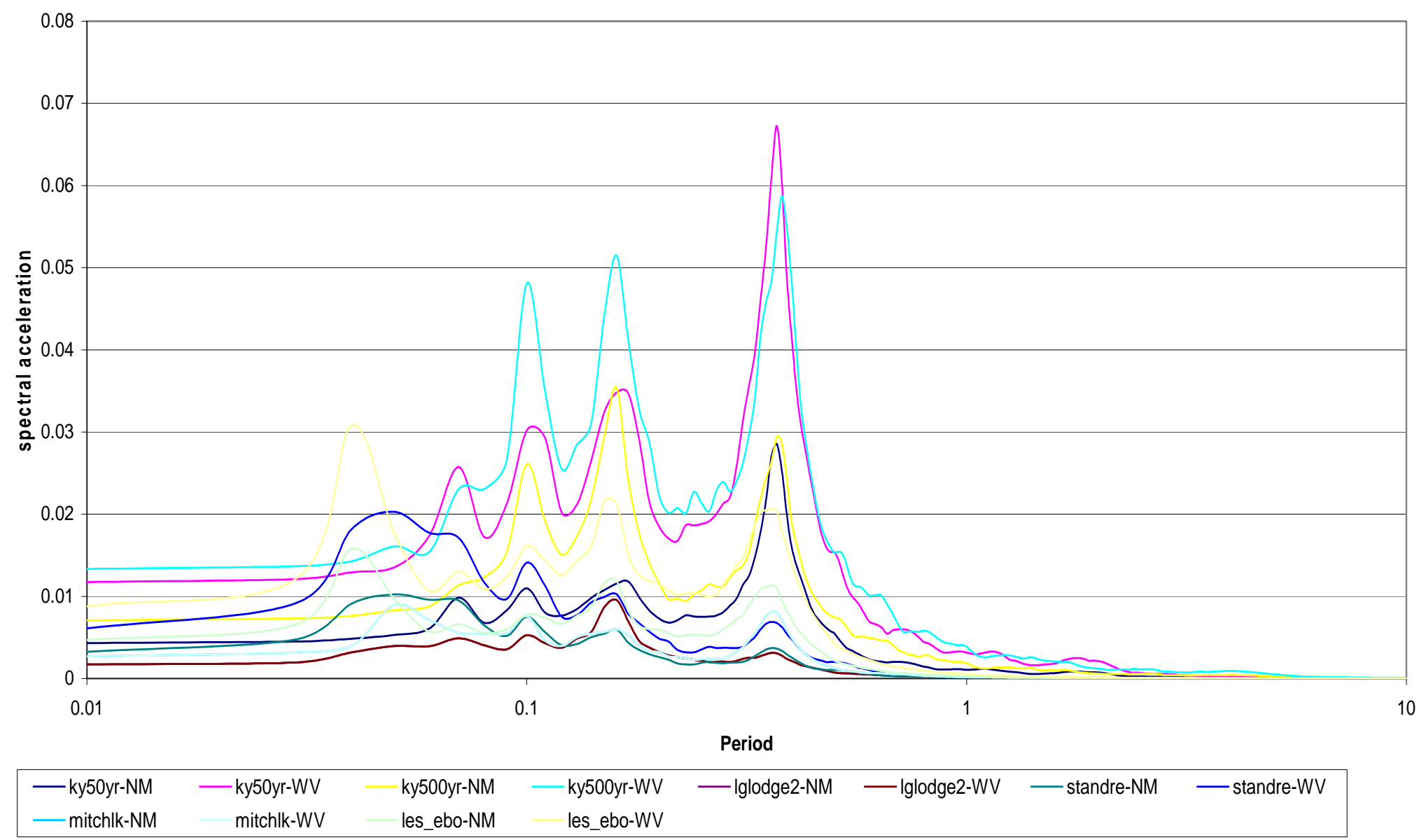

FIGURE 31 - Acceleration Spectra \#1 
Soil Profile \#2

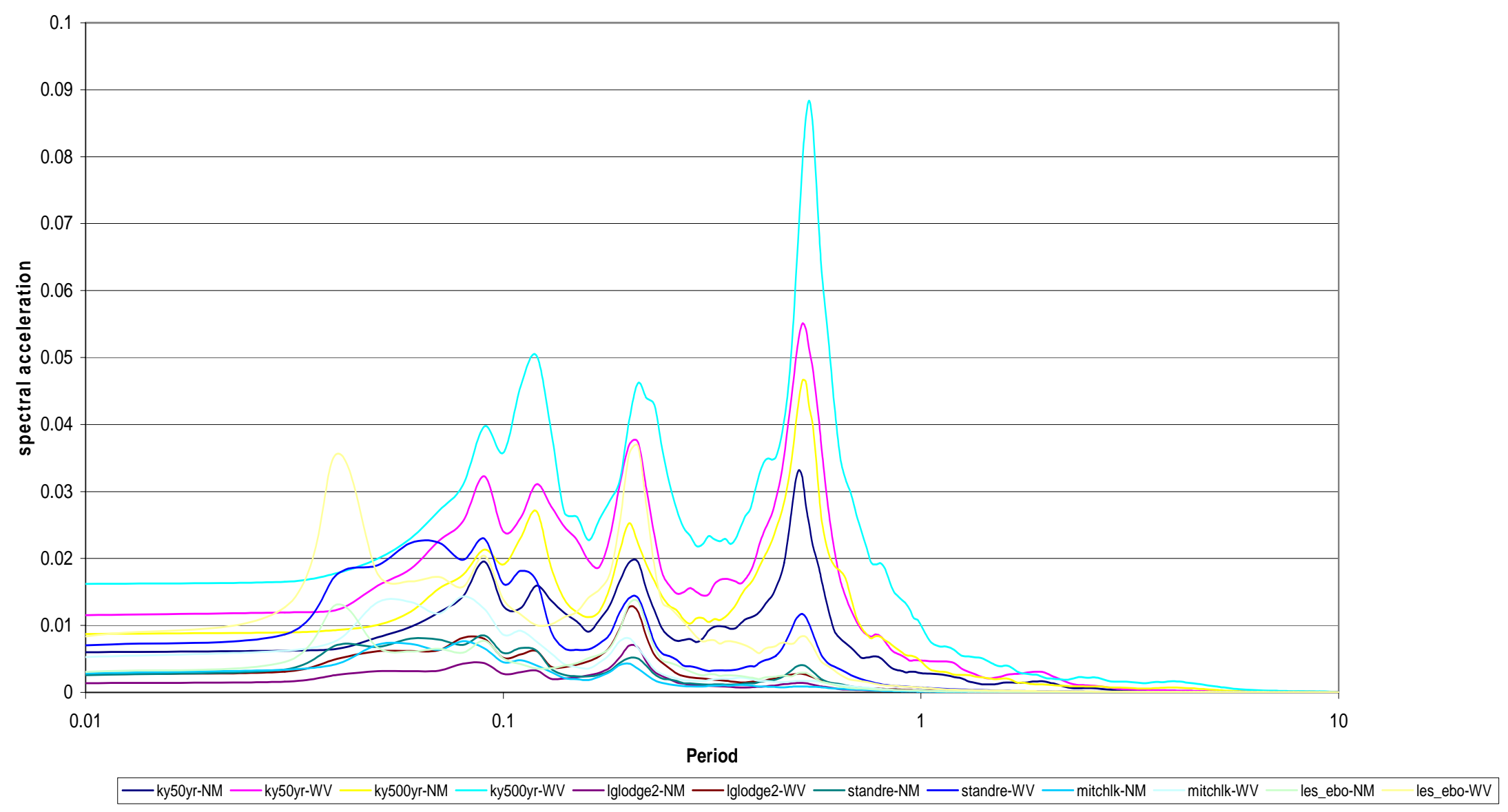

FIGURE 32 - Acceleration Spectra \#2 
Soil Profile \#3

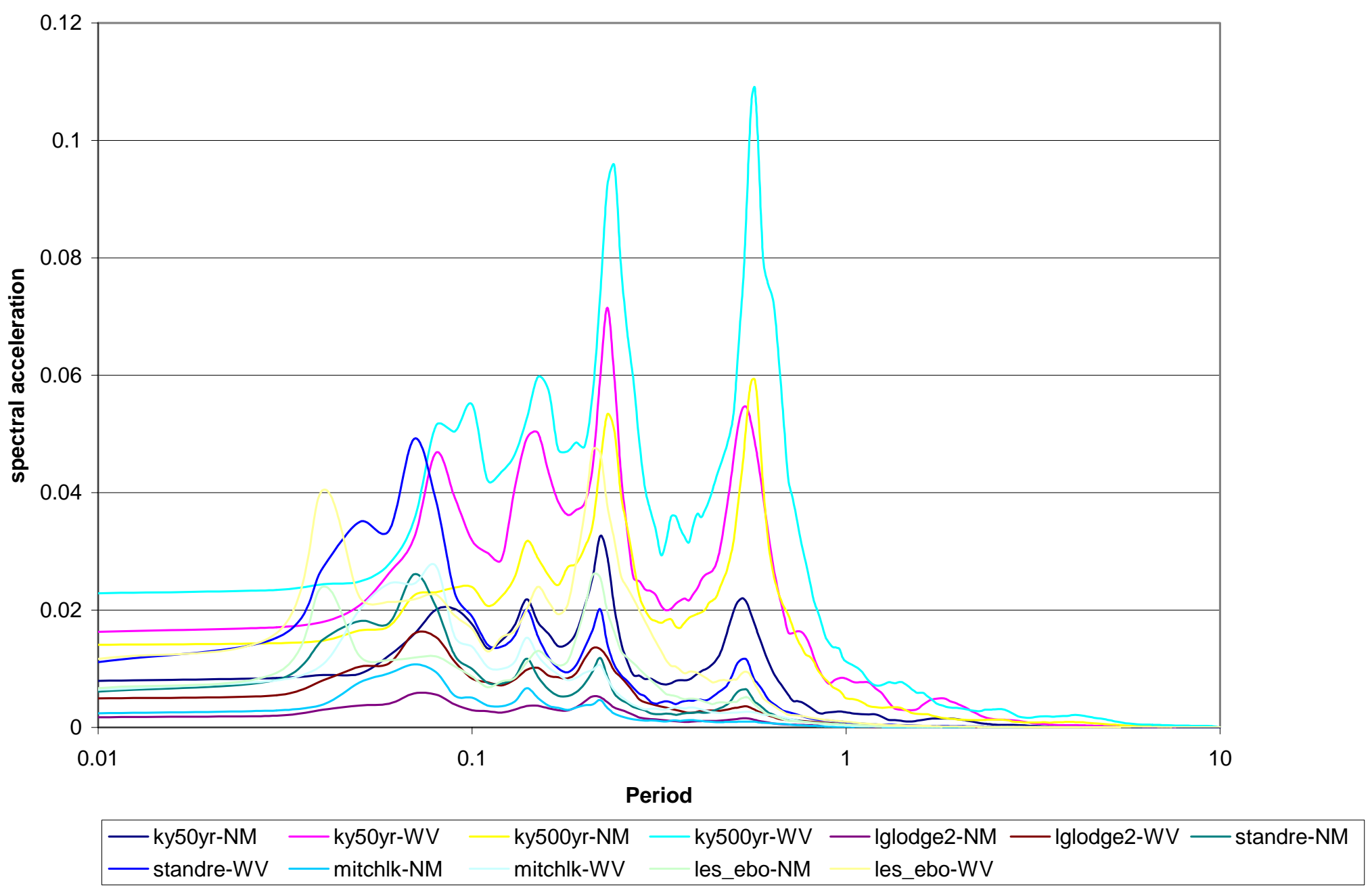

FIGURE 33 - Acceleration Spectra \#3 
Soil Profile \#4

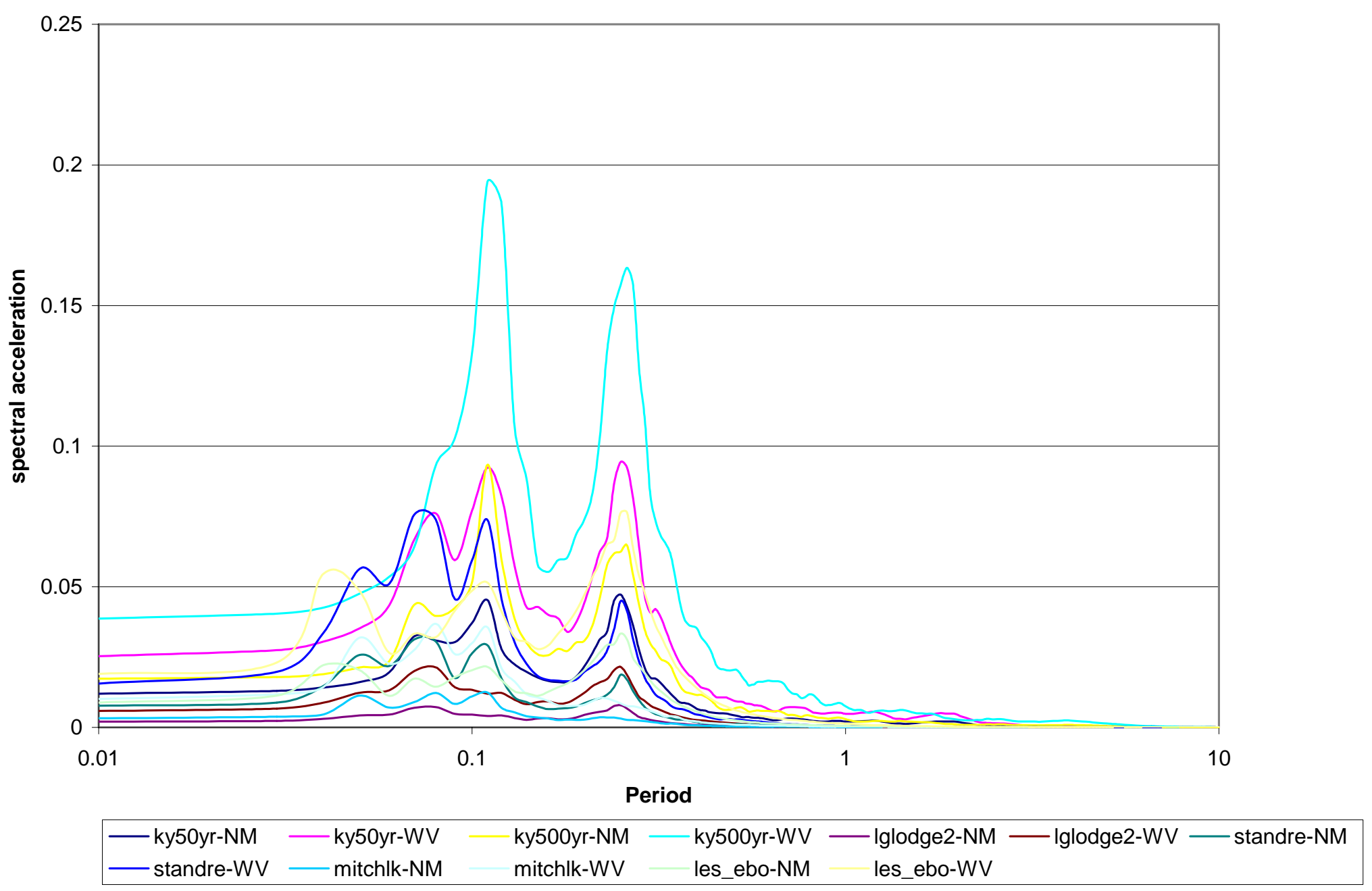

FIGURE 34 - Acceleration Spectra \#4 
Soil Profile \#5

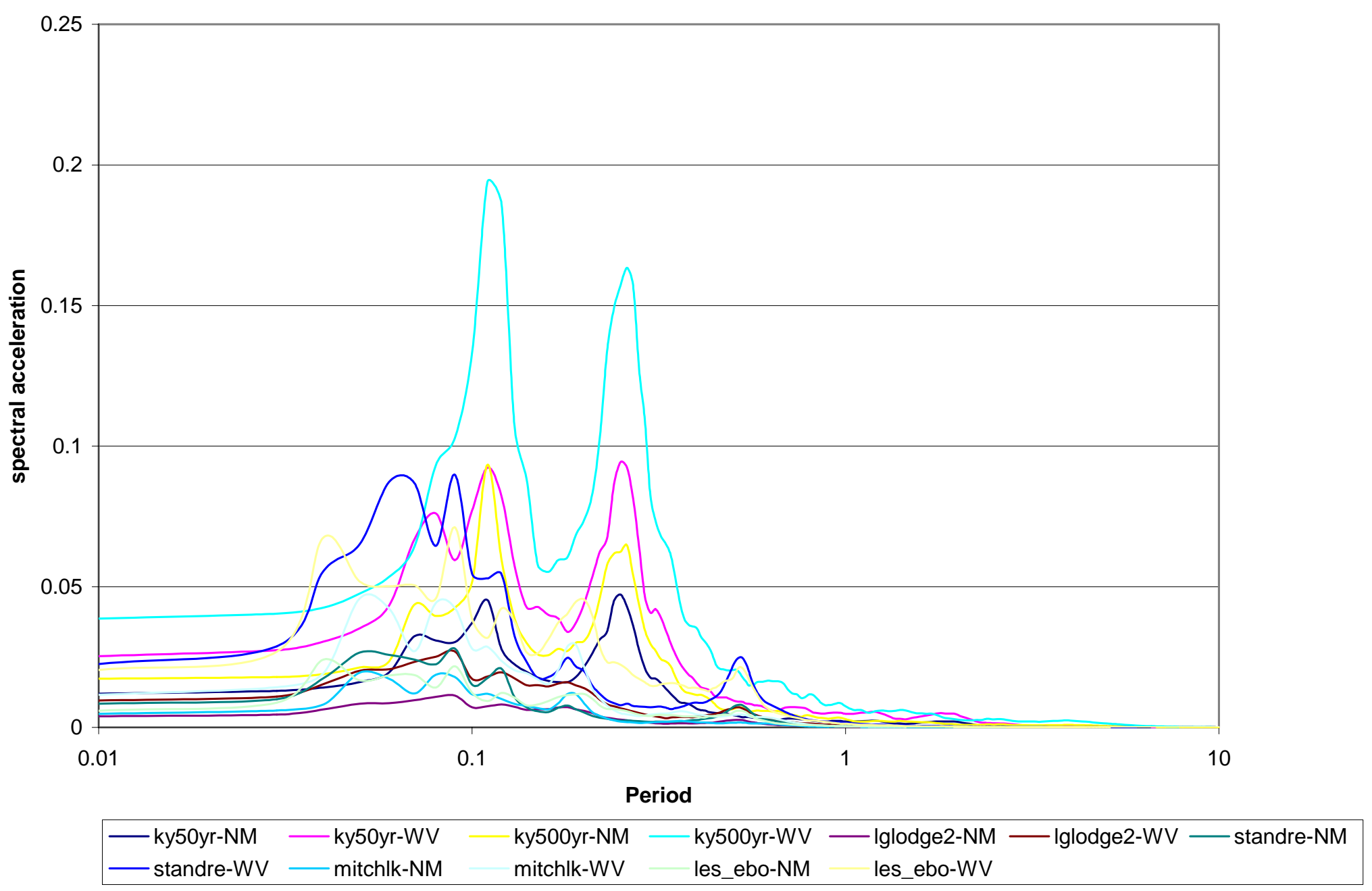

FIGURE 35 - Acceleration Spectra \#5 
Soil Profile \#6

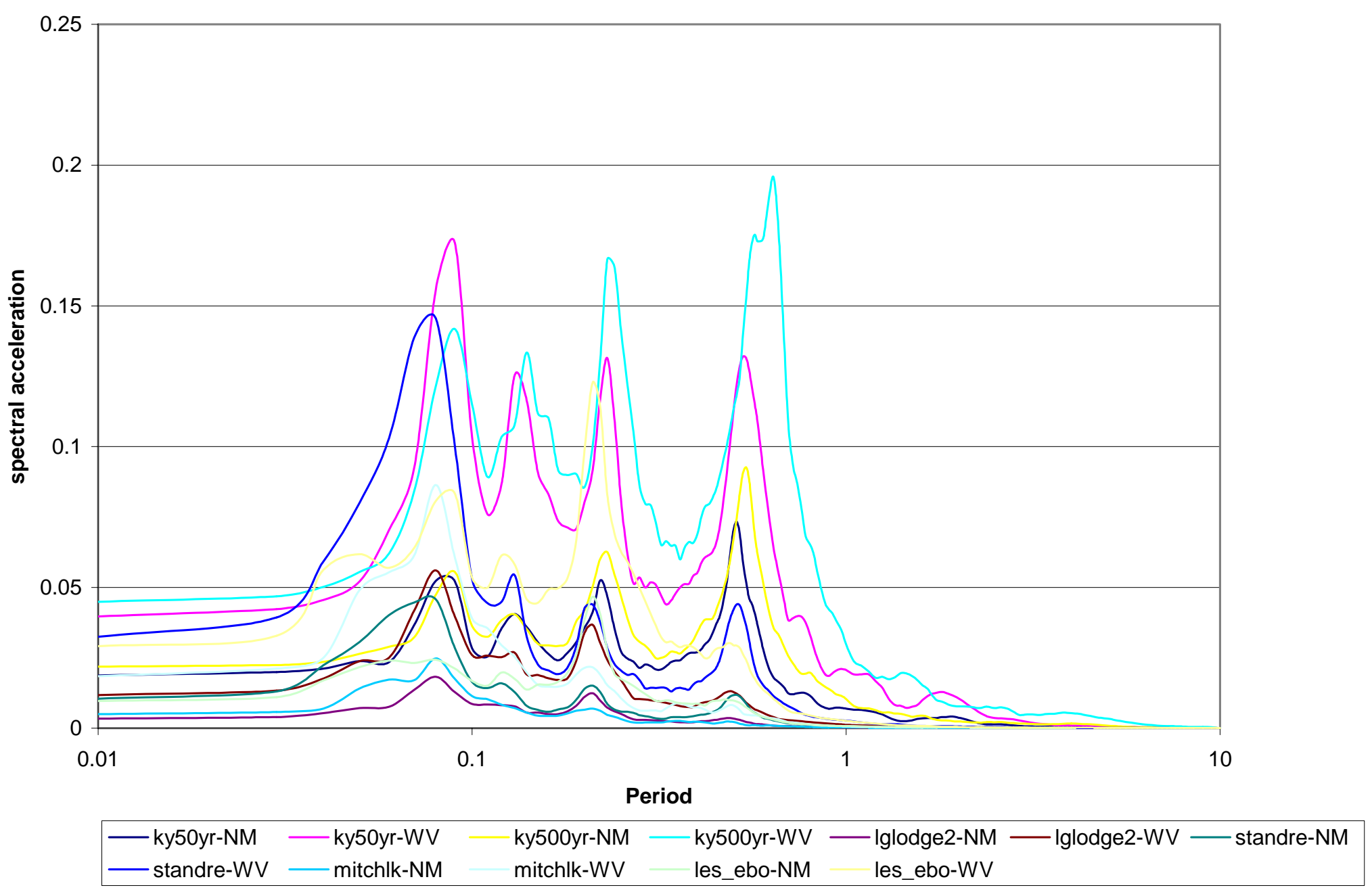

FIGURE 36 - Acceleration Spectra \#6 
Soil Profile \#7

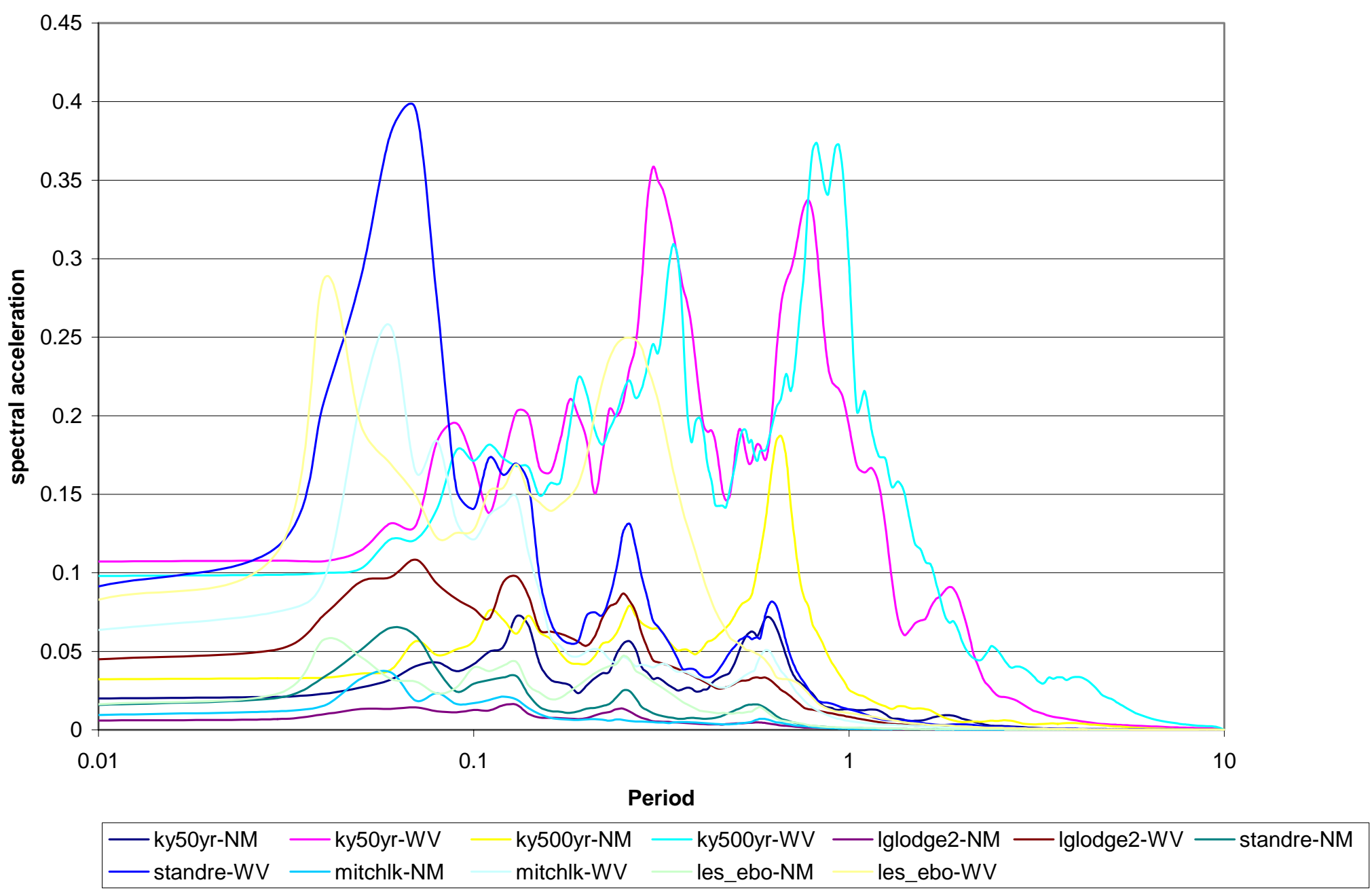

FIGURE 37 - Acceleration Spectra \#7 
Soil Profile \#8

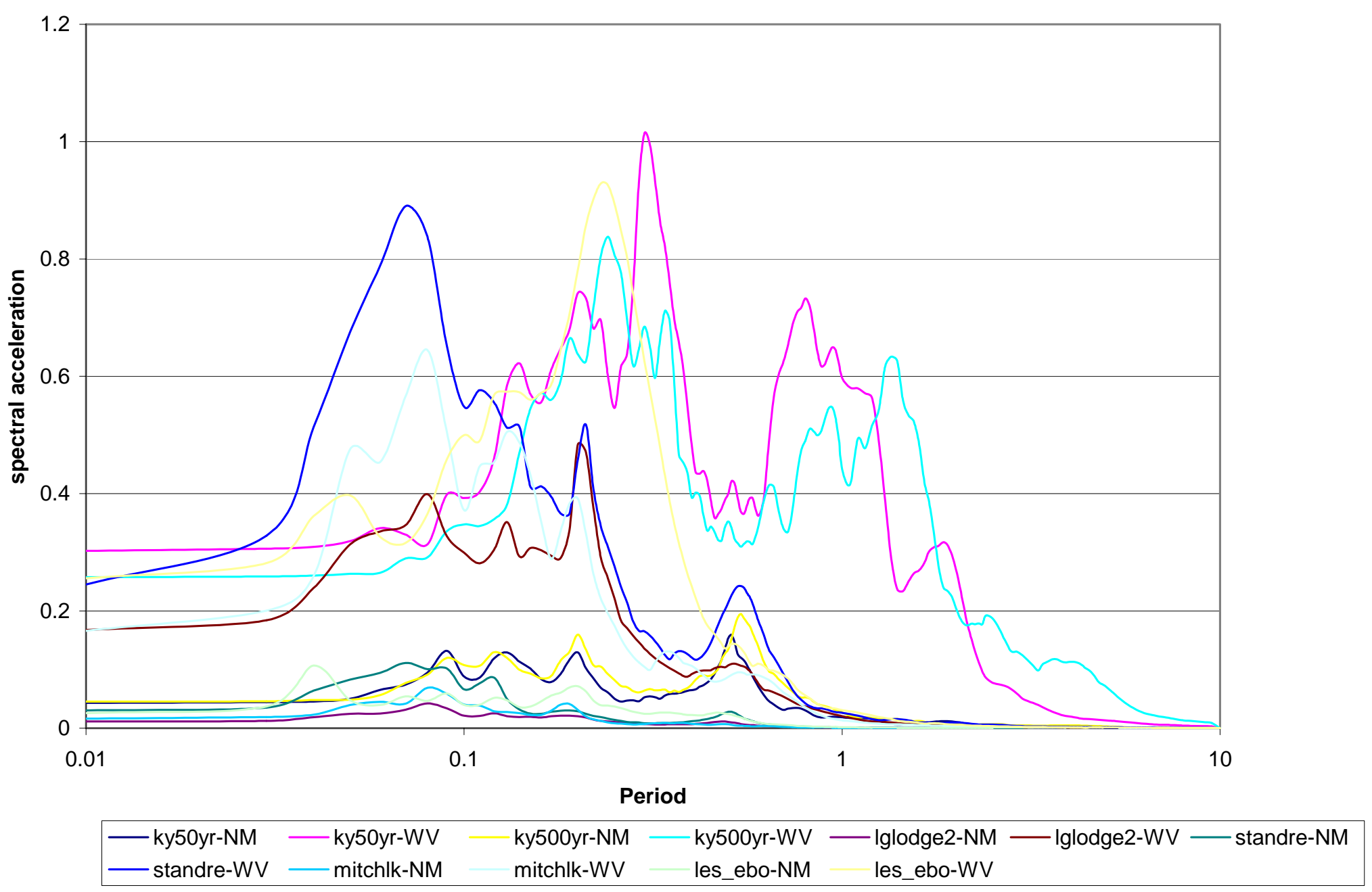

FIGURE 38 - Acceleration Spectra \#8 
Soil Profile \#9

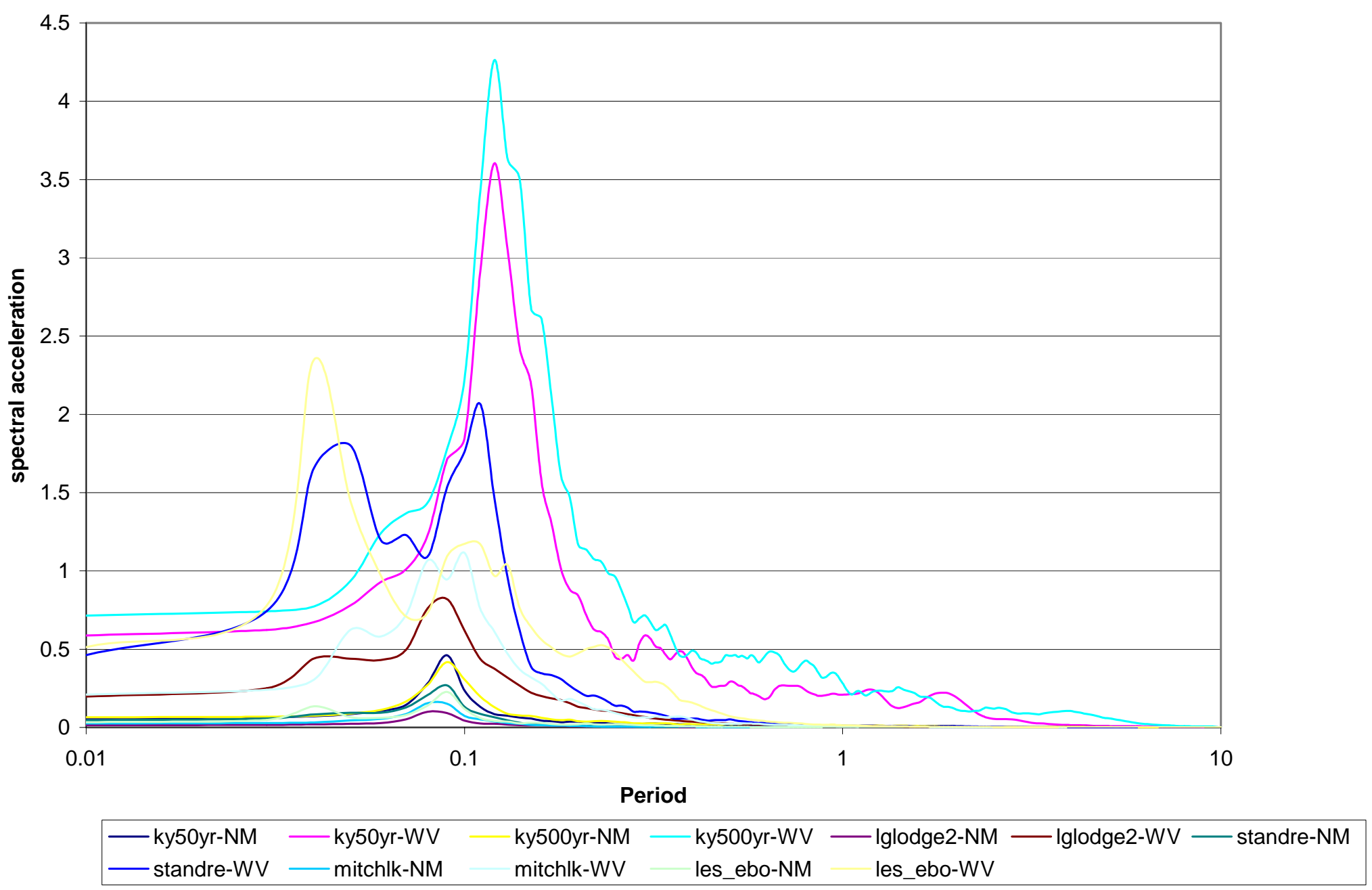

FIGURE 39 - Acceleration Spectra \#9 
Soil Profile \#10

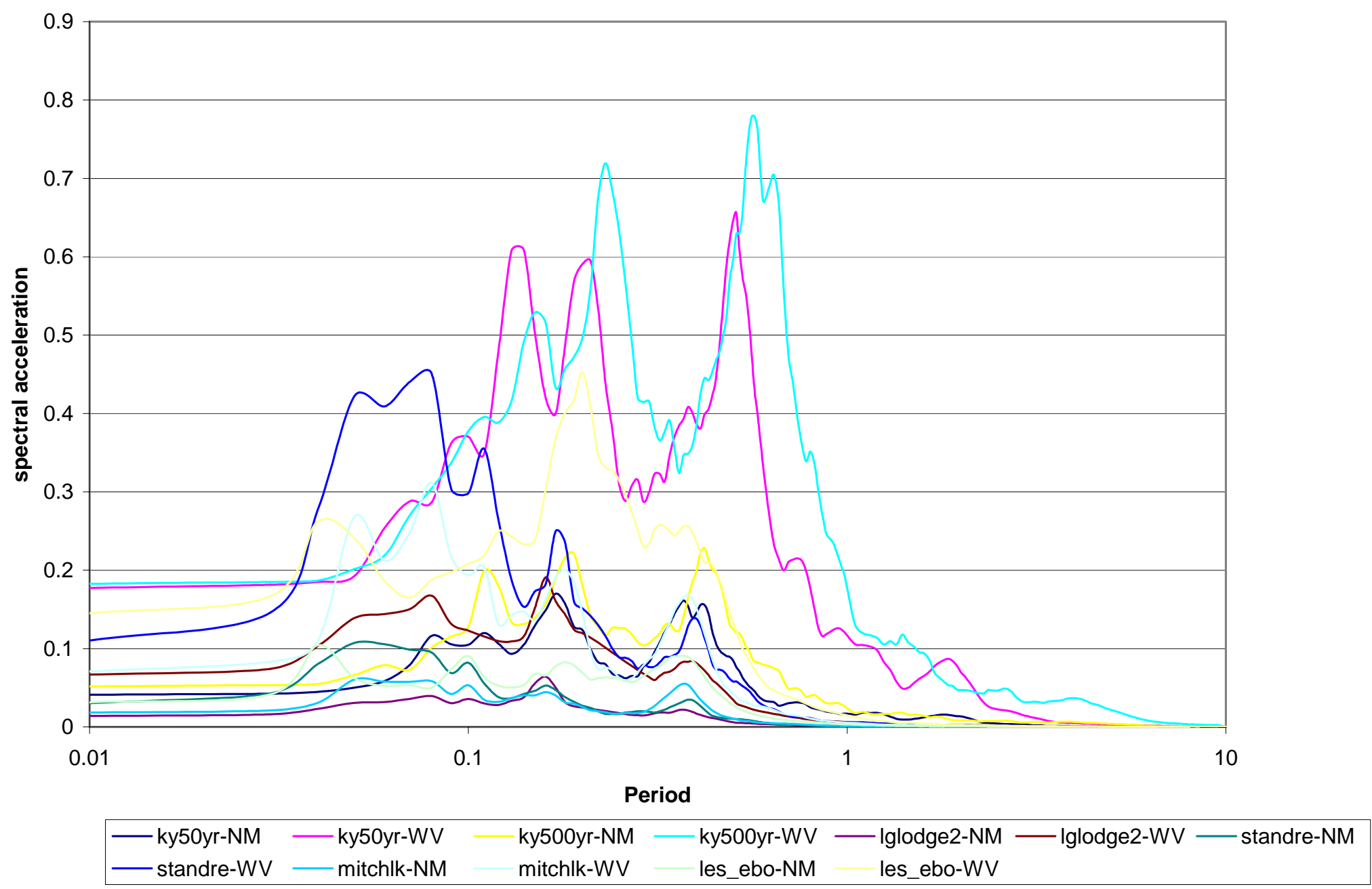

FIGURE 40 - Acceleration Spectra \#10 
Soil Profile \#11

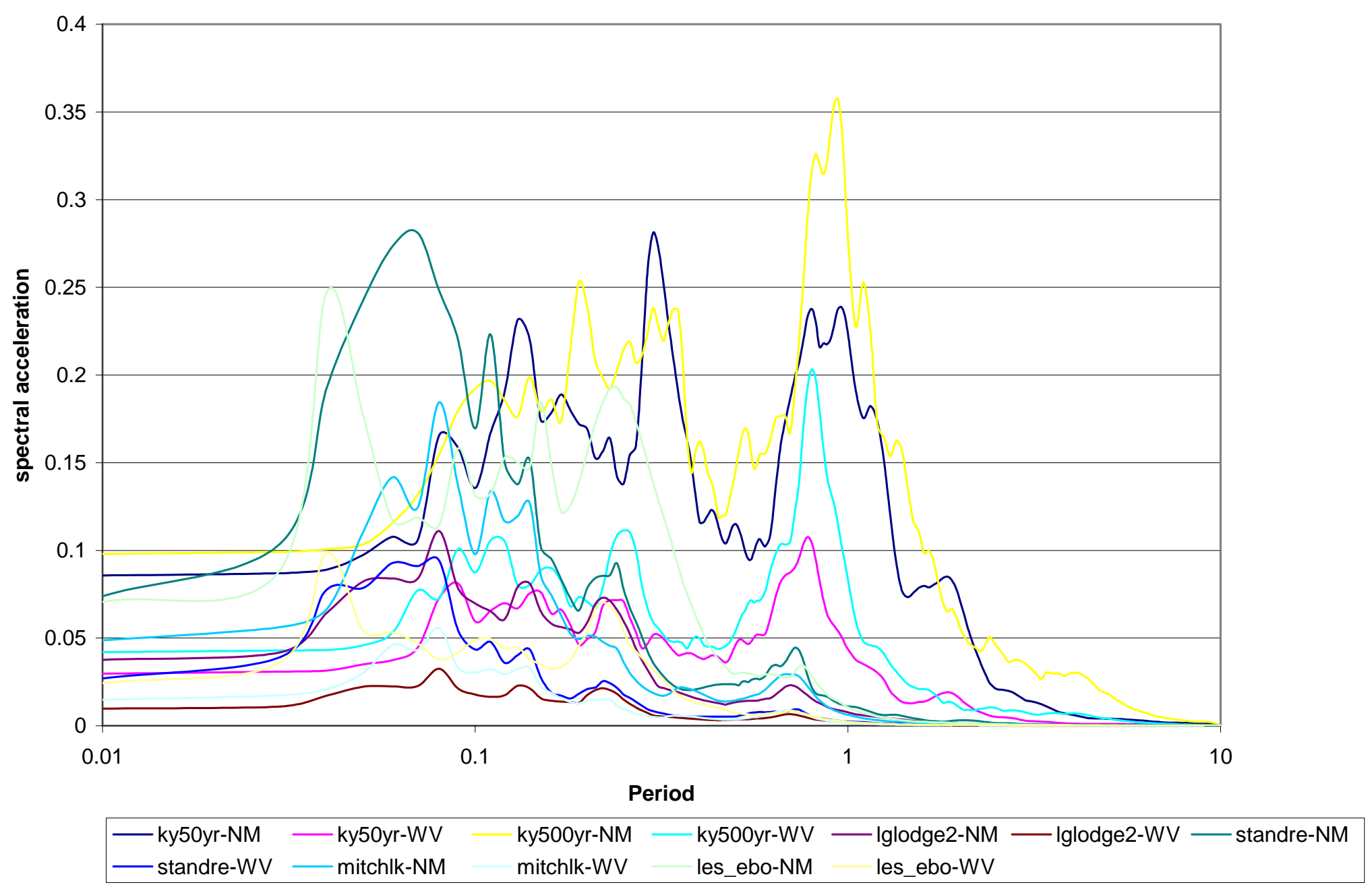

FIGURE 41 - Acceleration Spectra \#11 
Soil Profile \#12

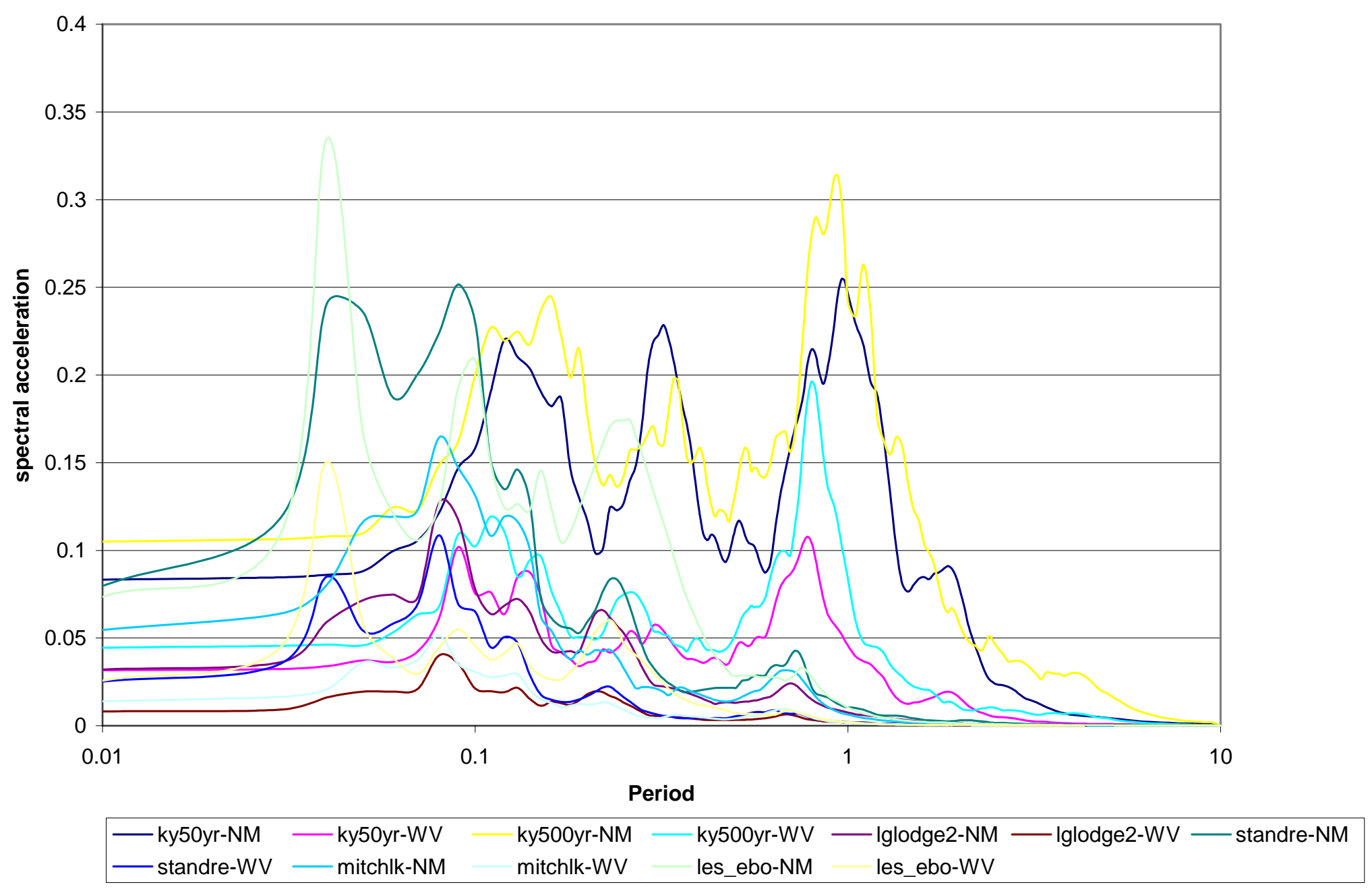

FIGURE 42 - Acceleration Spectra \#12 
Soil Profile \#13

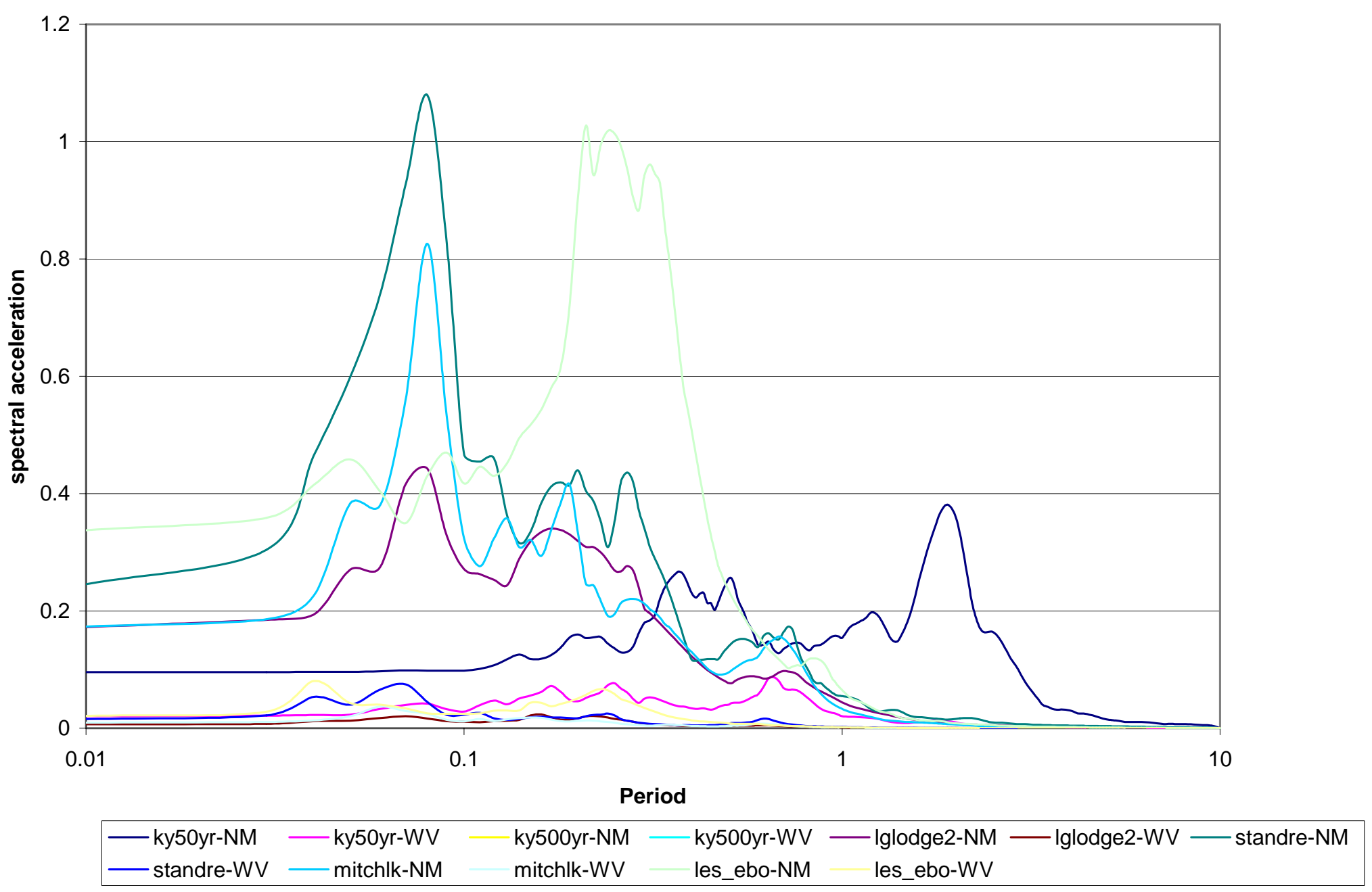

FIGURE 43 - Acceleration Spectra \#13 


\section{APPENDIX II}

\section{INITIAL TORO BEDROCK ACCELERATIONS}

Preliminary Information

Toro Equation:

$\ln Y=C_{1}+C_{2}(M-6)+C_{3}(M-6)^{2}-C_{4} \ln \left(R_{M}\right)-\left(C_{5}-C_{4}\right) \max \left[\ln \left(\frac{R_{M}}{100}\right), 0\right]-C_{6} R_{M}$

$+\varepsilon_{e}+\varepsilon_{a}, \quad$ where $R_{M}=\sqrt{R_{j b}^{2}+C_{7}^{2}}$

TABLE IV

TORO MODELING COEFFICIENTS

\begin{tabular}{|c|c|c|c|c|c|c|c|}
\hline Freq. & C1 & C2 & C3 & C4 & C5 & C6 & C7 \\
\hline PGA & 2.20 & 0.81 & 0.00 & 1.27 & 1.16 & 0.0021 & 9.3 \\
\hline
\end{tabular}

TABLE V

$R_{J B}$ VALUES USED IN ANALYSIS

\begin{tabular}{|c|c|c|}
\hline Soil Profile & NMFZ & WVFZ \\
\hline 1 & 593 & 426 \\
\hline 2 & 509 & 337 \\
\hline 3 & 472 & 293 \\
\hline 4 & 443 & 263 \\
\hline 5 & 385 & 206 \\
\hline 6 & 333 & 160 \\
\hline 7 & 201 & 45 \\
\hline 8 & 169 & 16 \\
\hline 9 & 169 & 16 \\
\hline 10 & 140 & 41 \\
\hline 11 & 49 & 140 \\
\hline 12 & 49 & 140 \\
\hline 13 & 9 & 177 \\
\hline
\end{tabular}


Initial Bedrock Accelerations as calculated by Toro

\section{TABLE XXVII}

Toro - Soil Profile \#1

New Madrid Fault Zone

$\mathrm{R}_{\mathrm{jb}}=$

593

$\mathrm{R}_{\mathrm{m}}=$

593.0729

Wabash Valley Fault Zone

$\mathrm{R}_{\mathrm{jb}}=$

426

$\mathrm{R}_{\mathrm{m}}=\quad 426.1015$

\begin{tabular}{|c|c|}
\hline $\mathbf{M}$ & $\mathbf{Y}$ (PGA) \\
\hline 5 & 0.000423 \\
\hline 5.5 & 0.000634 \\
\hline 6 & 0.00095 \\
\hline 6.5 & 0.001424 \\
\hline 7 & 0.002136 \\
\hline 7.5 & 0.003202 \\
\hline
\end{tabular}

\begin{tabular}{|c|c|}
\hline $\mathbf{M}$ & $\mathbf{Y}$ (PGA) \\
\hline 5 & 0.000881 \\
\hline 5.5 & 0.00132 \\
\hline 6 & 0.00198 \\
\hline 6.5 & 0.002968 \\
\hline 7 & 0.00445 \\
\hline 7.5 & 0.006672 \\
\hline
\end{tabular}

TABLE XXVIII

Toro - Soil Profile \#2

New Madrid Fault Zone

$\mathrm{R}_{\mathrm{jb}}=\quad 509$

$\mathrm{R}_{\mathrm{m}}=\quad 509.085$

Wabash Valley Fault Zone

$\mathrm{R}_{\mathrm{jb}}=$ 337

$\mathrm{R}_{\mathrm{m}}=\quad 337.1283$

\begin{tabular}{|c|c|}
\hline $\mathbf{M}$ & $\mathbf{Y}$ (PGA) \\
\hline 5 & 0.000602 \\
\hline 5.5 & 0.000902 \\
\hline 6 & 0.001353 \\
\hline 6.5 & 0.002028 \\
\hline 7 & 0.003041 \\
\hline 7.5 & 0.00456 \\
\hline
\end{tabular}

\begin{tabular}{|c|c|}
\hline $\mathbf{M}$ & $\mathbf{Y}$ (PGA) \\
\hline 5 & 0.001393 \\
\hline 5.5 & 0.002089 \\
\hline 6 & 0.003131 \\
\hline 6.5 & 0.004695 \\
\hline 7 & 0.007039 \\
\hline 7.5 & 0.010554 \\
\hline
\end{tabular}




\section{TABLE XXIX}

Toro - Soil Profile \#3

New Madrid Fault Zone

$\mathrm{R}_{\mathrm{jb}}=\quad 472$

Wabash Valley Fault Zone

$\mathrm{R}_{\mathrm{m}}=\quad 472.0916$

$\mathrm{R}_{\mathrm{jb}}=\quad 293$

$\mathrm{R}_{\mathrm{m}}=\quad 293.1476$

\begin{tabular}{|c|c|}
\hline $\mathbf{M}$ & $\mathbf{Y}$ (PGA) \\
\hline 5 & 0.00071 \\
\hline 5.5 & 0.001064 \\
\hline 6 & 0.001596 \\
\hline 6.5 & 0.002393 \\
\hline 7 & 0.003588 \\
\hline 7.5 & 0.005379 \\
\hline
\end{tabular}

\begin{tabular}{|c|c|}
\hline $\mathbf{M}$ & Y (PGA) \\
\hline 5 & 0.001797 \\
\hline 5.5 & 0.002694 \\
\hline 6 & 0.004039 \\
\hline 6.5 & 0.006056 \\
\hline 7 & 0.009079 \\
\hline 7.5 & 0.013613 \\
\hline
\end{tabular}

TABLE XXX

Soil Profile \#4

New Madrid Fault Zone

$\mathrm{R}_{\mathrm{jb}}=\quad 443$

Wabash Valley Fault Zone

$\mathrm{R}_{\mathrm{m}}=$

443.0976

$\mathrm{R}_{\mathrm{jb}}=$

263

$R_{m}=\quad 263.1644$

\begin{tabular}{|c|c|}
\hline $\mathbf{M}$ & $\mathbf{Y}$ (PGA) \\
\hline 5 & 0.000812 \\
\hline 5.5 & 0.001218 \\
\hline 6 & 0.001826 \\
\hline 6.5 & 0.002737 \\
\hline 7 & 0.004104 \\
\hline 7.5 & 0.006153 \\
\hline
\end{tabular}

\begin{tabular}{|c|c|}
\hline $\mathbf{M}$ & $\mathbf{Y}(\mathrm{PGA})$ \\
\hline 5 & 0.002169 \\
\hline 5.5 & 0.003252 \\
\hline 6 & 0.004875 \\
\hline 6.5 & 0.007309 \\
\hline 7 & 0.010959 \\
\hline 7.5 & 0.01643 \\
\hline
\end{tabular}




\section{TABLE XXXI}

Toro - Soil Profile \#5

New Madrid Fault Zone

Wabash Valley Fault Zone

$\mathrm{R}_{\mathrm{jb}}=$

385

$\mathrm{R}_{\mathrm{jb}}=$

206

$\mathrm{R}_{\mathrm{m}}=\quad 385.1123$

$\mathrm{R}_{\mathrm{m}}=\quad 206.2098$

\begin{tabular}{|c|c|}
\hline $\mathbf{M}$ & $\mathbf{Y}$ (PGA) \\
\hline 5 & 0.001079 \\
\hline 5.5 & 0.001618 \\
\hline 6 & 0.002426 \\
\hline 6.5 & 0.003638 \\
\hline 7 & 0.005454 \\
\hline 7.5 & 0.008177 \\
\hline
\end{tabular}

\begin{tabular}{|c|c|}
\hline $\mathbf{M}$ & $\mathbf{Y}$ (PGA) \\
\hline 5 & 0.003243 \\
\hline 5.5 & 0.004863 \\
\hline 6 & 0.007291 \\
\hline 6.5 & 0.010931 \\
\hline 7 & 0.016389 \\
\hline 7.5 & 0.024573 \\
\hline
\end{tabular}

TABLE XXXII

Toro - Soil Profile \#6

New Madrid Fault Zone

$\mathrm{R}_{\mathrm{jb}}=\quad 333$

$\mathrm{R}_{\mathrm{m}}=\quad 333.1298$

Wabash Valley Fault Zone

$\mathrm{R}_{\mathrm{jb}}=160$

$\mathrm{R}_{\mathrm{m}}=\quad 160.2701$

\begin{tabular}{|c|c|}
\hline $\mathbf{M}$ & $\mathbf{Y}(\mathrm{PGA})$ \\
\hline 5 & 0.001424 \\
\hline 5.5 & 0.002136 \\
\hline 6 & 0.003202 \\
\hline 6.5 & 0.0048 \\
\hline 7 & 0.007197 \\
\hline 7.5 & 0.010791 \\
\hline
\end{tabular}

\begin{tabular}{|c|c|}
\hline $\mathbf{M}$ & $\mathbf{Y}$ (PGA) \\
\hline 5 & 0.004785 \\
\hline 5.5 & 0.007174 \\
\hline 6 & 0.010756 \\
\hline 6.5 & 0.016126 \\
\hline 7 & 0.024178 \\
\hline 7.5 & 0.036251 \\
\hline
\end{tabular}




\section{TABLE XXXIII}

Toro - Soil Profile \#7

New Madrid Fault Zone

$\mathrm{R}_{\mathrm{jb}}=$

201

Wabash Valley Fault Zone

$\mathrm{R}_{\mathrm{m}}=$

201.215

$\begin{array}{lr}\mathrm{R}_{\mathrm{jb}}= & 45 \\ \mathrm{R}_{\mathrm{m}}= & 45.95095\end{array}$

\begin{tabular}{|c|c|}
\hline $\mathbf{M}$ & $\mathbf{Y}$ (PGA) \\
\hline 5 & 0.003372 \\
\hline 5.5 & 0.005056 \\
\hline 6 & 0.00758 \\
\hline 6.5 & 0.011365 \\
\hline 7 & 0.01704 \\
\hline 7.5 & 0.025548 \\
\hline
\end{tabular}

\begin{tabular}{|c|c|}
\hline $\mathbf{M}$ & $\mathbf{Y}$ (PGA) \\
\hline 5 & 0.028226 \\
\hline 5.5 & 0.042319 \\
\hline 6 & 0.063449 \\
\hline 6.5 & 0.095129 \\
\hline 7 & 0.142628 \\
\hline 7.5 & 0.213842 \\
\hline
\end{tabular}

TABLE XXXIV

Toro - Soil Profile \#8 / \#9

New Madrid Fault Zone

$\mathrm{R}_{\mathrm{jb}}=$

169

$\mathrm{R}_{\mathrm{m}}=$

169.2557

Wabash Valley Fault Zone

$\mathrm{R}_{\mathrm{jb}}=$

16

$\mathrm{R}_{\mathrm{m}}=\quad 18.50649$

\begin{tabular}{|c|c|}
\hline $\mathbf{M}$ & $\mathbf{Y}$ (PGA) \\
\hline 5 & 0.004408 \\
\hline 5.5 & 0.006608 \\
\hline 6 & 0.009908 \\
\hline 6.5 & 0.014855 \\
\hline 7 & 0.022272 \\
\hline 7.5 & 0.033392 \\
\hline
\end{tabular}

\begin{tabular}{|c|c|}
\hline $\mathbf{M}$ & $\mathbf{Y}$ (PGA) \\
\hline 5 & 0.094905 \\
\hline 5.5 & 0.142291 \\
\hline 6 & 0.213338 \\
\hline 6.5 & 0.319858 \\
\hline 7 & 0.479564 \\
\hline 7.5 & 0.719012 \\
\hline
\end{tabular}




\section{TABLE XXXV}

Toro - Soil Profile \#10

New Madrid Fault Zone

$\mathrm{R}_{\mathrm{jb}}=\quad 140$

$\mathrm{R}_{\mathrm{m}}=\quad 140.3086$

Wabash Valley Fault Zone

$\mathrm{R}_{\mathrm{jb}}=\quad 41$

$\mathrm{R}_{\mathrm{m}}=\quad 42.04153$

\begin{tabular}{|c|c|}
\hline $\mathbf{M}$ & $\mathbf{Y}$ (PGA) \\
\hline 5 & 0.005822 \\
\hline 5.5 & 0.008729 \\
\hline 6 & 0.013088 \\
\hline 6.5 & 0.019623 \\
\hline 7 & 0.02942 \\
\hline 7.5 & 0.04411 \\
\hline
\end{tabular}

\begin{tabular}{|c|c|}
\hline $\mathbf{M}$ & $\mathbf{Y}$ (PGA) \\
\hline 5 & 0.031861 \\
\hline 5.5 & 0.047769 \\
\hline 6 & 0.07162 \\
\hline 6.5 & 0.10738 \\
\hline 7 & 0.160995 \\
\hline 7.5 & 0.24138 \\
\hline
\end{tabular}

TABLE XXXVI

Toro - Soil Profile \#11 / \#12

New Madrid Fault Zone

$\mathrm{R}_{\mathrm{jb}}=$

49

Wabash Valley Fault Zone

$\mathrm{R}_{\mathrm{m}}=$

49.87474

$\mathrm{R}_{\mathrm{jb}}=$

140

$\mathrm{R}_{\mathrm{m}}=\quad 140.3086$

\begin{tabular}{|c|c|}
\hline $\mathbf{M}$ & $\mathbf{Y}$ (PGA) \\
\hline 5 & 0.025227 \\
\hline 5.5 & 0.037824 \\
\hline 6 & 0.056709 \\
\hline 6.5 & 0.085024 \\
\hline 7 & 0.127477 \\
\hline 7.5 & 0.191126 \\
\hline
\end{tabular}

\begin{tabular}{|c|c|}
\hline $\mathbf{M}$ & $\mathbf{Y}$ (PGA) \\
\hline 5 & 0.005822 \\
\hline 5.5 & 0.008729 \\
\hline 6 & 0.013088 \\
\hline 6.5 & 0.019623 \\
\hline 7 & 0.02942 \\
\hline 7.5 & 0.04411 \\
\hline
\end{tabular}




\section{TABLE XXXVII}

Toro - Soil Profile \#13

New Madrid Fault Zone

$\mathrm{R}_{\mathrm{jb}}=\quad 9$

$\mathrm{R}_{\mathrm{m}}=\quad 12.94179$

Wabash Valley Fault Zone

$\mathrm{R}_{\mathrm{jb}}=$

177

$\mathrm{R}_{\mathrm{m}}=$

177.2442

\begin{tabular}{|c|c|}
\hline $\mathbf{M}$ & $\mathbf{Y}$ (PGA) \\
\hline 5 & 0.151228 \\
\hline 5.5 & 0.226737 \\
\hline 6 & 0.339947 \\
\hline 6.5 & 0.509684 \\
\hline 7 & 0.764171 \\
\hline 7.5 & 1.145723 \\
\hline
\end{tabular}

\begin{tabular}{|c|c|}
\hline $\mathbf{M}$ & $\mathbf{Y}$ (PGA) \\
\hline 5 & 0.004108 \\
\hline 5.5 & 0.00616 \\
\hline 6 & 0.009235 \\
\hline 6.5 & 0.013847 \\
\hline 7 & 0.02076 \\
\hline 7.5 & 0.031126 \\
\hline
\end{tabular}




\section{VITA}

The author, Lindsay M. Ivey, was born in Indianapolis, Indiana on June 3, 1983, but she grew up in Owensboro, Kentucky. She graduated from Apollo High School in 2001 and entered the University of Louisville’s J.B. Speed School of Engineering in August 2001. The author completed the requirements for the Bachelor of Science in Civil Engineering in May 2005 and the requirements for the Masters of Engineering in Civil Engineering in August 2006. She will attend Georgia Institute of Technology in Atlanta beginning August 2006. There she received a research assistantship, and she will pursue a Doctor of Philosophy degree in Civil Engineering with a specialization in Geotechnical Engineering. 